ORIL- -6656

DE91 010493

\title{
Advanced Neutron Source (ANS) Project Progress Report
}

\author{
Principal Authors \\ $\begin{array}{ll}\text { D. L. Selby } & \text { R. M. Harrington }\end{array}$ \\ Oak Ridge National Laboratory \\ F. J. Peretz \\ Engineering Division \\ Martin Marietta Energy Systems, Inc.
}

Publisher

M. R. McBee

Oak Ridge National Laboratory

Editor

J. H. Campbell

Oak Ridge National Laboratory

Date Published - February 1991

Prepared by the

Oak Ridgc National Lab ratory

Oak Ridgc, Tennessce 37831 managed by

Martin Marictta Encrgy Systems, Inc. for the

U.S. DEPARTMENT OF ENERGY under Contract No. DE-AC05-840R21400 


\section{Contributine Anthors}
D. J. Alexander
W. R. Hendrich
R. G. Alsmiller
R. A Lillie
J. L Anderson
A. W. Longesi
R. E Battle
C. $\mathbf{R}$ Luttrell
A E Ruggles
W. K. Sartory
H. B. Shapira
N. C. J. Chen
J. A March-Leuba
W. F. Swinson
G. L. Copeland
B. H. Montgomery
R. P. Taleyarthan
B. Dámiano
J. A Mullens
C. D. West
D. K Felde
R. E Pawel
B. A Worley
M. L. Gildner
R. T. Primn, III
G. T. Yahr
G. L. Yoder, Jr.

J. E Hardy

Oak Ridge National Laboratory
J. W. Baker
B. S. Maxon
W. R. Reed
R. M. Beckers
T. J. McManamy
T. L. Ryan
R. A. Brown
G. R. McNutt
P. B. Thompson
C. C. Eberle
C. C. Queen
Engineering Division, Martin Marietta Energy Systems, Inc.
R. C. Birtcher
H. R. Thresh
G. L. Hofman
T. C. Wiencek
J. L. Snelgrove
Angonne Nrtional Laboratory
C. D. Fetcher
E L Redmond
J. M. Ryskamp
R. C. Thayer
Idaho National Engineering Laboratory

M. Ibn-Khayat

University of Tennessee

R. R. Fullwood

Brookhaven National Lisoratory

W. R. Gambill (Retircd) 


\section{Contents}

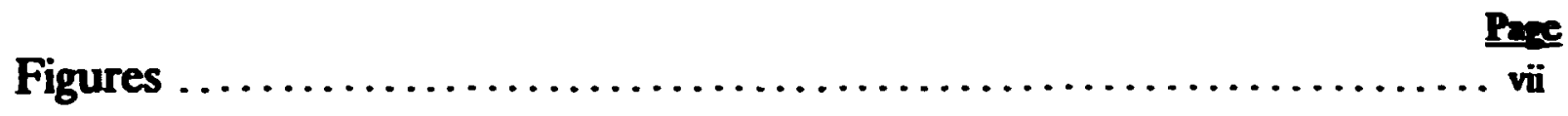

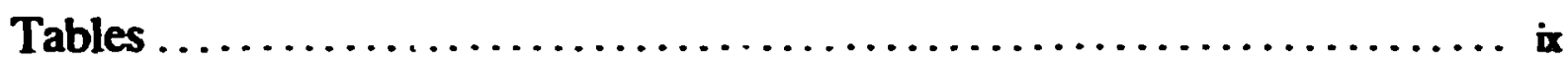

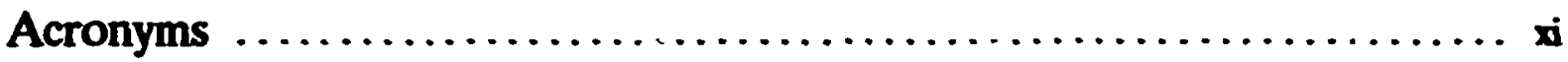

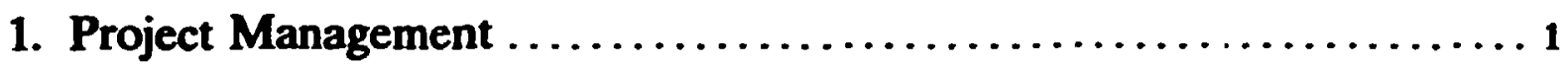

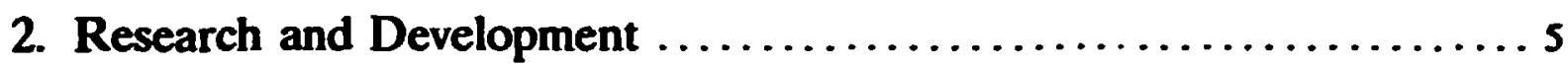

2.1 Reactor Core Development $\ldots \ldots \ldots \ldots \ldots \ldots \ldots \ldots \ldots \ldots \ldots \ldots$. 5

21.1 Development of Analysis Techniques ...................... s

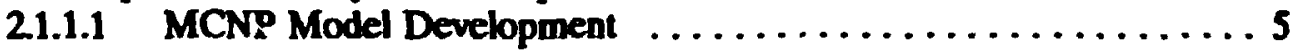

2.1.1.2 Treatment of Uncertainties $\ldots \ldots \ldots \ldots \ldots \ldots \ldots \ldots \ldots, \ldots$

2.1 .2 Support to Design ............................. 6

2.1.2.1 New Conceptual Core Geometry .................6

21.22 New Conceptual Core Evaluations ............... 7

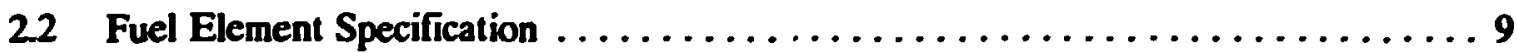

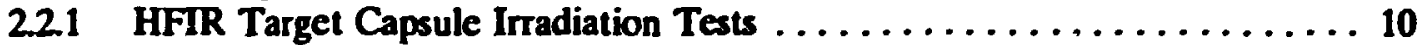

22.2 Fuel Performance Studies and Modeling $\ldots \ldots \ldots \ldots \ldots \ldots \ldots \ldots \ldots$

223 Fabrication Development $\ldots \ldots \ldots \ldots \ldots \ldots \ldots \ldots \ldots \ldots \ldots \ldots$

23 Corrosion Loop Tests and Analyses $\ldots \ldots \ldots \ldots \ldots \ldots \ldots \ldots \ldots \ldots \ldots \ldots$

2.3.1 Summary of Results: Update $\ldots \ldots \ldots \ldots \ldots \ldots \ldots \ldots \ldots \ldots \ldots \ldots \ldots \ldots$

2.3.2 Preliminary Correlation ...................

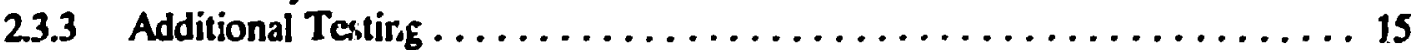

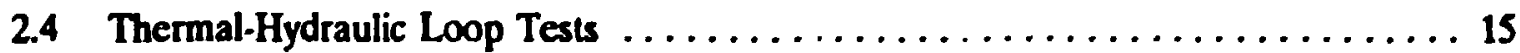

24.1 Test Loop .................................. 15

2.4.2 Thermal-Hydraulic Loop Schedule $\ldots \ldots \ldots \ldots \ldots \ldots \ldots \ldots \ldots \ldots$

2.5 Reactor Control and Shutdown Concepts $\ldots \ldots \ldots \ldots \ldots \ldots \ldots \ldots \ldots \ldots$

2.5.1 Basic Control and Shutdown System Concept $\ldots \ldots \ldots \ldots \ldots \ldots \ldots \ldots$

2.5.2 Critcria for the Co.atrol and Shutdown System ............... 17

2.5.3 Comprehensive Analysis of

the Control and Shutdown System .................... 18

2.6 Critica! and Subcritical Experiments $\ldots \ldots \ldots \ldots \ldots \ldots \ldots \ldots \ldots \ldots \ldots \ldots$

2.7 Material Data, Structural Tests, and Analysis $\ldots \ldots \ldots \ldots \ldots \ldots \ldots \ldots \ldots$

2.7.1 Core Pressure Boundary Tube ...................... 19

2.7.2 Characterization of Irradiatcd 6061 -T651 Aluminum ............ i9 


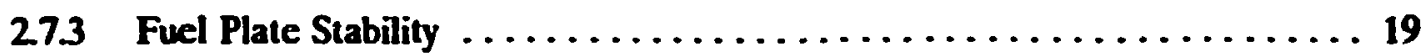

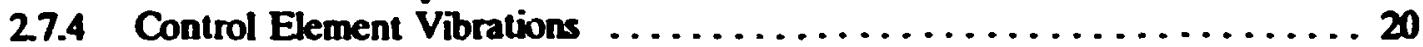

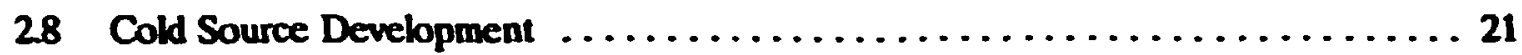

28.1 Cold Source Neutronics Modeling . . . . . . . . . . . . . . . 21

28.2 Cold Source Thermal-Hydraulic and Testing Program .......... 22

28.21 Cold Source Thermal-Hydraulic Analytical Model ......... 22

28.22 Cold Source Thermal-Hydraulic Testing Program ......... 23

29 Beam Tube, Guide, and Instrument Development ................ 23

29.1 Neutron Supermirrors ......................... 23

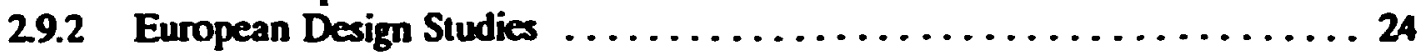

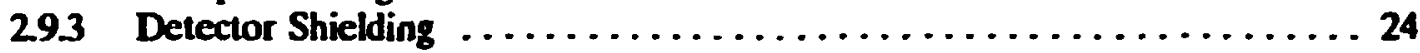

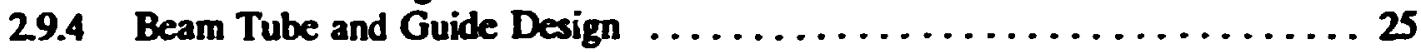

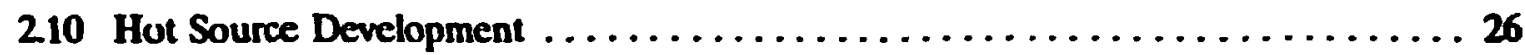

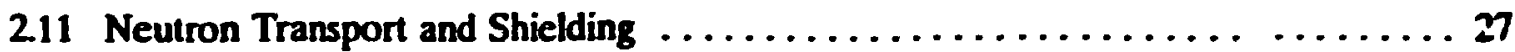

2.11.1 Component Heat Loads ........................ 27

2.11.2 Reactivity Eniect of Beam Tubes and Other Components ......... 28

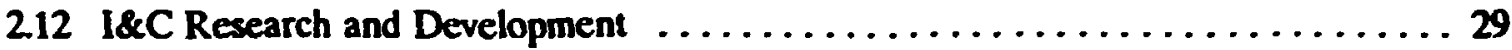

2.12.1 Protection and Contro! Strz:egy . . . . . . . . . . . . . . . . 29

2.12.2 Candidate Protection and Control Systems for the ANS $\ldots \ldots \ldots \ldots . \ldots 31$

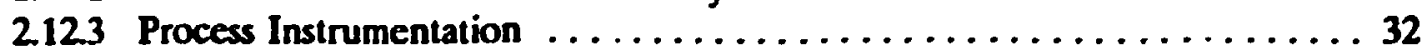

2.12.4 Analyses Supporting the Conceptual Design of the ANS Inner Control Rods and Drives ................... 34

2.12 .5 ANS Diagnostic and Surveillance System $\ldots \ldots \ldots \ldots \ldots \ldots \ldots \ldots \ldots \ldots \ldots \ldots$

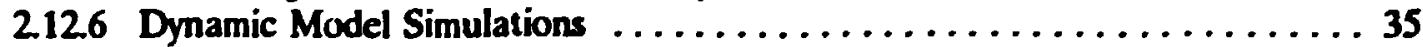

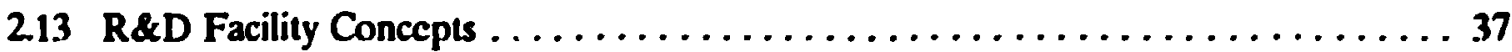

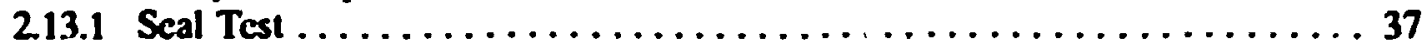

2.13.2 Reflector Vessel and Core Pressure Buundary Tube Tests .......... 38

213.2.1 Reflector Vessel Test ...................... 38

2.13.2.2 Core Pressure Boundary Tube Test ............... 38

2.13.3 Reactor Mockup ............................. 39

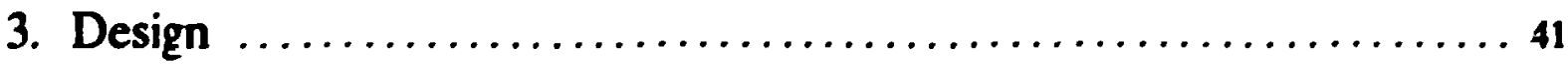

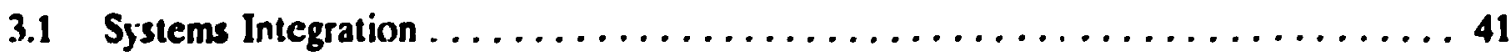

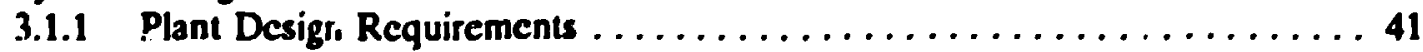

3.1.2 Systems Engincering Management Plan ................. 41

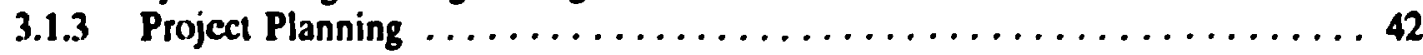

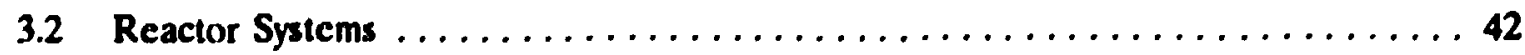

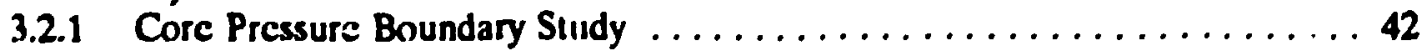

3.2.2 Refucling Study ........................... 43

3.2.3 Component Thermal and Stress Analysis ............... 45 


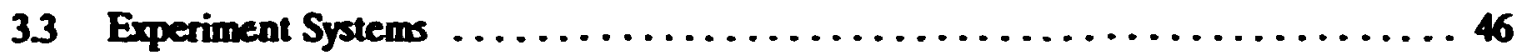

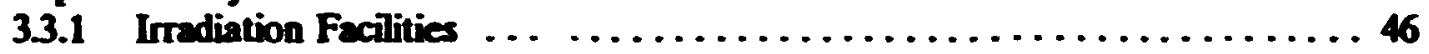

3.3.2 Second-Fkoor Beam Transport and Research Facilities ............ 48

3.3.3 Main Floor Beam Transport $\ldots \ldots \ldots \ldots \ldots \ldots \ldots \ldots \ldots \ldots \ldots, 48$

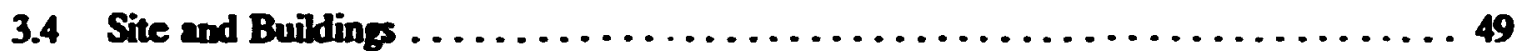

3.4.1 Preliminary Site Characterization $\ldots \ldots \ldots \ldots \ldots \ldots \ldots \ldots \ldots \ldots$. 49

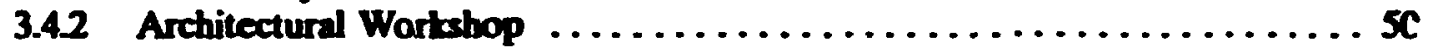

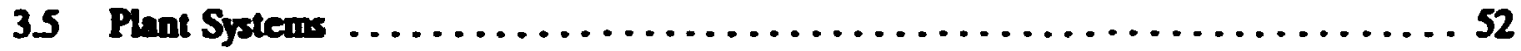

3.5.1 Reactor Cooling Systems ......................... 52

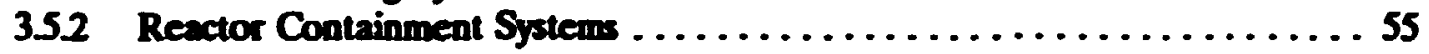

3.5.3 Heavy-Water Management, Cleanup, and Detritiation ............ 56

3.5.4 General Equipment Data Base $\ldots \ldots \ldots \ldots \ldots \ldots \ldots \ldots \ldots \ldots \ldots$

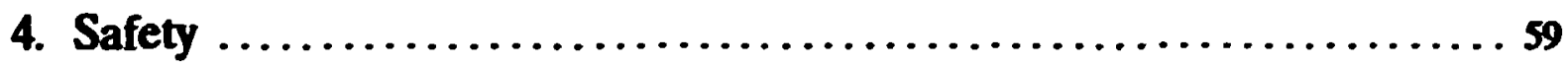

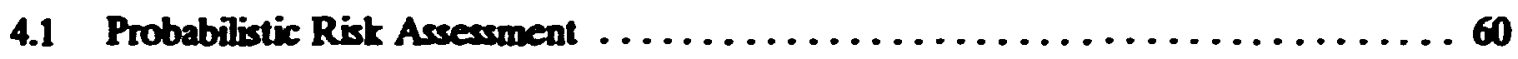

4.1.1 Failure-Modes Effects and Criticality Analysis ................6 61

4.1.2 Pipe Break Probability $\ldots \ldots \ldots \ldots \ldots \ldots \ldots \ldots \ldots \ldots \ldots \ldots \ldots, 6 \ldots \ldots$

4.2. Transient Thermal-Hydraulics $\ldots \ldots \ldots \ldots \ldots \ldots \ldots \ldots \ldots \ldots \ldots \ldots \ldots$

4.21 Planning for RELAPS Experimental Validation ............... 64

4.21.1 inumediate Response $\ldots \ldots \ldots \ldots \ldots \ldots \ldots \ldots \ldots \ldots, 64$

4.21.2 Long-Term Response .......................65

4.2.1.3 Pump Response ..........................65

4.21.4 Choking $\ldots \ldots \ldots \ldots \ldots \ldots \ldots \ldots \ldots \ldots \ldots \ldots \ldots \ldots \ldots \ldots \ldots, 65$

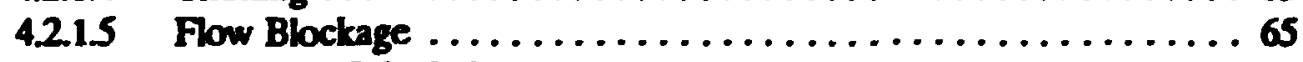

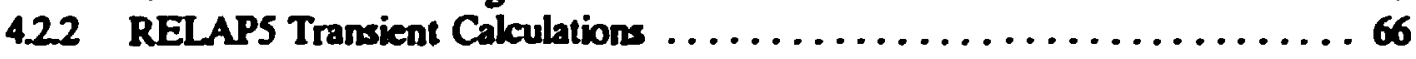

4.22. RELAPS Model ..........................66

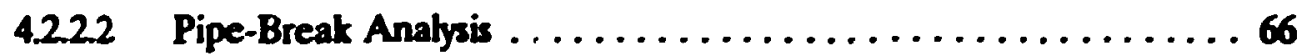

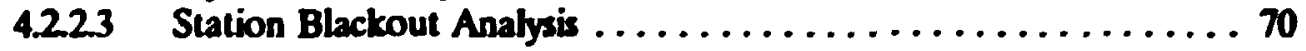

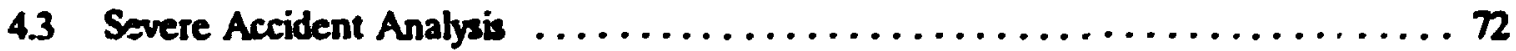

4.3.1 Core-Concrete Interactions ........................... 73

4.3.2 Core Melt Progression and Fission

Product Release Considerations for the ANS ............... 75

4.3.3 ANS Containment Response Evaluations $\ldots \ldots \ldots \ldots \ldots \ldots \ldots, \ldots$

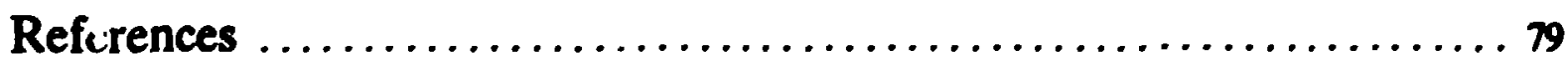




\section{Figures}

Fine

1.1 Budget and safety review schedule $\ldots \ldots \ldots \ldots \ldots \ldots \ldots \ldots \ldots \ldots \ldots \ldots \ldots$

1.2 Reference conceptual design of cooling system $\ldots \ldots \ldots \ldots \ldots \ldots \ldots \ldots \ldots \ldots$

21 Conceptual core geometry $\ldots \ldots \ldots \ldots \ldots \ldots \ldots \ldots \ldots \ldots \ldots \ldots \ldots \ldots$

22 Comparicon of BOC radial thermal flux variations for MCNP and PDQ $\ldots \ldots \ldots \ldots \ldots \ldots \ldots \ldots \ldots \ldots \ldots \ldots \ldots \ldots$

23 Reactivity effects of dilute light-water ingress into $\mathrm{D}_{2} \mathrm{O}$ reflector and inside CPBT at beginning and end of cycle $\ldots \ldots \ldots \ldots \ldots \ldots \ldots \ldots \ldots \ldots \ldots \ldots$

24 Film growth on $6061 \mathrm{Al}$ fcr CTEST No. 16 at three reference positions on specimen $\ldots \ldots \ldots \ldots \ldots \ldots \ldots \ldots \ldots \ldots \ldots \ldots$

25 Cross section from CTEST specimen exhibiting deep internal reaction zone $\ldots \ldots \ldots \ldots \ldots \ldots \ldots \ldots \ldots \ldots \ldots \ldots$

2.6 Isometric view of ANS thermal-hydraulic test loop $\ldots \ldots \ldots \ldots \ldots \ldots \ldots \ldots$

27 Comparison of geometrical predictions with neutronics calculations . . . . . . 21

2.8 Calculated mean liquid fraction vs pool depth for volume-heated, boiling $\mathbf{L D}_{\mathbf{2}}$ pool

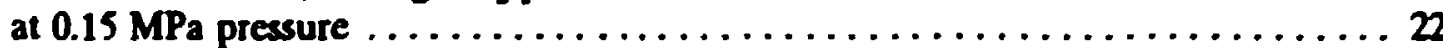

29 NIST reflectivity measurements for conventional nickel mirror and supermirror guide coating

2.10 Detector shielding attenuation factors in two spectral ranges for various thicknesses of $\mathrm{B}_{4} \mathrm{C}$ absorber behind $100 \mathrm{~mm}$ of high-density polyethylene moderator $\ldots \ldots \ldots \ldots \ldots \ldots \ldots \ldots \ldots$

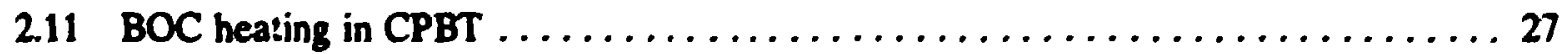

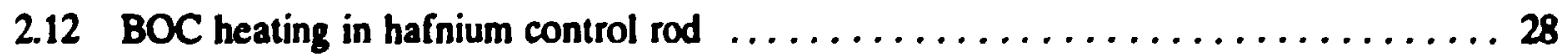

2.13 ANS instrumentation and control systcms $\ldots \ldots \ldots \ldots \ldots \ldots \ldots \ldots \ldots \ldots$

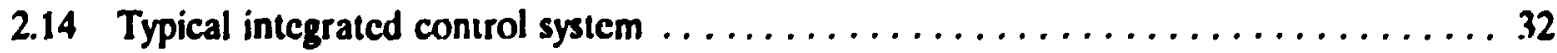

2.15 ANS instrument application diagram for primary coolant loop $\ldots \ldots \ldots \ldots \ldots . \ldots 33$ 
2.16 Macimum safe reactivity step as function of latch release time $\ldots \ldots \ldots \ldots \ldots 36$

2.17 Hot-leg temperature sensitivity to emergency heat exchanger heat transfer area $\ldots \ldots \ldots \ldots \ldots \ldots \ldots \ldots \ldots, \ldots \ldots$

3.1 ANS major project schedule components and milestones $\ldots \ldots \ldots \ldots \ldots \ldots \ldots$

3.2 CPBT arrangement with bolted flanger $\ldots \ldots \ldots \ldots \ldots \ldots \ldots \ldots \ldots . \ldots . \ldots . \ldots$

3.3 Reactor core showing CPBT and irradiation facilities $\ldots \ldots \ldots \ldots \ldots \ldots \ldots \ldots$. 48

3.4 Layout of facilities on second boor of reactor building $\ldots \ldots \ldots \ldots \ldots \ldots \ldots$. 49

3.5 Elevation view of isotope separation on-line facility $\ldots \ldots \ldots \ldots \ldots \ldots \ldots$. 50

3.6 Standard beam tube and biological shield plug $\ldots \ldots \ldots \ldots \ldots \ldots \ldots \ldots \ldots$

3.7 A portion of sample form for site and facility criteria data base element $\ldots \ldots \ldots \ldots \ldots \ldots \ldots \ldots \ldots \ldots \ldots \ldots \ldots \ldots$

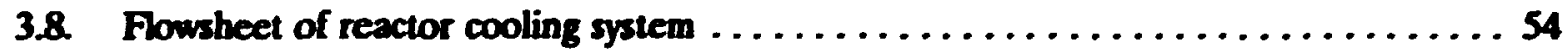

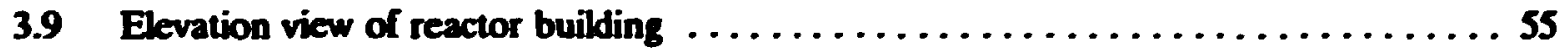

3.10 Fowsheet of annulus exhaust and treatment system $\ldots \ldots \ldots \ldots \ldots \ldots \ldots$

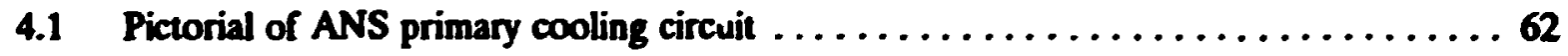

4.2 Nodalization of ANS RELAPS system model $\ldots \ldots \ldots \ldots \ldots \ldots \ldots \ldots \ldots \ldots \ldots \ldots \ldots \ldots$

4.3 Small pump-discharge break long-term primary system pressures $\ldots \ldots \ldots \ldots \ldots 68$

4.4 Small pump-discharge break lower-core hot-stripe fuel plate centerline temperatures $\ldots \ldots \ldots \ldots \ldots \ldots \ldots \ldots \ldots \ldots \ldots . \ldots \ldots$

4.5 Comparison of primary coolant pressure transient between base case (no accumulator) and case 2 (one $10-m^{3}$ accumulator at cold leg distribution header) $\ldots \ldots \ldots \ldots \ldots \ldots \ldots 72$

4.6 Variation of ablation depth with concrete type,

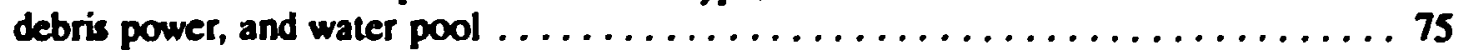




\section{Tables}

Trbles

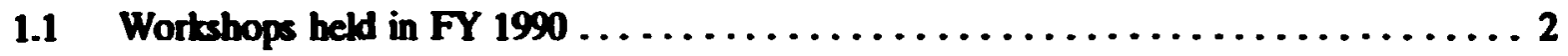

21 Effects of $\mathrm{D}_{2} \mathrm{O}$ voiding on core reactivity $\ldots \ldots \ldots \ldots \ldots \ldots \ldots \ldots \ldots \ldots, \ldots \ldots \ldots$

22 Corrosion test loop: Completed tests and parameters $\ldots \ldots \ldots \ldots \ldots \ldots \ldots \ldots$

2.3 Design and performance of optimized

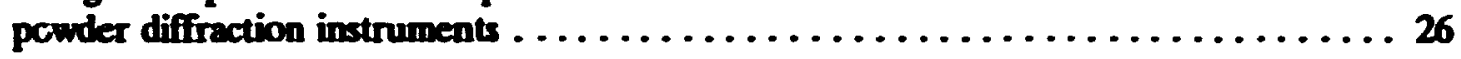

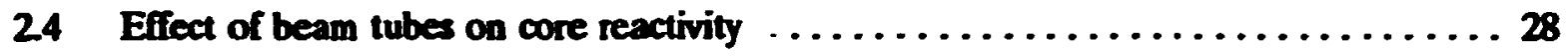

25 Reactivity effects of two slant tubes and various sample materials $\ldots \ldots \ldots \ldots \ldots \ldots \ldots \ldots \ldots \ldots \ldots \ldots, 29$

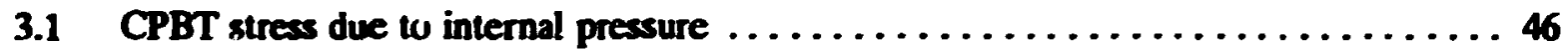

3.2 CPBT stress due to pressure and temperature effects $\ldots \ldots \ldots \ldots \ldots \ldots \ldots \ldots$

4.1 Comparison of core damage frequencies: HFIR PRA results and scoping ANS PRA $\ldots \ldots \ldots \ldots \ldots \ldots \ldots \ldots \ldots, \ldots \ldots \ldots$

4.2 Geometric mean primary pipe leak and break frequencies $\ldots \ldots \ldots \ldots \ldots \ldots 63$

4.3 Summary of RELAPS ANS pipe break analyses $\ldots \ldots \ldots \ldots \ldots \ldots \ldots \ldots \ldots \ldots$

4.4 CORCON results as a function of concrete type $\ldots \ldots \ldots \ldots \ldots \ldots \ldots \ldots . \ldots \ldots$ 


\section{Acronyms}

\begin{tabular}{|c|c|}
\hline $\begin{array}{l}\text { ALARA } \\
\text { ANL } \\
\text { ANS } \\
\text { ANSR } \\
\text { ASME } \\
\text { ATR } \\
\text { BEW } \\
\text { BNL } \\
\text { BOC } \\
\text { CCD } \\
\text { CFD } \\
\text { CHF } \\
\text { CPBT } \\
\text { DOE } \\
\text { EOC } \\
\text { ER } \\
\text { FCI } \\
\text { FMECAS } \\
\text { HFBR } \\
\text { HFIR } \\
\text { IAD } \\
\text { ILL } \\
\text { INEL } \\
\text { JAERI } \\
\text { MCCI } \\
\text { NE } \\
\text { NIST } \\
\text { NRC } \\
\text { OADCS } \\
\text { ORNL } \\
\text { ORO } \\
\text { PDR } \\
\text { PRA } \\
\text { PRAISDPD } \\
\text { PWR } \\
\text { QA } \\
\text { R\&D } \\
\text { RERTR } \\
\text { RPS } \\
\text { SAR } \\
\text { SDD } \\
\text { SEMP } \\
\text { SPDS }\end{array}$ & $\begin{array}{l}\text { As Low as Reasonably Achievable } \\
\text { Argonne National Laboratory } \\
\text { Advanced Neutron Source } \\
\text { Advanced Neutron Source Reactor } \\
\text { American Society of Mechanical Engineers } \\
\text { Advanced Test Reactor } \\
\text { Babcock and Wilcox Company } \\
\text { Broothaven National Laboratory } \\
\text { Beginning-of-Cycle } \\
\text { Conceptual Core Design } \\
\text { Computational Fluid Dynamics } \\
\text { Critical Heat Flux } \\
\text { Core Pressure Boundary Tube } \\
\text { Department of Energy } \\
\text { End-of-Cycle } \\
\text { Office of Energy Research } \\
\text { Fuel-Coolant-Interaction } \\
\text { Failure-Modes Eflects and Criticality Analyses } \\
\text { High Flux Beam Reactor } \\
\text { High Flux Isotope Reactor } \\
\text { Instrument Application Diagram } \\
\text { Institut Laue Langevin } \\
\text { Idaho National Engineering Laborato.y } \\
\text { Japan Alomic Energy Research Institute } \\
\text { Molten-Core-Concrete-Interactions } \\
\text { Office of Nuclear Energy } \\
\text { National Institute of Standards and Technology } \\
\text { Nuclear Regulatory Commission } \\
\text { Open Architecture Distributed Control System } \\
\text { Oak Ridge National Laboratory } \\
\text { Oak Ridge Operations } \\
\text { Plant Design Reguirement } \\
\text { Probabilistic Risk Assessment } \\
\text { PRAISE Discrete Probability Distributions } \\
\text { Pressurized Water Reactors } \\
\text { Quality Assurance } \\
\text { Research and Development } \\
\text { Reduced Enrichment for Research and Test Reactors } \\
\text { Reactor Protection System } \\
\text { Safety Analysis Report } \\
\text { System Design Descriplion } \\
\text { Systems Engincering Management Plant } \\
\text { Safcty Parameter Display Systcm }\end{array}$ \\
\hline
\end{tabular}


SRL

TEM

THTL

VCN

WBS
Savannah River Laboratory

Transmission Electron Microscopy

Thermal-Hydraulic Test Loop

Very-Cold Neutron

Work Breakdowin Structure 


\section{1 \\ Project \\ Management}

\begin{abstract}
A major event affecting the progress and status of the Advanced Neutron Source (ANS) Projoct in this reporting period was the decision (effective on December 7, 1989) by U.S. Secretary of Energy Watkins to transfer management responsibility for the Department of Energy (DOE) Office of Energy Research's (ER's) operating and planned reactors to the Office of Nuclear Energy (NE). Responsibility for funding and justifying the ANS Project remains with ER.

At the major annual programmatic review of the project, held last year in May and chaired jointly by ER and NE, alternative new si hedules drawn up by the project in resf unse to guidance received from those offices were presented. The schedule proposed and endorsed by a similar review the previous year called for a three-year, designonly line item beginning in FY 1991.' The line item was not included in the president's budget request; there'ore, a new schedule was recommended with a onc-year slippage in completion, including a two-year, designonly line item for FYs 1992 and 1993, folI owed by detailed design and construction beginning in FY 1994 (Fig. 1.1). The proposal, endorsed by the review team, provided an ordered and integrated program of safety analysis, environmental studics, design, and research and development (R\&D) that would match the budget and safety review schedulc associated with Fig. 1.1.

In August and September, an Encrgy Systcms Acquisition Advisory Board, chaircd by the DCE undersecretary, was convened.
\end{abstract}

The board formally authorized the conceptual design phase of the ANS Project. Subsequently, Martin Marietta Energy Systems, Inc., (Energy Systems) was authorized by Oak Ridge Operations (ORO) and Headquarters to place a Commerce Business Daily advertisement seeking an Architect-Engineer to participate in the conceptual design. This long-awaited event marks a major step forward for ANS.

Two other significant actions took place: the issuance for use (following approvals by ORO) of the project's Quality Assurance (QA) Plan and the first issue of the Plant Design Requirements (PDR) document. Both of these, iscued as controlled documents with a formal mechanism for approving and disseminating changes, are important elements of the management control system. The ANS Project chose to prepare and implement them at a very early stage (other projects have not issued these documents until after the construction phase began) because we perceive a special need for traceable controls at every stage of a nuclear facility project.

We have continued to make extensive use of workshops to nove forward the design of the ANS reactor and facilitics (Table 1.1).

The Safety Workshop held in October 1988 continues to exert a strong influence on the project; in particular, the workshop's recommendation to continue the scarch for passive safety features is strongly reflected in the reference conceptual design of the conling sustem (Fig. 1.2). The new cooling system 


\section{ADVANCED NEUTRON SOURCE}

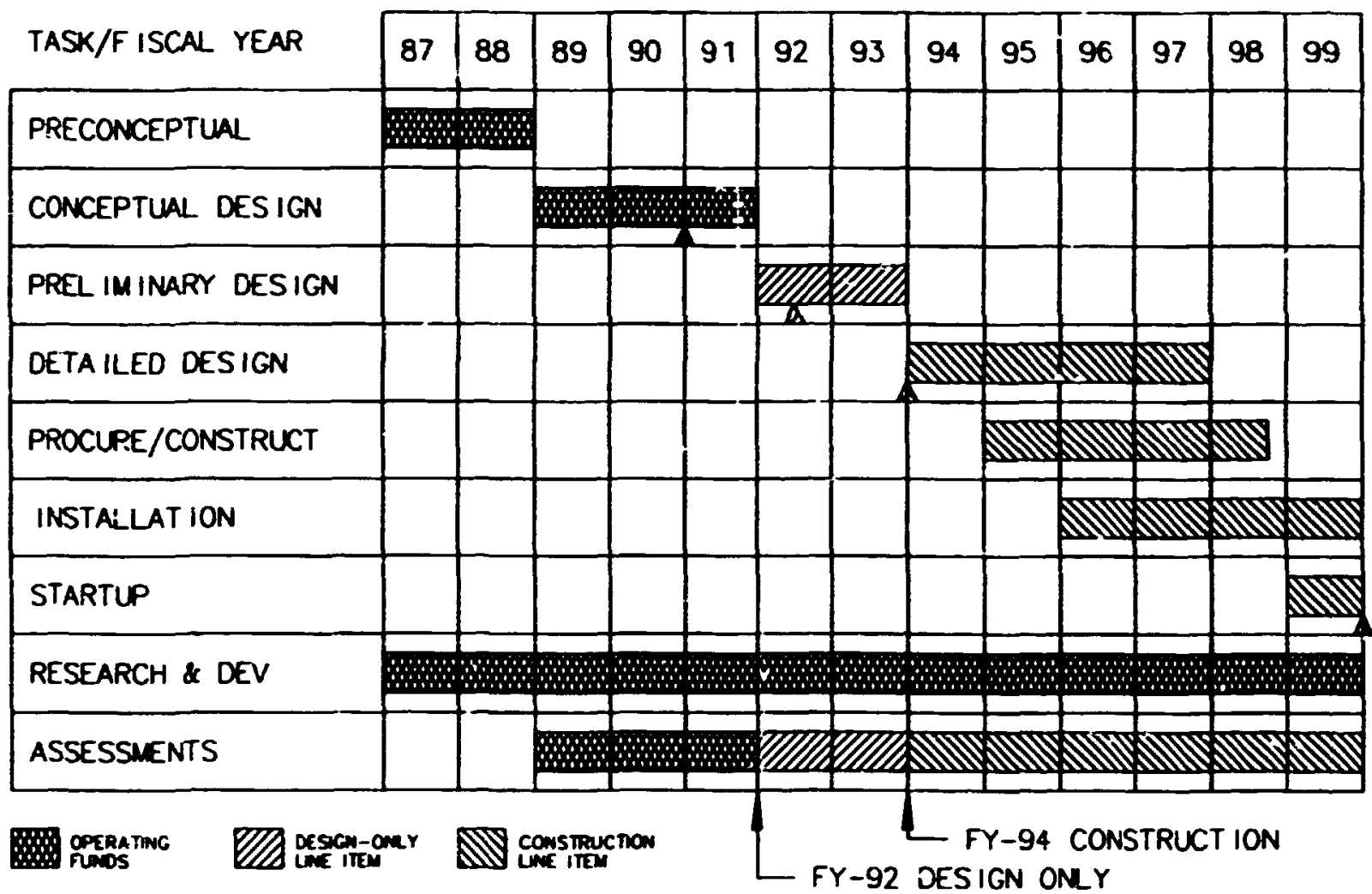

Fig 1.1. Bodget and safety revien schodule.

Table 1.1. Worksops beld in FY 1990

Workshop

Sitc and Facility Planning

Corc Pressure Boundary Tube

Reactor Cooling Sys!cm

Containment
Datc

October 18-19, 1989

Fcbruary 12, 1990

February 15-16, 1900

August 23-24, 19\%n
Workshop to collect basic information for usc in the architectural planning of the ANS site and buildings.

Workshop to review options for connections and scals on the core pressure boundary tubc.

Workshop to revicw progress of the reactor cooling system design team and recommended concepts for design of the ANS conling circuits.

Workshop to review progress of the reactor containment system design team and recom. mended concepts for containment design. 


\section{SOME SAFETY FEATURES OF THE ADVANCED NEUTRON SOURCE REACTOR DESICN}

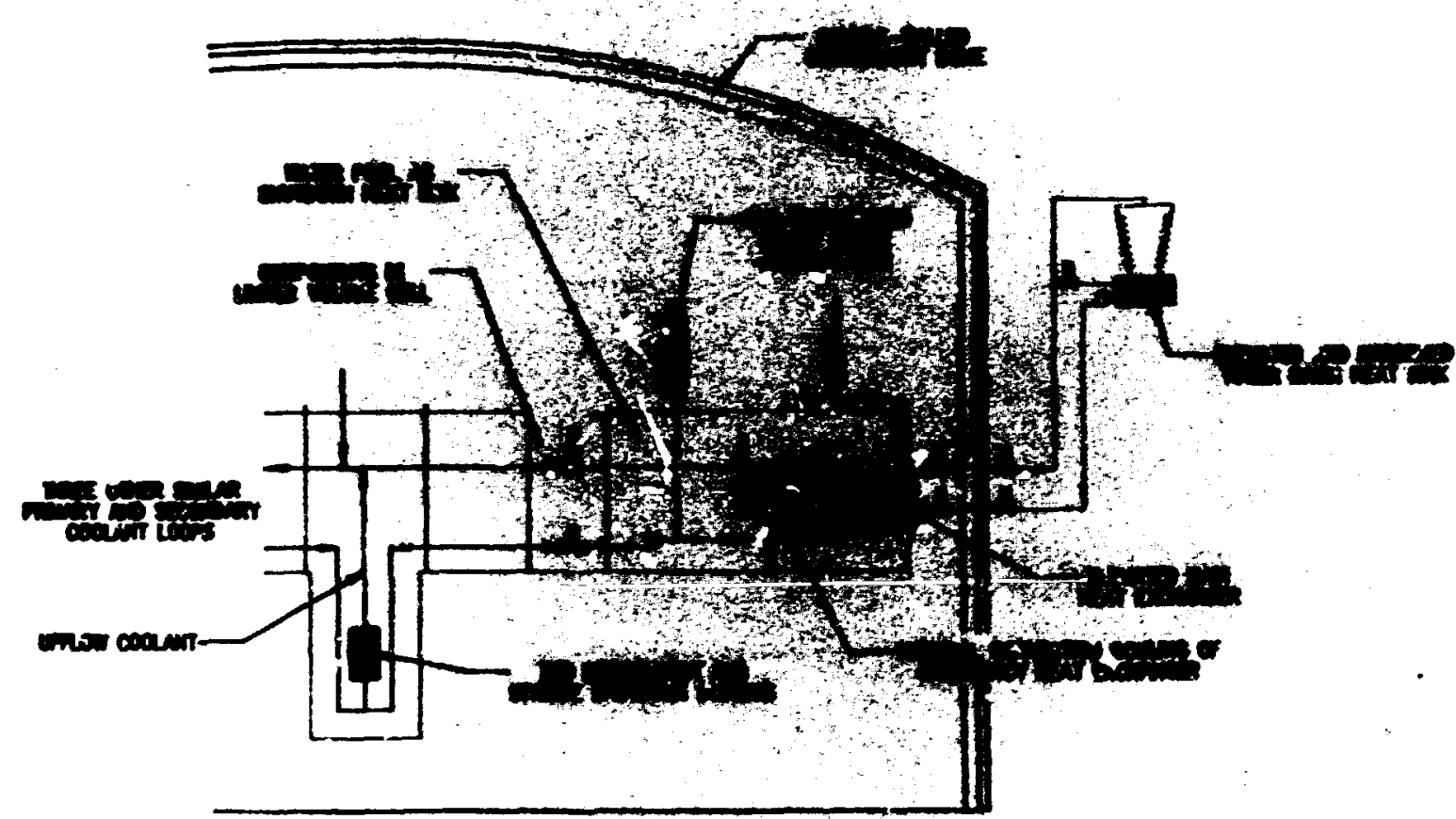

Fig 1.2 Reference conceptual dexigh of the cooling sytem.

was presented to the Advisory Committie on Nuclear Facility Safety, a top-level DOE committee reporting to the sccretary, in January 1990 , with favorable results.

Within the Laboratory, the post of scientific director for the ANS Project was created, reporting to the associate director for Physical Sciences and Advanced Materiais. The scientific director's task is to interact with the national and international scientific user community; to identify new instrumentation and experimental facilities needed for ANS in the arcas of neutron scattcring, materia's testing and irradiation, I.uclear physics, and isotope production; to represent ANS at scientific and professional meeting: and bricfings; and to provide scicntific suppoit to the ANS Project.
During the past year, the ANS quality program has matured in many areas. The ANS QA plan was approved by DOE-ORO and was issued under controlled distribution to all personnel working on the project and to associated key personnel outside the project organization. Six ANS Projectspecific policies and procedures were developed and approved for issue by the Project Review Committee. Detailed quality program provisions for controlling the development and use of software for the project have been developed and will be implemented throughout the proj! : in 1991.

Internal project $\mathrm{QA}$ monitoring activitics have been conducted during the year, beginning with 3 key activity revicw of the PS.2 preconceptual reference core development. 
No major technical problems were identified, but some administrative records were identified as needing upgrading and have been corrected. The improvements were also factored into the development process for the conceptual core design (CCD). An extensive surveillance of the ANS corrosion test loop activities was conducted. Again, no major technical problems were identified, but some administrative Jetaik needed improvement and have been completed. A program of quality assurance audits of project support contractors was initiated this year with audits performed at Argonne National Laboratory (ANL) on fuels development support activities and at Idaho National Engineering Laboratory (INEL) on seutronics and safety analysis support activities.

Early in FY 1990, the project conducued its first quality investigation. The investigation dealt with the loss of ANS cold source development data from the Lawrence Livermore National Laboratory's Cray computer. The investigation identified deficiencies with the formal administrative controls over the use of off-site computer facilities and difficulties in doing cost-effective backups of programs and data runs. Corrective actions were taken within the project to provide better controls over critical data computing, and recommendations were made to the laboratory to improve the formal administrative controls over use of off-site computer facilities.

ANS has become involved with the National DOE Reactors QA Managers group and hosted their February meeting. This group meets periodically to share ideas and discuss common concerns relative to the quality assurance programs for DOE-owned, contractor-operated reactors. The group's goal is to achieve a higher level of quality through a relatively unified approach to solving common quality problems.

The project continued to receive frequent expert reviews ( 28 in the last 24 months), giving strong assurance of the souridness of our approach and providing a valuable addition to the internal $Q A$ efforts. 


\section{2 \\ Research \& Development}

Thirteen R\&D tasks have been identified as essential to the ANS project. These R\&D tasks are required to address feasibility issues, to provide some of the data needed for the preparation of the Conceptual Design Report, to produce the data necessary to make a rational decision when alternative desigrs concepts are identified, and to examine and demonstrate the applicability of technological advances. This chapter summarizes progress on these tasks for the reporting period and includes activities at ANL, Babcock and Wilcox (B\&W), Brookhaven National Laboratory (BNL), INEL, Martin Marietta Engineering, National Institute of Standards and Technology (NIST), Oak Ridge National Laboratory (ORNL), Science Applications International Corporation, the University of Tennessee, and the University of Virginia.

\subsection{REACTOR CORE DEVELOPMENT}

The reactor core development task provided the support that helped lead to the selection of a reference conceptual corc geometry during this report period. By the end of the report period, tasks had heen initiated to provide a comprehensive cvaluation of the performance characteristics of this CCD. The major activitics during the report period for this task are summarized in Scets. 2.1.1 and 2.1.2.

\subsubsection{Development of Analysis Techniques}

This task includes the development of analysis techniques and involves software and basic data deemed necessary to perform numerical analyses of the reactor core performance. Two major activities, $\mathrm{MCNP}^{2}$ model development and examination of techniques for treatment of uncertainties, were addressed during the report period.

\subsubsection{MCNP Model Development}

A three-dimensional (3-D) continuousenergy coupled neutron-gamma Monte Carlo model of the ANS reactor core was developed using the MCNP Version 3b computer code. During this report period, the model matured from a simple representation of the ANS core to a complex model that included control rods, shutdown rods, beam tubes and other experimental facilities. This model was used in evaluations (such as control rod worths, voiding analysis, and beam tube worths) to support the ANS conceptual core characterization activities.

\subsubsection{Treatment of Uncentaintica}

Although many reactor analyses are performed based on nominal or best estimate information, uncertainties must be accounted for in the cvaluation of reactor performance. In the past, this issuc has sometimes been 
avoided by the use of upper limit evaluations. This approach. however, can lead to ultraconservatism that results in overdesign and, in the end, actual margins or confidence levels are still not known. Therefore, a task was initiated during this report period to identify and develop an appropriate approach for the accounting of uncertainties in order to determine safe reactor conditions that are compatible with a given quantified confidence level. It was decided that the statistical Monte Carbo technique was the best approach to achicve this goal. Using this approach, input parameters are ureated as distributions rather than single values, and the output is obtained in the form of a distribution that can then be evalicated statistically.

This technique requires detailed error cistributions for each of the parameters that appreciably affect or limit the reactor performance. If such data are not available, the results of such a sophisticated technique can be meaningless. Therefore, a detailed ANS reactor core uncertainty analysis plan was developed to provide the means for determining error distributions for appropriate parameters as well as the conversion of analysis techniques to the use of statistical distributions.

At the end of the reporting period, the conversion of the ANS steady-state thermalhydraulics code to a statistical methodology was nearly complete. In addition, preliminary distributions had been developed for many of the major input parameters. Although there is considerable effort needed over the next seven years to provide a full development of the treatment of uncertainties for the ANS, it appears that a viable approach has been identified and progress has been made toward its implementation.

\subsubsection{Support to Design}

The R\&D program provided support to the design of the reactor core in the following two major arcas during the report period: (1) the development of a conceptual core geometry, and (2) the comprehensive analysis of this new conceptual core geometry.

\subsection{New Conceptual Core Goometry}

A reference conceptual core geometry was selected to form the basis of continuing conceptual design studies. This core geometry shown in Fig. 21 differs but little from the final preconceptual core geometry. ${ }^{3}$ The minor dimensional changes vere made to respond to or take advantage of new knowledge generated by the R\&D program. Specifically, the radial thickness of the fuel region was reduced to increase the critical coolant velocity for plate collapse. This reduction in the fuel cross section was accompanied by a 33- $\mathrm{mm}$ increase in the fueled length to maintain the same active volume $(67.4 \mathrm{~L})$ as the final preconceptual

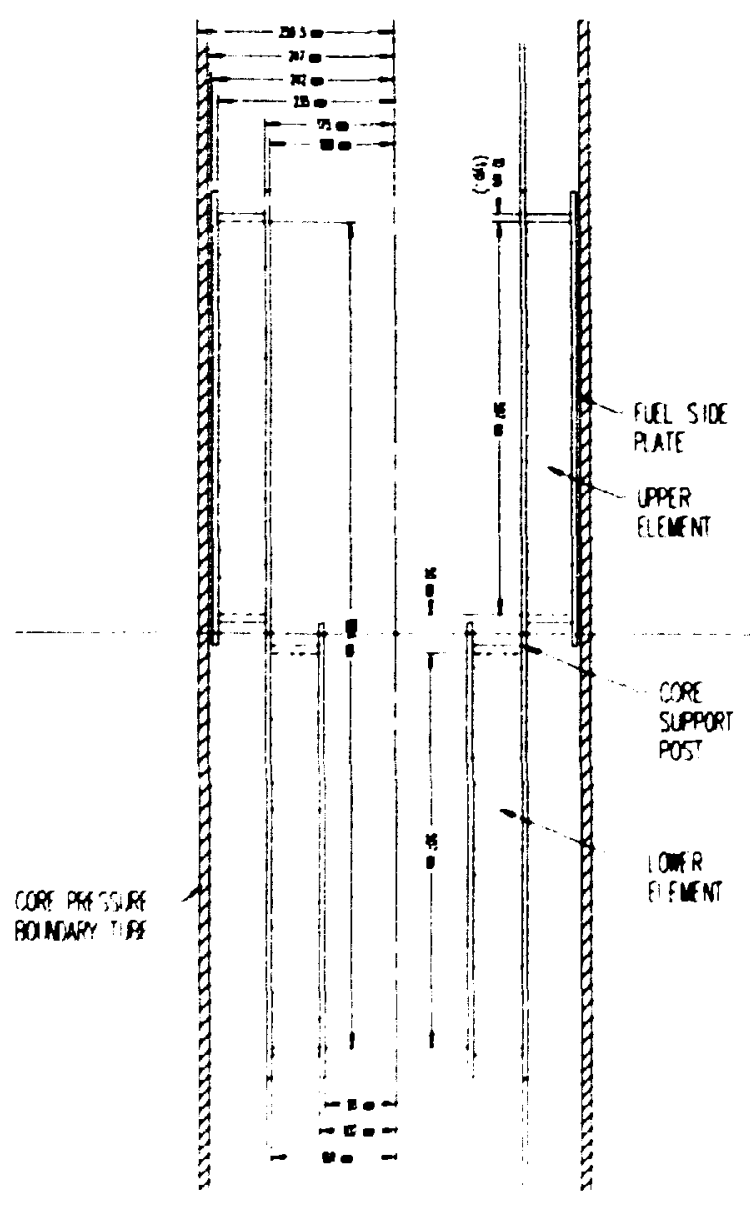

Fig 21. Conceptual core geometry. 
core geometry. In addition, improvements in the fuel grading protile allowed for an increase of $7.5 \mathrm{MW}$ in the amount of heat that could be removed by the core coolant while simultaneously increasing the margin to the incipient boiling limit and maintaining the same nominal unperturbed neutron flux level $\left(8.5 \times 10^{19} \mathrm{~m}^{-2} \cdot \mathrm{s}^{-1}\right)$.

\section{New Conceptual Core Evaluation}

A series of evaluations was performed for the new conceptual core geometry to characterize its performance. The neutronics work discussed in this section was performed at INEL using the PDQ diffusion code (2-D R-Z ANS model) and the MCNP Monte Carlo code (3-D ANS model). Additional work not covered in this report includes the ORNL steady-state thermal-hydraulics activities and the fuel grading work
Radial thermal tux profile New radial flux profiles (shown in Fig. 2.2) have been calculated using both the PDQ and MCNP computer codes. At the time of these calculations, the fuel grading process, which will have some effect on the radial flux profile, had not been completed

Eirects of $\mathrm{D}_{2} \mathrm{O}$ voiding on core reactivity. For the new reference conceptual core, the reactivity effect of voiding has been examined for various regions using the 3-D Monte Carlo model. The results of these evaluations are presented in Table 21. As indicated by the data in this table, all information to date indicates that voiding has a negative reactivity effect at power conditions. However, it should be noted that within the statistical uncertainty of the Monte Carlo analysis, the voiding of $\mathrm{D}_{2} \mathrm{O}$ in the bypass channel and the voiding of the region inside the control rods could be a small but positive effect. If

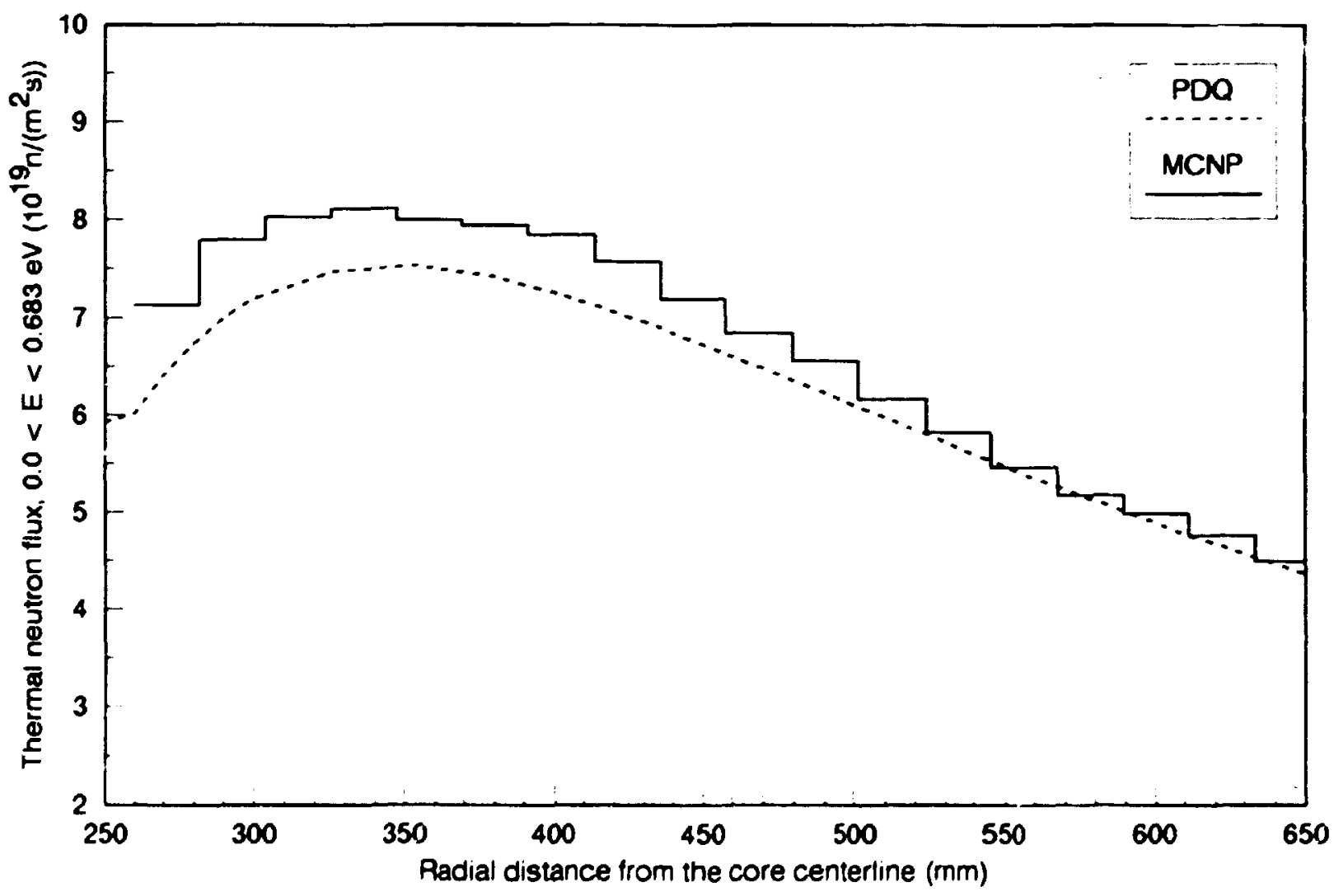

Fig 22 Comparian of BOC redial thermal Alu variations for MCNP and PDQ. 
Table 21. Effects of $D_{2} D$ voiding on core reactivity

\begin{tabular}{|c|c|c|}
\hline Region voided & $\begin{array}{l}\text { Core } \\
\text { multiplication } \\
\text { factor }\end{array}$ & $\begin{array}{l}\text { Reactivity } \\
\text { difference } \\
\text { (\%) }\end{array}$ \\
\hline None & $1.0188+.0035$ & Refere ce \\
\hline $\begin{array}{l}\text { None with rods } \\
\text { fully inserted }\end{array}$ & $0.8962 \pm .0034$ & Reference \\
\hline $\begin{array}{l}\text { Central hole } \\
\text { entire region } \\
\text { above midplane } \\
\text { below midplane }\end{array}$ & $\begin{array}{l}0.9480 \pm .0032 \\
1.0068 \pm .0030 \\
0.9502 \pm .0026\end{array}$ & $\begin{array}{l}-7.20 \pm 0.46 \\
-1.19 \pm 0.46 \\
-6.98 \pm 0.43\end{array}$ \\
\hline Inside control rods & $1.0176+.0042$ & $-0.12 \pm 0.55$ \\
\hline $\begin{array}{l}\text { Inside control rods } \\
\text { with rods fully } \\
\text { inserted }\end{array}$ & $0.9067 \pm .0038$ & $+1.16 \pm 0.46$ \\
\hline Bypass channel & $1.0156+.0025$ & $-0.31 \pm 0.33$ \\
\hline
\end{tabular}

more accurate analysis indicates that these regions have positive voiding effects, the design of these regions will be re-examined. The positive voiding effect shown in Table 21 when the control rods are fully inserted is not an issue because the system is very subcritical under these conditions. Voiding of the fuel coolant channels was previously evaluated for the preconceptual core and fourd to have a negative effect on reactivity, but those calculations have not yet been repeated for the conceptual core geometry. Further voiding analyses, including partial voiding, will be performed during the next year.

Light water contamination effecta. The results of a study of dilute light-water ingress into the $\mathrm{D}_{2} \mathrm{O}$ reflector and core region at various concentrations are displayed in Fig. 2.3. This study, performed with PDQ, agrees with earlicr studics performed on the preconceptual core. Ingress into the $\mathrm{D}_{2} \mathrm{O}$ reflector results in a sharp drop in core reactivity. Partial light-water ingress inside the core pressure boundary tube (CPBT) causes the highest reactivity insertion. As shown in Fig. 2.3, light-water concentrations of 5 to $15 \%$ within the CPBT would result in significant positive reactivity effects. Although this is considered to be a low probability event, a more dynamic analysis will be necessary to determine the actual safety implications.

Neutronics cvaluation of alternative fucl (UAl2). The uranium silicide fucl was originally selected for the ANS reactor for iwo major rcasons: high-thermal conductivity and high-uranium density. Over the last two years, the proposed core volume has in. creased. This decreased the average uranium loading required to maintain a 14-day cycle. Thus, even though the uranium silicide fucl is still the preferred fuel duc to its higher thermal conductivity, other fuel forms may 


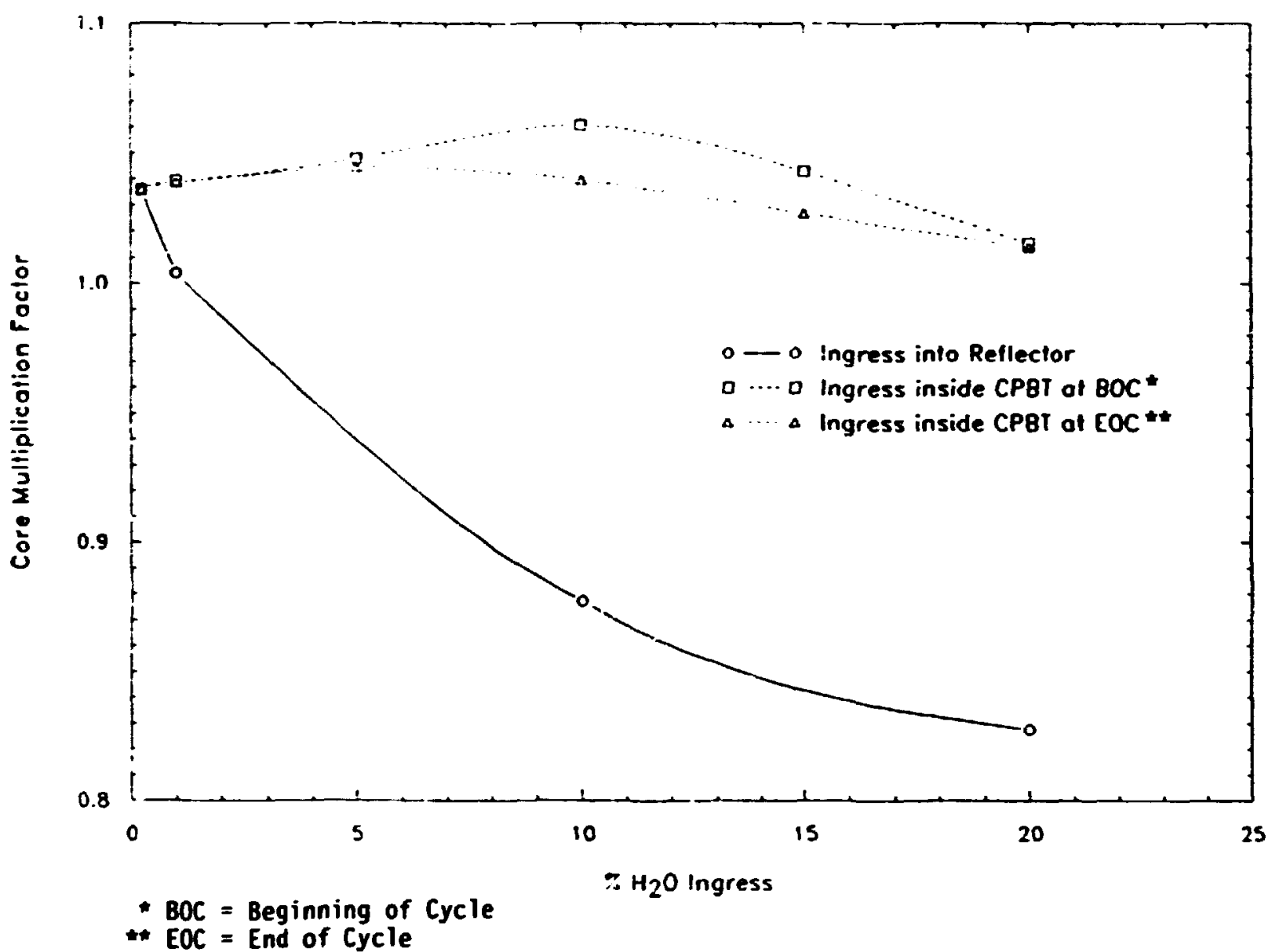

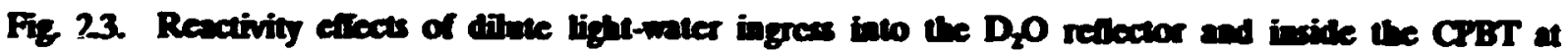

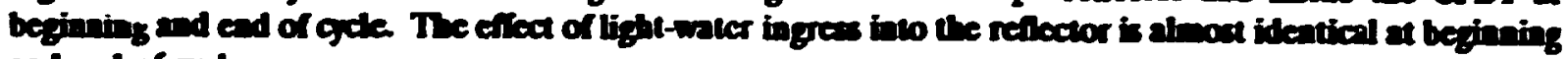
and end of crate

now be considered as backups. The uranium aluminide (UA) $\mathbf{J}_{\mathbf{z}}$ type fuel may be an acceptable substitute if, for example, the tests on the $\mathrm{U}_{3} \mathrm{Si}_{2}$ show unacceptable performance at high burnup rates. Therefore, a study was initiated to examine the neutronics impact of substituting $\mathrm{UAl}_{\mathbf{z}}$ for the uranium silicide fisel.

The diffusion theory code PDQ was used to perform this neutronics evaluation. $\mathrm{UAl}_{3}$ [the fuel commonly used in rescarch and test reactors such as the Advanced Test Reactor (ATR)] was cvaluated first and its impact was only a $0.06 \%$ reduction in reactivity. Other $\mathrm{UAl}_{\mathrm{z}}$ fuel forms were examined, and the maximum effect was found to be $0.11 \%$. It was dete:rmined that the use of $\mathrm{UAl}_{\mathrm{x}}$ fucl would have only minor impact on the core's neutronics performance and thus should be considered as a viable backup fuel.

\subsection{FUEL ELEMENT SPECIFICATION}

As stated in the previous section, the $\mathrm{U}_{3} \mathrm{Si}_{2} / \mathrm{Al}$ mixture continues to be the reference fuel for the ANS reactor core. The highlight of the year for the fuel development effort has been the restart of the High Fux Isotope Reactor (HFIR) and the irradiation of the first ANS fuel capsule in the target region. Progress is continuing in the und.crstanding and analytical modeling of fission. induced swelling of $U_{3} S_{i}$ through 
detailed study of irradiation data generated earlier in the Reduced Enrichment for Research and Tes! Reactors (RERTR) program. Refinements this year in the ANS core design, primarily in the optimization of fuel grading, have had relatively litte impact on the expected fuel fabrication or performance. Fabrication development efforts have concentrated on producing a set of developmental fuel plates with both axial and radial fuel gradients and on methods of evaluating the gradients and the overall homogeneity of the fuel.

\subsubsection{HFIR Target Capsule Irradiation Tests}

The first ANS capsule was irradiated in the target region of the HFIR during cycle 289, which ended on September 7, 1990. The capsule is now awaiting the availability of the hot cell facility for evaluation. The capsule contains 18 separate fuel holders, each containing two small samples of fuel/sluminum mixture. The test consists of $\mathrm{U}_{3} \mathrm{Si}_{2}$ at planned temperatures of from $250 \mathrm{tu} 425^{\circ} \mathrm{C}$, and $t$ imup is expected to range from $8-16 \times 10^{7}$ fissions $/ \mathrm{m}^{3}$ in the fuel particles, which is compurable to the estimated $9 \times 10^{27}$ average burnup for the ANS conceptual core. Additionally, $\mathrm{U}_{3} \mathrm{Si}$ is included at two temperatures. The fuel holders for a second test have been completed to the point of machining the final diameters (which control the temperatures). Final machining will await evaluation of the actual temperatures from the first capsule. The second test will include some $\mathrm{UAl}_{2}, \mathrm{UA}_{2}$ and $\mathrm{U}_{3} \mathrm{O}_{2}$ in addition to $\mathrm{U}_{3} \mathrm{Si}_{2}$ since these are considered viable backup fuels at the currently envisioned fuel loadings.

\subsubsection{Fuel Performance Studies and Modeling}

Analytical modeling of the performance of $\mathrm{U}_{3} \mathrm{Si}_{2}$ fucl has been significantly advanced by improving the basic model for fissioninduced swelling of $\mathrm{U}_{3} \mathrm{Si}_{2}$ that is employed in the compuier code DART! This was accomplished through detailed study of postirradiation data and samples generated earlier in the RERTR program.

It was found that swelling of $\mathbf{U}_{3} \mathrm{Si}_{2}$ consists of two stages having distinctly different rates as a function of burnup and that the onset of the second, more rapid stage was delayed by increased fissicn rate. These observations could not be explained with accepted swelling modek generated (primarily for $\mathrm{UO}_{2}$ ) through many years of experimental and theoretical work. A physically plausible modification of these modek, which yields a good fit to the $\mathrm{U}_{3} \mathrm{Si}_{2}$ swelling data, was developed by introducing a mechanism of fission-induced grain refinement. This phenomenon had been observed in high burnup irradiations of $\mathrm{UO}_{2}$ in the earty 1960s, and preliminary experimental work suggests that it does indeed occur in $\mathrm{U}_{3} \mathrm{Si}_{2}$

Further experimental and theoretical work, including ion bombardment and neu. tron diffraction studies, is expected to yield a detailed physical description of the irradiation behavior of $\mathrm{U}_{3} \mathrm{Si}_{2}$ as well as dispersion fuels in general. This will provide a much improved description of the irradiation performance of the ANS fuel elements.

\subsubsection{Fabrication Development}

Six developmental fuel plates containing the reference loading of $\mathrm{U}_{3} \mathrm{Si}_{2}$ with both an axial and radial gradient have been fabricated by B\&W. Four fuel plates with tungsten as a surrogate fuel and an avial gradient only were fabricatcd by ANL These plates are currently being evaluated for gradient geometry and fucl homogeneity. The fucl distribution will be determined by several techniques. The technique developed at $A N L$, vidco digitization of radiographs, will be compared to the more conventional techniques of digitization of radiographs by densitomicter and direct $x$-ray transmission scanning. 


\subsection{CORROSION LOOP TESTS AND ANALYSES}

In order to prevent axide film growth and other cortosion-related phenomena from compromising the performance of the fuel cladding in the ANS core, the corrosion bebrvior of aluminum alloy 6061 is being studied in a special test bop facility under an appropriately wide range of thermalbydraulic parameters. The teat bop, described in eartier reports, ${ }^{47}$ is a pressurized, forced-flow water loop fabricated entirely of $304 \mathrm{~L}$ stainless steel components and is capable of exposing aluminum alloy specimens at heat fures up to approximately $20 \mathrm{MW} / \mathrm{m}^{2}$ and coolant water velocities in excess of $30 \mathrm{~m} / \mathrm{s}$. The heat flux from the aluminum to the coolant channel is produced by self-resistance heating of the specimen by a dc power : spply. Instrumentation and equipment are available to maintain suitable water chemistry within the loop. In the past year, we have significantly increased our knowledge of this important reaction, including film growth, spallation, and internal reactions, and have expanded our data base describing the film growth kinetics. A preliminary correlation of the kinetic data was developed that provides for conservative calculations of oxide thickness, and thence the time-dependent temperature increases at various positions in the cladding and fuel for a designated range of conditions.

\subsubsection{Summary of Results: Update}

Our discovery that the inlet temperature to the test section (representative of the water temperatures in the stainless steel sections of the loop) was an important independent contributor to the film growth characteristics on $6061 \mathrm{~A}$ was the motive for designating $49^{\circ} \mathrm{C}$, the expected ANS value, for this variable in ensuing lests. Becausc the teat loop was designed prior to the new discovery, the stipulation of a $49^{\circ} \mathrm{C}$ inlet presently limits our ability to investigate all combinations of thermal-hydraulic parameters envisioned for ANS operation. Nevertheless, a wide range remains available for experimentation, and we are investigating methods to cxtend it further.

Since the last progreas report,' we have completed eight additional experiments in the ANS Corrosion Test Loop. Table 22 presents the test schedule for this report period and includes values for the controlled thermal-hydraulic parameters as well as the local coolant temperatures, interface temperatures, and heat fluxes for three arial posiions on each specimen. Since several of these parameters vary slightly with time, only the average values are given. The extent of the Fe-rich surface layer on each specimen is ateo indicated, as well as a comparison of the observed film thickness with that predicted by the Griess Correlation. While the nominal coolant pH during each test was 5 , maintained by nitric acid additions to the demincralized water in the bypass section of the loop, pH control problems were persistent in many of these tests. Comparatively small variations (i.e, $\pm 0.2 \mathrm{pH}$ units) were preh ably responsible for some inconsistencies in the measured oxidation kinetics. Thus, in the table, the $+/ 0 /$ - suffx on the $\mathrm{pH}$ value gives a qualitative ascessment of the effective $\mathrm{pH}$ for the experiment based on the observed variations.

(1) CTEST Nos. 15 and 16 completed a series of tests (along with CTEST No. 14) where the average heat flux was increased methodically while holding the coolant inlet temperature, velocity, and pH constant. The highest average heat flux utilized in this program to date was $18.7 \mathrm{MW} / \mathrm{m}^{2}$ in CTEST No. 16. The calculated growth curves for the oxide (bochmite) at the three reference positions on the specimen for this test are shown in Fig. 24. The values of the coolant velocity, $V_{c}$ inkt and outlet temperatures, $T_{c i}$ and $T_{\infty}$ and the average heat fux, $\phi_{\text {wy }}$ are listed on the figure; the local interface temperature, $T_{\text {we }}$ and heat flux, are also indicated for times near the beginning and near the 
Teble 22 Conraion lea bops. Completad lects and perneters

\begin{tabular}{|c|c|c|c|c|c|c|c|c|c|c|}
\hline IEST & ctr15 & cT16 & CI17 & crîs & cT19 & CT20 & CT21 & & & \\
\hline 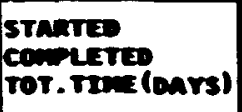 & $\begin{array}{l}9 / 12 / 99 \\
10 / 6 / 65 \\
24\end{array}$ & $\begin{array}{l}10 / 17 / 9 \\
10 / 20 / 9 \\
2.4\end{array}$ & I1119s & $\begin{array}{c}12 / 13 / 9 \\
1 / 3 / 50 \\
21\end{array}$ & $\begin{array}{l}1 / 16 / 99 \\
2 / 6 / 50 \\
21\end{array}$ & $\begin{array}{l}3 / 15 / 90 \\
3 / 20 / 5 \\
5\end{array}$ & $\begin{array}{c}4 / 9 / 9 \\
4 / 27 / 5 \\
21\end{array}$ & $6 / 12 / 90$ & $\begin{array}{c}7 / 2 / 99 \\
7160 \\
16\end{array}$ & $7 / 31 / 5$ \\
\hline & $5.0(-)$ & $5.0(0)$ & $5.0(0)$ & $5.0(+1)$ & $5.0(-)$ & 5.010 & $5.0(+)$ & $5.0(+)$ & $5.0(0)$ & 5.010 \\
\hline$(\mathrm{S} / \mathrm{m})$ & $500-650 \mid$ & 550 & $350-550$ & $260-450 \mid$ & $450-550$ & 450 & $|300-400|$ & $250-400 \mid$ & 450 & 50 \\
\hline ImLT TES & 49 & 49 & 49 & 49 & 49 & 49 & 49 & 49 & 49 & 49 \\
\hline Veloctn & 25.6 & 25.6 & 25.5 & 10.0 & 20.1 & 15.1 & 25.6 & 25.6 & 25.8 & 25.6 \\
\hline pouren (di) & 4.8 & 67.0 & 21.8 & 22.2 & 45.0 & 45.0 & 4.7 & 22.2 & 44.7 & 2.8 \\
\hline 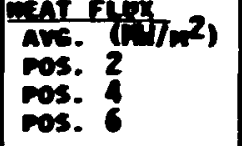 & $\begin{array}{l}12.5 \\
12.3 \\
12.8\end{array}$ & $\begin{array}{l}18.7 \\
17.3 \\
17.2 \\
80.2\end{array}$ & $\begin{array}{l}6.1 \\
6.1 \\
6.1 \\
6.1\end{array}$ & $\begin{array}{l}8.3 \\
8.2 \\
8.3 \\
6.5\end{array}$ & $\begin{array}{l}12.5 \\
12.1 \\
12.5 \\
13.4\end{array}$ & $\begin{array}{l}12.6 \\
12.3 \\
12.7 \\
13.5\end{array}$ & $\begin{array}{l}12.4 \\
11.9 \\
12.3 \\
13.2\end{array}$ & $\begin{array}{l}6.2 \\
6.2 \\
6.2 \\
6.2\end{array}$ & $\begin{array}{l}12.5 \\
12.3 \\
12.4 \\
12.6\end{array}$ & $\begin{array}{l}6.2 \\
6.2 \\
6.2 \\
6.2\end{array}$ \\
\hline $\begin{array}{l}\cos 2 \sin \\
\cos .2 \\
\cos .4 \\
\cos .6\end{array}$ & $\begin{array}{l}53 \\
62 \\
71\end{array}$ & $\begin{array}{l}56 \\
62\end{array}$ & $\begin{array}{l}51 \\
56 \\
60\end{array}$ & $\begin{array}{l}55 \\
\mathbb{c} \\
\pi\end{array}$ & $\begin{array}{l}55 \\
65\end{array}$ & $\begin{array}{l}57 \\
72 \\
87\end{array}$ & $\begin{array}{l}53 \\
62 \\
71\end{array}$ & $\begin{array}{l}51 \\
56 \\
60\end{array}$ & $\begin{array}{l}54 \\
62\end{array}$ & $\begin{array}{l}51 \\
55 \\
55\end{array}$ \\
\hline $\begin{array}{l}\text { Intengace T(C) } \\
\cos .2 \\
\cos .4 \\
\cos .6\end{array}$ & $\begin{array}{l}136 \\
152 \\
152\end{array}$ & $\begin{array}{l}\frac{169}{101} \\
\frac{201}{201}\end{array}$ & 104 & $\begin{array}{l}145 \\
154 \\
164\end{array}$ & $\begin{array}{l}152 \\
162 \\
176\end{array}$ & $\begin{array}{l}190 \\
\frac{192}{203}\end{array}$ & $\begin{array}{l}134 \\
142 \\
153\end{array}$ & $\begin{array}{r}95 \\
102\end{array}$ & $\begin{array}{l}136 \\
142 \\
149\end{array}$ & $\begin{array}{r}95 \\
102 \\
102\end{array}$ \\
\hline FE-RICM LAYER? & meavr & Lrent & Lerent & meavr & mears & mearr & medorum & 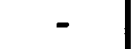 & - & wearr \\
\hline $\begin{array}{l}\text { oxroe Paoouct } \\
\text { (JK EArESS) } \\
\text { SPALL AT Nos6? }\end{array}$ & $\begin{array}{c}\text { Less? } \\
m\end{array}$ & $\begin{array}{l}\text { sane } \\
\text { res }\end{array}$ & $\begin{array}{r}\text { Less } \\
\text { mo }\end{array}$ & $\begin{array}{r}\sin x \\
\sin \end{array}$ & Less & $\begin{array}{l}\text { sane } \\
\text { res }\end{array}$ & $\begin{array}{r}\text { Less } \\
\text { rEs }\end{array}$ & $\begin{array}{c}\text { sane? } \\
-\end{array}$ & $\begin{array}{c}\text { Less } \\
-\end{array}$ & $\begin{array}{c}\text { Less? } \\
m\end{array}$ \\
\hline
\end{tabular}

- TEAR-SMEET DATA.

end of the test. Because of the aggressive thermal-hydraulic conditions, specimen temperature increases were rapid and the experiment was terminated after only about 2.5 days. In this experiment, the comparatively large axial temperature gradient along the specimen caused significant variation-withposition and changes-with-lime in the local heat flux and, thus, the interface temperatures along the specimen. For example, as shown in Fig. 24, the heat flux at position 6 (near the coolant exit) changed from 19.4 MW/m $\mathrm{m}^{2}$ carly in the experiment to $21.1 \mathrm{MW} / \mathrm{m}^{2}$ near the end. As the average power was maintained at a constant level, decreases in the heat flux were observed at position 2 (near the inlet). Compared to scveral other CTESTs that exhibited rapid film growth, CTEST No. 16 was distinguished by substantially higher heat fuxes and interface temperatures, factors that govern the effective temperature of the growing oxide film and its growth rate. The relatively moderate rates of film growth in this instance demonstrate the effect of lower coolant inlet temperatures noted above. While not apparent from the behavior of the rate curve for position 6 , spallation of the bochmitc film was found at the hot end of the specimen at the conclusion of the experiment.

While at first glance spallation appcars to offer some potential bencfits for improved heat transfer in the system, it has been reported in our work," and carlier by Gricss," that spallation in the 6061 alloy is associated 


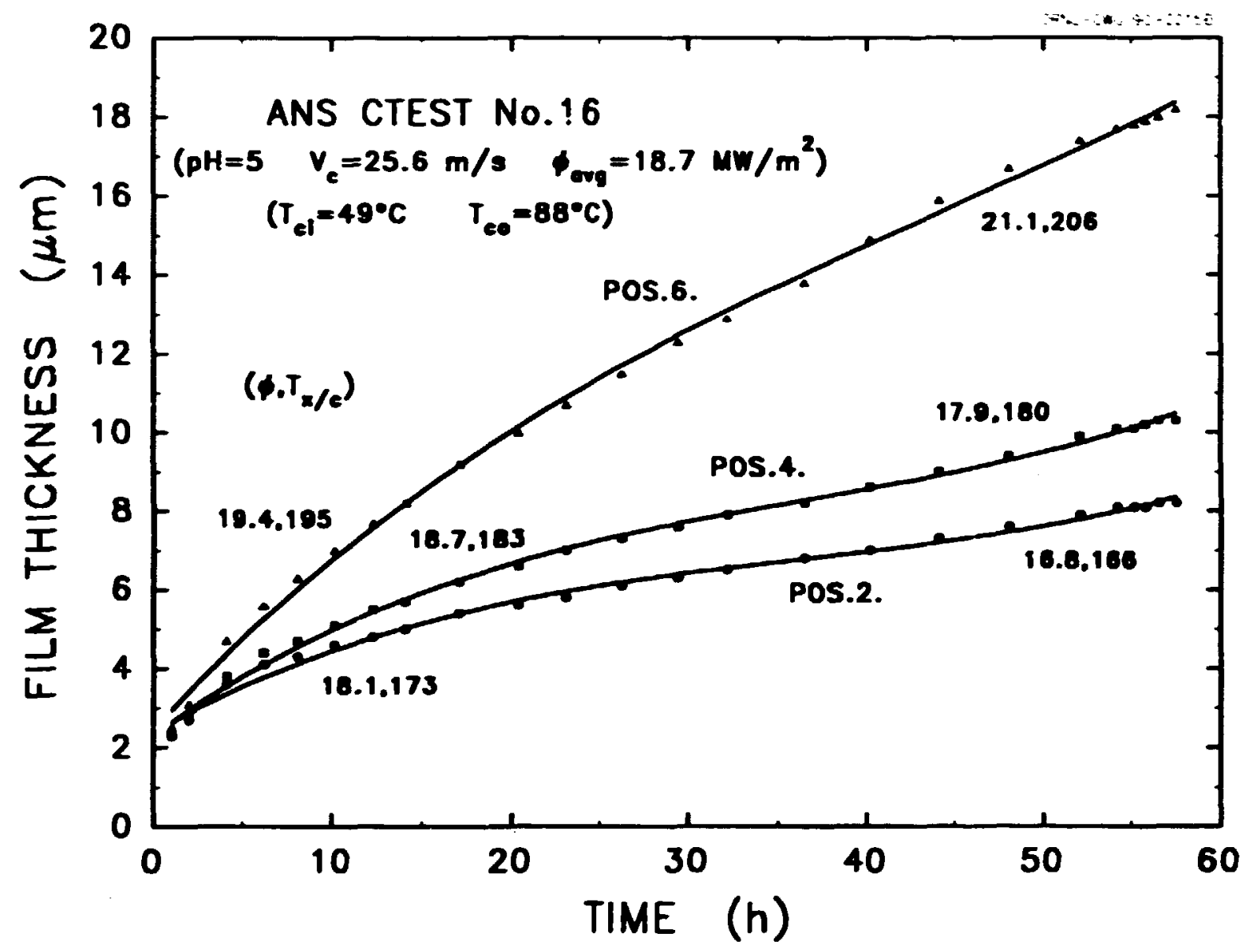

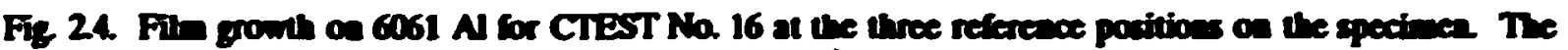
ved was conducted a a a arage beat bur of $187 \mathrm{MW} / \mathrm{m}^{2}$.

with the onset of extensive internal reactions beneath the oxide. Metallographic inspection of cross sectinns of such specimens often revealed severe attack within the metal undertying the spalled film. An example is given in Fig. 2.5 that shows a cross section from a spalled region with a deep zone of intemal reaction. While the remnants of the boehmite product film are visible in the upper portion of the micrograph, the central area clearly shows both grain boundary and intragranular attack, as well as apparent voids and internal reaction products. Similar behavior in ANS fucl cladding would be unacceptable. No internal reaction zones werc observed bencath unspalled films, even when examination by transmission clectron micros- copy (TEM) was accomplished, ${ }^{10}$ implying that these features were a result of spallation rather than the cause.

(2) In CTEST No. 17, we attempted to emulate a cladding local hot spot by machining a transverse notch in the test specimen near its midpoint. Subsequent cvaluation indicated that the axjal dimension of the notch was too small to provide an effective hot spot. Due to the high thermal conductivity of the aluminum, the intended concentration of the local heat flux was attenuated, accounting for only minor effects being observed.

(3) CTEST Nos. 18, 19, and 20 werc tests designed to produce data for a range of parametcrs appropriatc to the hotter (ncarexit) sections of the ANS core. In these tests, 


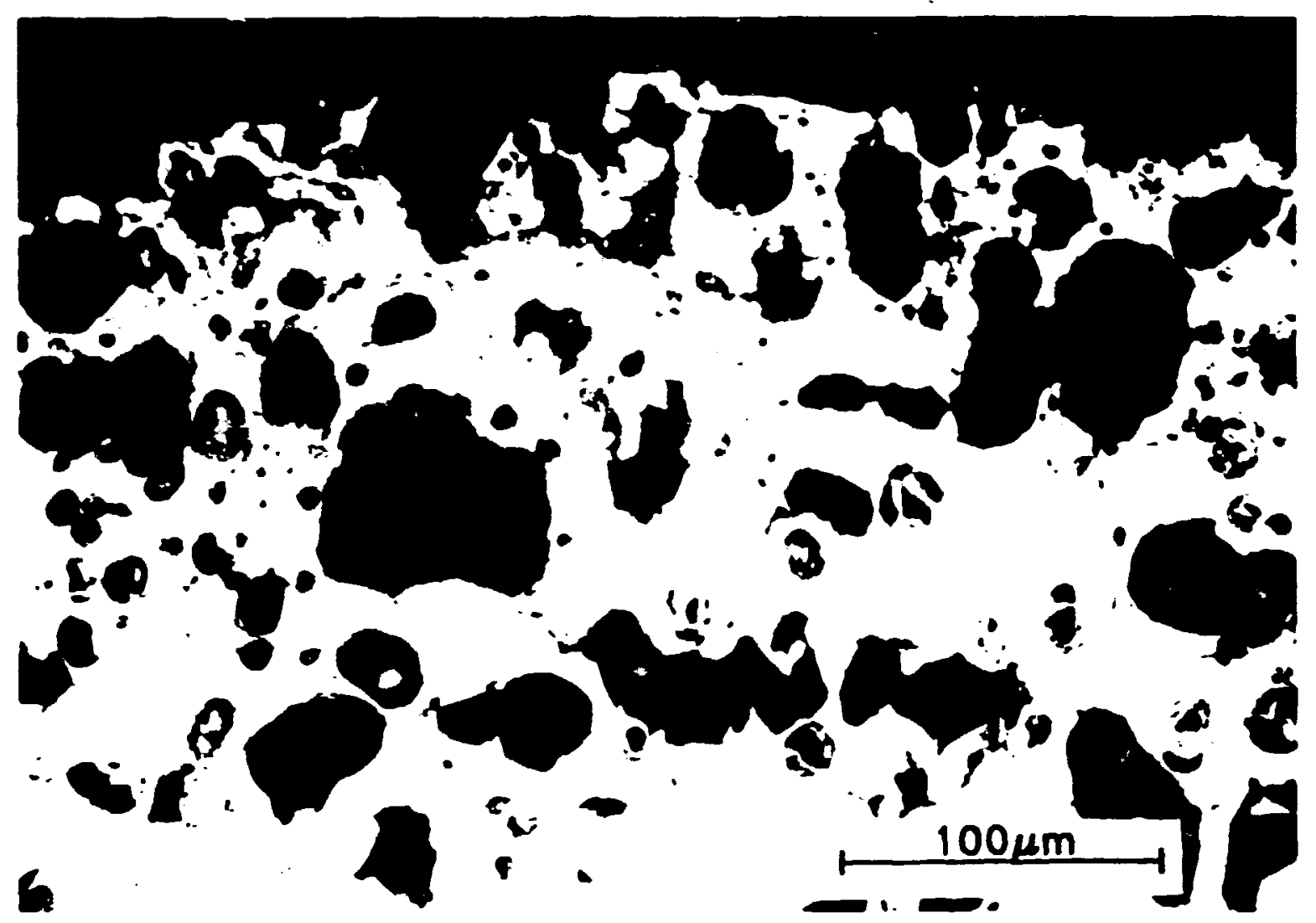

Fig 25. Cross section from a CTEST specinen exibiting a docp internd reaction sone Nole attact along

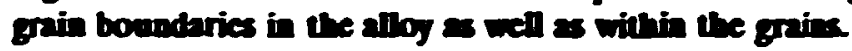

the heat flux and coolant velocity were adjusted to produce higher interface and oxide temperatures than those attained previously. While results of these tests were significant, quantitative comparisons were clouded duc to small inadvertent variations in the coolant chemistry. The importance of such tests is high, and several will be repeated. In fact, CTEST No. 21 essentially duplicated an carlier test, onc objective being to check the scnsitivity of film growth to changes in coolant $\mathrm{pH}$.

(4) In CTEST No. 22, the coolant and interface tempcratures were shifted scveral times during the test by changing the heat .1ux. While this test has not yet been analyzed completely, the film growth rates responded to these changes in a predictable manner, suggesting that our assumed model for film growth is reasonable.

\subsubsection{Preliminary Correlation}

The ANS designers need the means to predict the oxjde growth at any point on the cladding as a function of its thermalhydraulic history so as to ensure that excessive temperatures are not reached in either the fucl or the cladding during the life of the core. Experimental measurements from the ANJ Corrosion Test Loop describing the growth of the bochmite $\left(\mathrm{Al}_{2} \mathrm{O}_{3} \cdot \mathrm{H}_{2} \mathrm{O}\right)$ films on the exposed aluminum surfaces are now available for a range of coolant conditions and heat fluxcs, and these results have been analyzed to demonstrate the influence of several important experimental variables. 
During this report period, a subset of our data base particularty appropriate to the ANS conditions presently anticipated was used in develop a preliminary correlation' based on an empirical oxidation model used to describe the rate curves. These data were taken from tests through CTEST No. 16 and were limited to those tests conducted with coolant pH of 5 , coolant inlet temperatures between 39 and $49^{\circ} \mathrm{C}$, and coolant velocities of 25 to $26 \mathrm{~m} / \mathrm{s}$. The analysis correlated the oride growth rates to the local coolant temperature and heat flus, and resulted in the following expression:

$$
d x / d t=t / x,
$$

where

$$
\begin{aligned}
& \mathbf{d x} / \mathrm{dt}=\text { rate of layer growth, } \mu \mathrm{m} / \mathrm{h} ; \\
& \mathrm{x}=\text { layer thickness, } \mu \mathrm{m} ; \\
& \mathrm{n}=\text { constant, } 0.351 ; \\
& \mathbf{k}=\text { rate constant, } 6.992 \mathrm{E} 5 \\
& \exp \left[-7592 /\left(\mathrm{T}_{\mathrm{c}}+10 \mathrm{~s}\right)\right] \mu \mathrm{m}^{1351} / \mathrm{h} ; \\
& \mathrm{T}_{\mathrm{c}}=\text { local coolant temperature, } \mathrm{K} ; \\
& \phi=\text { local heat flux, } \mathrm{MW} / \mathrm{m}^{2} .
\end{aligned}
$$

This expression conservatively predicts oxide thicknesses and can be used as noted above to determine temperature changes in the cladding and fuel at given points on the clad surface.

In addition, data analyses of all tests through CTEST No. 16 for coolant pH - 5 and a heat flux of $-12 \mathrm{MW} / \mathrm{m}^{2}$ show that the growth rate increased rapidly with local coolant temperature in those tests where the inlet temperature was $57^{\circ} \mathrm{C}$ or higher; for tests with inlet temperatures below $50^{\circ} \mathrm{C}$, the growth rate remained low even at higher local temperatures. From this observation, we have recommended that the reactor designers maintain the reactor primary coolart inlet at $<50^{\circ} \mathrm{C}$. Also, on the basis of our tests performed under approximate steadystate coolant and power conditions, we have proposed that spallation of the oxide film, an undesirable event for ANS fucl cladding, takes place only when the temperature at the oxide-metal interface has increased by more than $114^{\circ} \mathrm{C}$ or when the temperature drop across the oxide film exceeds $119^{\circ} \mathrm{C}$ (which is an almost equivalent condition).

\subsection{Additional Testing}

Experimental efforts are continuing. It is apparent that an expanded data base, in conjunction with improved oxidation models and analyses, will provide a better predictive capability for film growth on aluminum alloy surfaces under beat transfer conditions. The ANS Corrosion Test Loop is a unique tool that provides the means to test, and eventually to improve, clad performance as a greater understanding of this complicated reaction evolves.

\subsection{THERMALHYDRAULIC LOOP TESTS}

The thermal-hydraulic performance of the ANS reactor will directly influence both normal and off-normal operational limits and behavior. Characterization of this behavior will require correlations and models that accurately predict the important thermalhydraulic phenomena. This task will include the measurement and the analysis necessary to validate correlations and models that, in turn, will be used to assess the capability for forced and natural convection under estimated hot channel conditions. The specific phenomena that are to be examined are (1) single-phase heat transfer coefficients and friction factors, (2) the point of incipient boiling. (3) nucleate boiling heat transfer coefficients, (4) two-phase pressure-drop characteristics in the nucleate boiling regimes, (5) flow instability limits, and (6) critical heat flux (CHF) limits.

\subsubsection{Test Loop}

Several sets of experiments will be required to establish the thermal-hydraulic 
operating limits of the ANS reactor. Some of these tests will be performed in the ANS Thermal-Hydraulic Test Loop (THTL) presently under construction. The loop is designa: to provide known thermal-hydraulic conditions to a test section which simulates a full-kngth aluminum coolant subchannel of the ANS core. An isometric diagram of the bop and its primary components is shown in Fig 26. A Moyno pump with a variable speed drive which approximi tes positive displacement type performance will provide coolant velocities over a wide range (up to
$35 \mathrm{~m} / \mathrm{s}$ ). In combination with a variable bypass leg, the loop should allow operating in natural circulation regimes. A high-pressure maiceup pump in combination with a letdown value provides pressure control for the loop. Two de power supplies of 18,000 and 25,000 A provide direct eiectrical-resilance heating of the test section. A low-pressure loop provides water chemistry control capability and the source of makeup water for the high-pressure portion of the loop. Instrumentation will include test-section temperature measurements along its length and fast

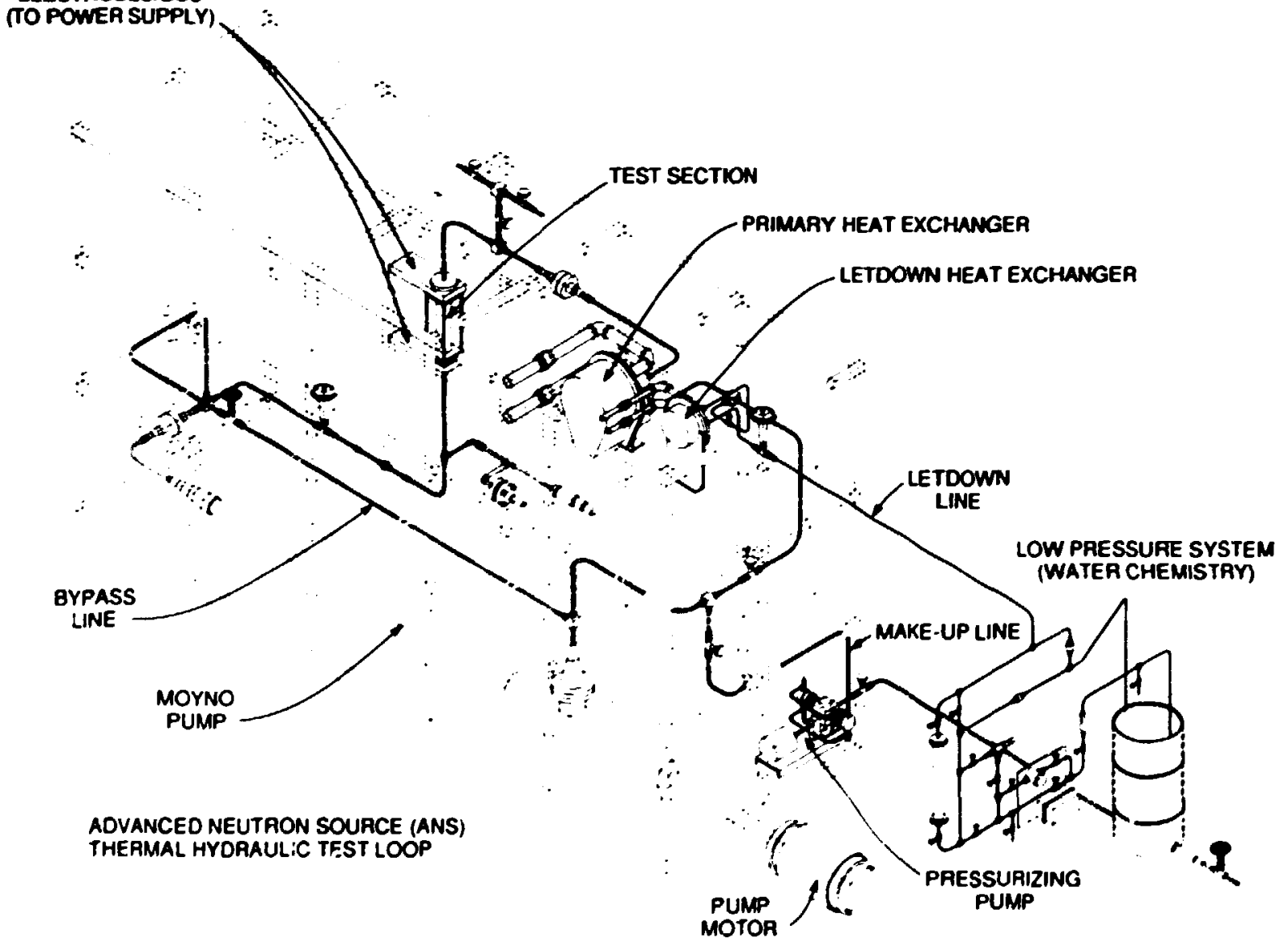

FH:ATIIRF:

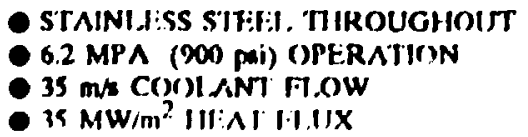

369 kW SPFCIMEN PIDWF:R

- CONTROI. (OF WATER CIIF:MISIRY

- cOOLANT TFMPI:RATURF CONTROI.

- COMPIITHERIZJED CONITRII., SAJTETY.

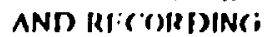

Fie 26. Lometric view of the ANS thermal-bydraulic teat loop. 
responsc measurement of flow, differential pressure, and absolute pressure for transient conditions.

\subsubsection{Thermal-Hydraulic Loop Schedule}

At the end of this reporting period, the loop was under construction. Significant delays have been encountered in delivery of the primary pump and in obtaining necessary environmental compliance approvals for the system cooling water source. It is expected that the loop will be operational early in the second quarter of FY 1991. An initial series of 55 tests is planned to cover the range of conditions expected during ANS operation, with follow-up testing as needed. Reductions in the FY 1991 budget for this activity will allow for only ten of these tests during the coming year. The first series of tests will be used to shake down the loop and to benchmark the loop against existing test data. The second series of tests will be aimed at parametrically varying the coolant conditions around the operating point. The third serics is aimed at examining the low-flow CHF/flo:v instability behavior. The fourth $\mathbf{s e}^{-} \mathrm{s}$ of tests will examine the effect of oxide on the thermal limits, and the fifth series vill substitute $\mathrm{D}_{2} \mathrm{O}$ for $\mathrm{H}_{2} \mathrm{O}$ as the coolant to confirm the thermal limit behavior.

\subsection{REACTOR CONTROL AND SHUTDOWIN CONCEPTS}

Since the last report period, a basic control and shutdown system concept has been identified, the performance criteria for the control and shutdown systems have teen better defined, and a comprehensive analysis of the basic concept has becn initiated.

\subsubsection{Basic Control and Shutdown System Concept}

Control and shutdown of the reactor system is provided by two independent systems: a control and shutdown system located in the central hole region of the reactor core (referred to as the inner rod system) and a shutdown-only system located in the reflector region (referred to as the reflector rod system).

The inner rod system is composed of four rods located in the central hole with hafnium used as the absorber material. This system provides approximately -10.55 of shutdown even if one of the four rods and all of the reflector shutdown rods fail to scram. These rods are used to control excess reactivity and to provide a fast scram capebility. When fully inserted, these rods extend from just above the upper fuel element to just belor: the lower fuel element. These rodi are withdrawn upward to near the core midplane to achieve criticality at beginning-of-cycle (BOC). During the cycle, the rods are slowly withdrawn upward so that at end-of-cycle (EOC) the bottom of the rods is just above the upper fuel element.

The reflector shutdown system is composed of eight rods which also use hafnium as t'. $e$ absorber material. The reflector shutdown system provides approximately $-15 \$$ of shutdown with seven of eight rods inserted, even if the inner control system fails to scram. These rods are fully withdrawn at all times during the cycle and are parked below the core elevation.

\subsubsection{Criteria for the Control and Shutdown System}

The two major performance criteria for the inner rod system are to provide (1) adequate shutdown with one stuck rod and appropriate uncertainties, and (2) is of negative rcactivity in $80 \mathrm{~ms}$, including release time, even at EOC when the rods have their lowest incremental worth. Although adequatc shutdown margin has not been finally defined for the conceptual core, it appears clear that the -10.55 provided by this system is sufficient to meet the criteria. At present, these inner :ods ar: accelcrated at $6 \mathrm{~g}$, following a scram signal providing 15 of nega- 
tive reactivity insertion in about $70 \mathrm{~ms}$. This allows the system to cope with a 1.25 reactivity step insertion without exceeding fuel specification limits.

The reflector rod system has similar criteria. This system must also provide (1) adequate shutdown with one stuck rod and appropriate uncertainties, and (2) fast scram capability. The $-15 \$$ obtained by insertion of seven of eight rods provides sufficient shutdown. The fast scram criteria, however, are still being examined. The tradeoff of a vet y fast scram system (70-100 ms to obtain -15 such as that for the inner rod system) us a somewhat slower scram system (1 to $2 \mathrm{~s}$ for the same worth) is being evaluated. The very fast system would require that the rods be parked in a relatively high-worth region, resulting in cooling and burnup problems for the rods as well as igher impact on beam tube fluxes. A 1 to $2 \mathrm{~s}$ time frame for a negative insertion of 15 would allow these rods to be parked in the lower regions of the reflector.

\subsubsection{Comprehensive Analysis of the Control and Shutdown System}

At the end of the repcr' period, evaluations had been initiated to examine the coolability, structur al stability, minimum hafnium loading, and rad lifetime for the inner rods. Evaluations for the reflector rods cannot be performed until the issue of location is resolved.

ine ability to cool the inner rods has not yet been demonstrated. Initial analytical results indicate that cooling of the halnium is at best marginal. Hafnium is a high $\mathrm{z}$ matcrial, and therefore the gamma hrating of hafnium produces relatively high heat loads. At the end of the reporting period, geometry changes and reductions in hafnium loadi. $g$, as well as possible absorber material changes, were being examined to resolve this issue.

The control rod lifetime for the inner rods has not been established. However, ini- tial analysis indicates that irradiation damage rather than hafnium burnup will be the limiting factor. Based on ATR experience, it would appear that the hafnium rods would have at least a 4-month lifetime. However, more detailed structural analysis will have to be performed before a defensible control rod lifetime can be identified.

\subsection{CRITICAL AND SJB- CRITICAL EXPERIMENTS}

This task has not becn initiated. Due to budget shortfalls for FY 1990, the planning for this task was again deferr $\sim 1$. In the present R\&D program, a preliminary critical and subcritical experiment plan would be developed over the last half of FY 1991. This would be followed by approximately a year of preanalysis of the planned experiments and discussion with facility personnel to produce a final experiment plan. The experiments would then start around the beginning of FY 1994 and are expected to last for about a year. Analysis of the experiments would proceed into 1995 and provide input to the final core geometry decision scheduled for late 1995. Additional critical and/or subcritical experiments beyond this schedule may be necessary but have not yet been defined.

\subsection{MATERIAL DATA, STRUCTURAL TESTS, AND ANALYSIS}

Long-term successful operation of the ANS requires research in several areas to ensure structural adequacy because of the extremely high neutron fluence and the high coolant flow rates. Work during this report perind has focused on four primary areas: (1) CPBT, (2) characterization of irradiated 6061-T651 aluminum, (3) fucl plate stability, and (4) control element vibration. Progress in cach of these areas is discussed in the following sections. 


\subsection{Core Pressure Boundary Tube}

The CPBT concept employs a primary pressure containment that is of just sufficient diameter to envelop the reactor core and a small bypass flow section. This allows the surrounding reflector vessel, which contains the various guide tubes and beam tubes, to operate at a relatively low pressure.

After careful consideration of candidate materiak, 6061-T651 aluminum was selected as the referenre CPBT structural material Alhough it has been used in previous research reactors, 6061-T651 aluminum has not been included in : he American Society of Mecnanical Engineers (ASME) Boiler and Pressure Vessel Code for Class 1 nuclear construction. The project has formally requested the ASME Boiler and Pressure Vessel Code Committee to include 6061-T6 and 6061T651 aluminum as an acceptable material for Clasi: 1 components. That request must be corssiciered and approved by a series of Code committees up through the Main Committee of the ASME Boiler and Pressure Vessel Committee. The request was considered and approved at the subgroup level during the September 1990 Code meetings and passed on to the Subcommittee on Nuclear Power for their consideration. Code approval for use of 6061-T6 and 6061-T651 aluminum in Class 1 nuclear construction may be obtained in 1991.

\subsubsection{Characterization of Irradiated 6061-T651 Aluminum}

The extremely high neutron flux is expected to produce embrittleinent of the CPBT and reflector tank. It is anticipated that embrittement of the 6061-T651 aluminum will limit the life of the CPBT. A major irradiation program is planned to provide data requ.-ed for estimating the loss of fracture toughness caused by irradiation.
Design of the first HFIR target capsule assembly for irradiation of aluminum fracture toughness specimens at temperatures in the neighborhood of $95^{\circ} \mathrm{C}$ has been completed. This assembly will occupy four HFIR target positions and will contain sixteen $27.4-\mathrm{mm} \times$ 28.6-mm $\times 11.4-m m$-thick (1.080-in $\times 1.125$ in $\times 0.450$-in.-thick) aluminum compact specimens stacked in a column approximately $500-\mathrm{mm}$ (20-in) high. Sandwiched between the compact specimens will be a total of fifteen 26-mm (0.10-in.) thick aluminum packets, each with space provided for a miniature flat tensile specimen, several TEM specimens, two field-ion-microscope-atom probe needle specimens, and a neutron dosimetry capsule. The fracture toughness specimens will be in direct contact with reactor cooling water flowing downward over all four faces of the column.

Preliminary scoping calculations were done to determine the maximum stable flaw size in the CPBT. The J-R (crack-growth resistance) curve for unirradiated 6061-T651 aluminum was determined at $95^{\circ} \mathrm{C}$. On the basis of some subsize Charpy impact data" measured on specimens obtained from a highly irradiated 6061-T6 aluminum control rod follower from the High Flux Beam Reactor (HFBR), the J-R curve for irradiated 6061-T6 aluminum was estimated to be lowered by a factor of ten. The critical length of a through-thickness flaw in the CPBT was estimated to be reduced from about six times the wall thickness before irradiation to about the wall thickness after irradiation. These flaws are large enough to be detected by non-destructive examination techniques, but are so small that it will probably not be possible to make a leakbefore-break case for the irradiated CPBT.

\subsubsection{Fuel Plate Stability}

Structural stability of arrays of parallel fuel plates with coolant flowing through them has been a problem of intense interest to reactor designers for many years. Analytical treatments of the problem have been 
published, 12-14 as have experimental studies on flat plates. ${ }^{15-18}$ Analytical predictions based on the classical Miller ${ }^{12}$ approach indicated that the January 28, 1988, ANS reference core might not have sufficient margin between the planned flow velocity of $27.4 \mathrm{~m} / \mathrm{s}$ and the cakculated critical flow velocity.

An improved analytical solution' of the hydraulic stability of arrays of involute plates was developed this year. Curved-shell equations for the involute ANS fuel plates were coupled to 2-D hydraulic channel flow equations that include fluid friction. A complete set of fluid and plate boundary conditions was applied at the entrance and exit and along the sides of the plate and the channel. The coupled system was linearized and solved to assess the hydraulic instability of the plates. The inclusion of fluid friction in the analysis increased the calculated critical velocity of the ANS fuel plates by $13 \%$ to $26 \%$. This new analysis was used to arrive at acceptable dimensions for the conceptual core fuel elements.

Although the analytical methods have been demonstrated to compare well with tests on arrays of flat plates, they have not been benchmarked against test data on arrays of involute plates. Benchmark tests of arrays of aluminum involute plates and proof tests of complete dummy fuel elements are required. The flow rates and pressures required to ensure that plate instability can be reached are fairly large.

A single involute plate made from epoxy with flow channels formed by rigid walls was tested. The lower modulus of elasticity of the epoxy compared to aluminum reduces the critical velocity so that modest flow rates and pressures could be used. The maximum velocity that could be achieved in the test because of facility limitations was $121 \%$ of the critical velocity predicted using the Miller analysis but was only $95 \%$ of the critical velocity according to the Sartory ${ }^{19}$ analysis. No instability was observed during the test. The plate did deflect as much as $25 \%$ of the channel width at the maximum velocity. A method for predicting the deflection was developed ${ }^{20}$ that indicates that the maximum plate deflection in the ANS fuel plates would be $17 \%$ of the channel width.

A five-plate, six-channel test facility is being assembled. Initial tests will be on epoxy involute plates to velocities as high as twice the Sartory-predicted critical velocity. These tests will provide a basis for evaluating the analytical methods. Subsequent tests on aluminum involute plates in the same facility will be run at velocities $30 \%$ above the design velocity to examine the potential for vibrations.

\subsection{Control Element Vibrations}

The four control elements are confined to a very small space inside the core and, as a result, have a large length-to-diameter ratio. Flow-induced vibrations of these long slender cylinders are a major concern because of the large unsupported length immersed in a turbulent flow condition. Buckling of these long slender rods due to large axial scram accelerations is also being investigated.

Finite element analyses of the current inner control rod configuration indicate that their fundamental frequency is on the order of $10 \mathrm{~Hz}$. Contact between the control elements and the inner core cylinder is a major concern because large displacements would result from ony excitation at this low frequency. Modifications to the design of the control elements and their support structure are being pursued.

Modal tests will be conducted to measure the critical modes of the control elements and to measure the structural damping. Plans are being developed for a test facility that can be used in the development of control rods that will simulate anticipated conditions, including realistic flow and scram. The operation of the elements in a realistic flow envircnment will be tested to demonstrate that all functional and safety-related critcria can be met over their anticipated lifetime. 


\section{COLD SOURCE DEVEL DMENT}

The cold source development activity has been divided into two major areas: (1) neutronics work, and (2) thermal-hydraulic and testing programs. During the report period, the work in both of these areas was slowed due to a shortfall of funding within the project.

\subsection{Cold Source Neutronics Modeling}

An evaluation of data obtained from 2-D transport calculations indicates that for certain ranges of geometry, the gain from a cavity in the cold source can be correlated very closely with the volume of $\mathrm{LD}_{2}$ remain . ing and with the volume of $\mathrm{D}_{2} \mathrm{O}$ removed by the guide tube. It was found that the gain factor for the 0-degree current in a fully illuminated guide tube could be expressed as

$$
\begin{aligned}
\text { Gair factor }= & G=0.2996+55.380 \times \\
& V_{L_{2}}-12.745 \times\left(R_{2}\right)^{2},
\end{aligned}
$$

where $V_{\mathrm{LP}_{2}}$ is the $\mathrm{LD}_{2}$ volume expressed in cubic metres and $R_{z}$ is the guide tube radius in metres. (Note that in the 2-D anabysis the guide tubes are treated as cylinders rather than the actual rectangular shape.) For the O-degree cases, the correlation factor with the data was 0.993. It was ako found that the same equation could be used to calculate the gain factor for the 1- and 2-degree current in a guide as long as the guide is fully illuminated for the angle in question. Although the correlation factor was not as good as that obtained for the 0-degree case, the agreement with the 2-D transport calculations was still very good as shown in Fig 27.

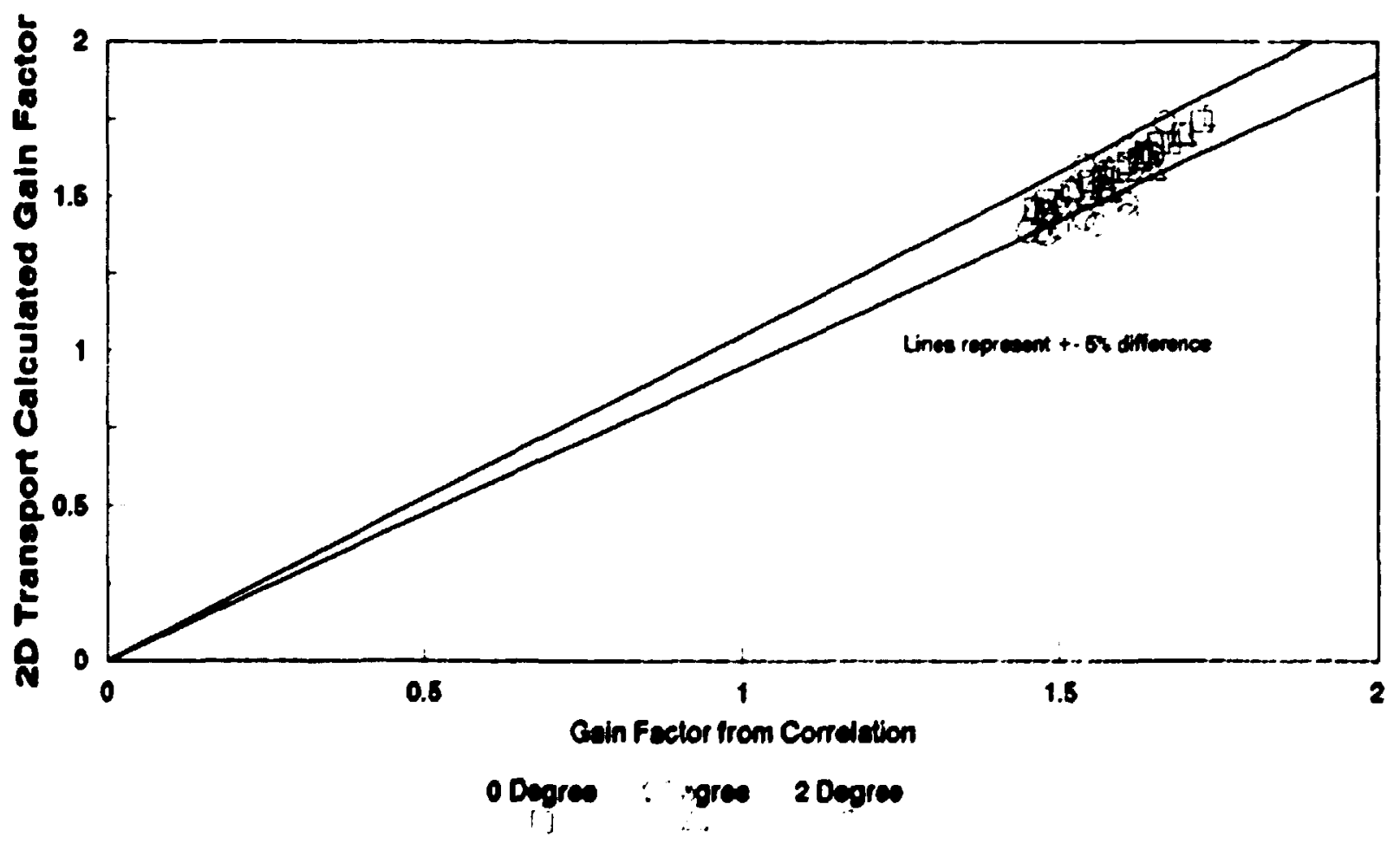

Fif 27. Compartson of geometricil predictions with sevtronics calculations. 


\subsubsection{Cold Source Thermal- Hydraulic and Testing Program}

The R\&D program continued to search for proven techniques to predict thermal performance and stability limits of the cold source. This information must be obtained to design and operate the cold source successfully. The key issues to be resolved are estimation of (1) system stability control, (2) liquid level control, and (3) mean and local two-phase density for all thermal loading conditions.

\section{Cold Source Thermal-Hydraulic Analytical Model}

Several analytical modek were studied for predicting the liquid volume fraction of an $\mathrm{LD}_{2}$ boiling pool. Each model was based on the drift flux model for one-dimensional flow and on a specific set of assumptions regarding method of heat load removal, fluid boiling mechanisms, flow regimes, system geometry, and other considerations. While each model demonstrated limitations, they did suggest two important hypotheses:

1. The liquid fraction of the boiling pool can be increased by elevating system operating pressure. However, raising the operating pressure would require structural and operational modifications that may be unacceptable.

2 If the fluid properties and heating density are fixed, the liquid fraction is dependent only on collapsed liquid height, assuming that pool cross-sectional dimensions are large compared to bubble dimensions. Thus, changing the pool's cross section does not affect the mean liquid fraction.

The results of these models have provided further insight into the dynamics of the cold source and will be helpful for subsequent model development. The models studied showed reasonably good results for predicting the mean liquid fraction; however, errors for prediction of mean and local vapor fraction by these models were unacceptable, and the models must be further refined. The plot shown in Fig. 28, generated from the results of these modek, shows liquid fraction vs pool depth at Institut Laue Langevin (ILL) and ANS hesing loads.

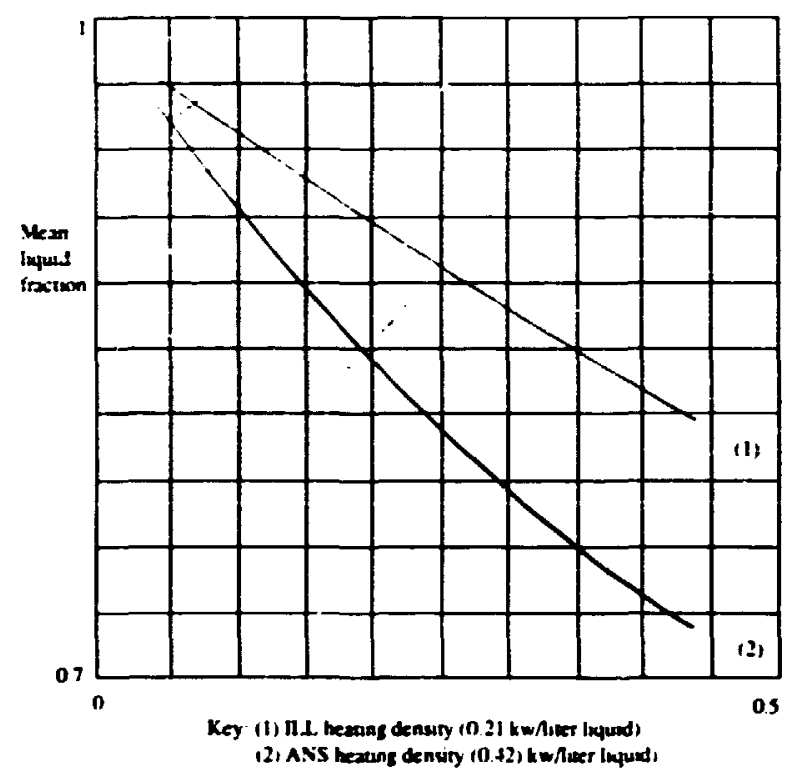

Fif is. Caloulated mene liquid fraction vs pool depth for volame-heated, boiling $\mathbf{L D}_{2}$ pool at 0.15 MPa pressure.

Development of the single-phase, onedimensional flow model on PATRAN for interface with the FIDAP fluid dynamics/ heat transfer analyzer was abandoned. Limitations of existing Computational Fluid Dynamics (CFD) turbulence models, extensive computational costs, and the intrinsic uncertainties associated with the liberal assumptions for this model prompted the abandonment of this effort in favor of other modeling programs.

A data base of relevant cold source literature was created to help project participants in the task of locating information. Houston Wood, a CFD/Numerical Methods modeling expert from the University of Virginia, studied existing models and is developing an independent model based on two-phase, two-dimensional flow. This work 
is progressing apace with evaluation of offsaturation thermal coefficients of $\mathbf{L D}_{\mathbf{2}}$ and will continue into FY 1991.

\section{Cold Source Thermal-Hydraulic Testing Program}

Fabrication and installation sctivities for the $\mathbf{L N}_{2}$ test facility ocintinued. Some delays resulted from fabrication difficulties and strict tolerancing requirements. The stresses developed in the viewport windows, caused by high thermal gradients, have been monitozed and compared to vendor information and are not expected to cause any complications. Preliminary pressure testing of the facility has been successfully completed, and the test system is nearty ready for batch mode operation. Completion of the facility and subsequent testing will occur in FY 1991.

\section{BEAM TUBE, GUIDE, AND INSTRUMENT DEVELOPMENT}

The beam tube, guide, and instrumentation R\&D program is currently giving highest priority to the optimization of beam transport systems which lie on the critical path for the reactor design, but groundwork continues on instruments and guide systems. We have benefitted from collaborations with many groups, particularly at BNL (Neutron Scattering and LWR Systems Groups), INEL, NIST (Neutron Scattering Group), and the University of Rhode Island, as well as within ORNL (Solid State and Instrument \& Controls Divisions).

\subsubsection{Neutron Supermirrors}

Neutron supermirrors, which reflect neutrons at angles much larger than are possible with conventional total-reflection mirrors, are a key clemen! in providing neutron guides and focussing optical devices for the ANS, as well as in improving the performance of current neutron instrumentation at many labora- wries. This has been recognized by the Department of Commerce and by DOE, both of whom have provided funding for a significant U.S. research effort in this field. Much of this wort has been undertaken at NIST in collaboration with ORNL (especially through ANS R\&D funding) and the University of Missouri, with industrial support by the Ovonics $\mathrm{Ca}$ of Troy, Michigan, and the Optoline Ca. of Andover, Massachusetts, through the DOE Small Business Innovative Research program.

This research has been so successful that the problem of producing appropriate supermirrors may be considered effectively solved at the laboratory scake, and the emphasis is now turning to the production of practical, full-scale neutron supermirror guides at reasonable cost. The NIST group, led by C. F. Majkzak, has led the effort that identified, understood, and overcame three fundamental problem areas to achicve this breakthrough:

1. Supermirrors rely on producing multiple, thin (about $10 \mathrm{~nm}$ ), atomically-flat layers of different metak. The different atomic sizes lead to an intrinsic tendency for such layers to be rough, which leads to loss of intensity from the reflected beam into diffuse sidebands. Improved deposition techniques now suppress this diffuse scattering by two orders of magnitude.

2. Layer thicknesses and densities must be controlled through many multilayers to maintain phase coherence in the structure, or the angular range of reflectivity is greatly diminished. For many years, this has led to a performance barrier for automated production, which limited reflectivity to about twice that of nickel mirrors. The layer deposition quality control is now sufficiently good to exceed routinely the performance of nickel by a factor of three, as seen in Fig 2.9, where the reflectivity of a supermirror (triangles) is compared with that of a nickel mirror (circles) that defines the $100 \%$ reflectivity level. 


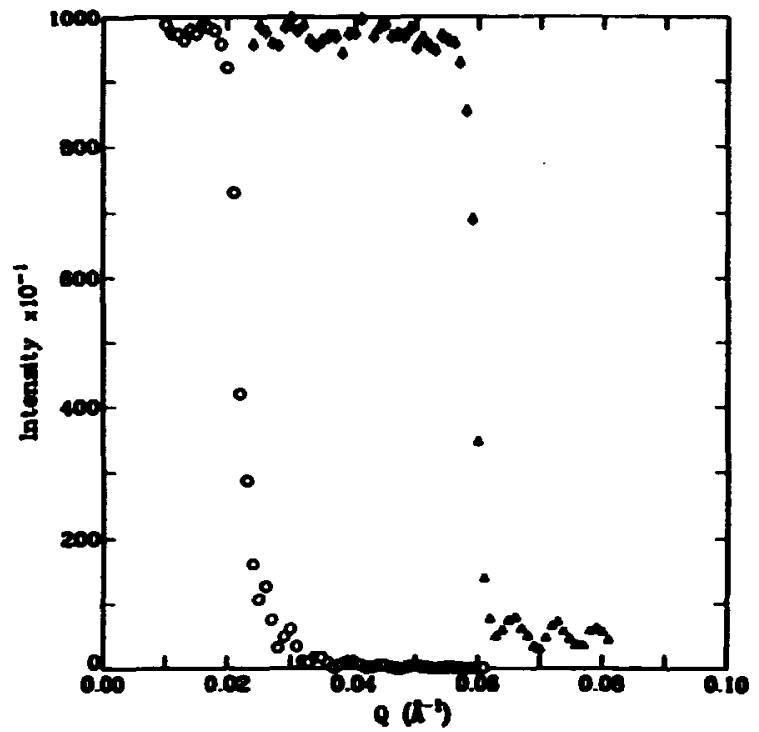

Fiz 29. NIST refloctivity messurencats for a conventional nicted mintor (circles) and a supen irror givide coating (triangles).

3. For certain applications, particularly transmission applications as filters or polarizers, close-to-perfect rellectivity is required. Apart from difficulties of fabrication, it is nontrivial even to design a perfect supermirror, since the optical problem is ill-conditioned. Simulation studies showed that the best solution yet proposed is that of the ORNL group, but no experimental tests were available until recently. Data on mirrors designed using the ORNL algorithm now show that it does, in fact, give measurable improvement in mirror quality.

\subsubsection{European Design Studies}

The ANS will require the world's best design and construction in several areas in which there is little or no experience in this country: reactor-based sources of hot, cold, and very cold ncutrons; thermal and cold neutron guides; and many new types of neutron instrumentation, including backscattering and neutron-spin echo. J. B. Hayter and T. J. McManamy (both working on cxpcriment systems), and F. J. Perctz, C. C.
Queen, and D. L Selby (reactor systems), visited the three foremost European centers of excellence in reactor-based neutron scattering (ILL, Grenoble; KFA, Julich; and LLB, Saclay) to obtain first-hand knowedge-through discussions with those responsible for equipment design and construction and with end users of the equipment, and through observation of the operating hardware-of the new techniques that have been developed and implemented in the past few years. At each site, a great deal of information was obtainad that will be invaluable in belping the ANS Projoct avoid unnecescary tasks and in identifying some potential problems earty enough to allow us to addreas them in our RAD plans.

Advantage was also taken of a recent visit to Oak Ridge by representatives of the neutron guide manufacturer, CILAS (France), to hold an informal meeting on new developments in guide technology around the world. In the past two years, CILAS has accomplished an amazing variety of innovations, most of which required considerable R\&D. Among these are

- guides for beam compression in fast chopper spectrometers,

- transparent guide sidewalls to permit monochromatic beam extraction,

- improved illumination using extending guide plates, and

- improved surface finish on polished float-glass for guides.

Much of the recent work has been on installations at HMI (Berlin), ILL (Grenoble), NAEA (Indonesia), LANL (Los Alamos) and NIST (Gaithersburg), and we obtained many design ideas for guide systems, including vacuum systems, windows, foundations, structural penetrations, beam shutters, and safety gate values.

\subsubsection{Detector Shielding}

J. F. Carew's group at Brookhaven has completed the feasihility study of the use of 
new detector shielding materials to improve signal-to-noise on ANS spectrometers. The ANISN calculations were carricd out in two steps: (1) the calculation of the neutron spectrum incident on the detector shield, and (2) the determination of the energydependent attenuation of the potyethylenel $B_{4} C$ shield. In the first step, a 69-group P-3 ANISN model of the HFBR, from the core out through the biological shield, was constructed, and the neutron spectra leaking from (1) the biological shicid, (2) a typical monochromator, and (3) the beam were calculated. A neutron spectrum measured at the H-9 beam port was abo obtained. Using these input spectra, the energy-dependent attenuation of the detector shicld was computed using a 69-group ANISN model.

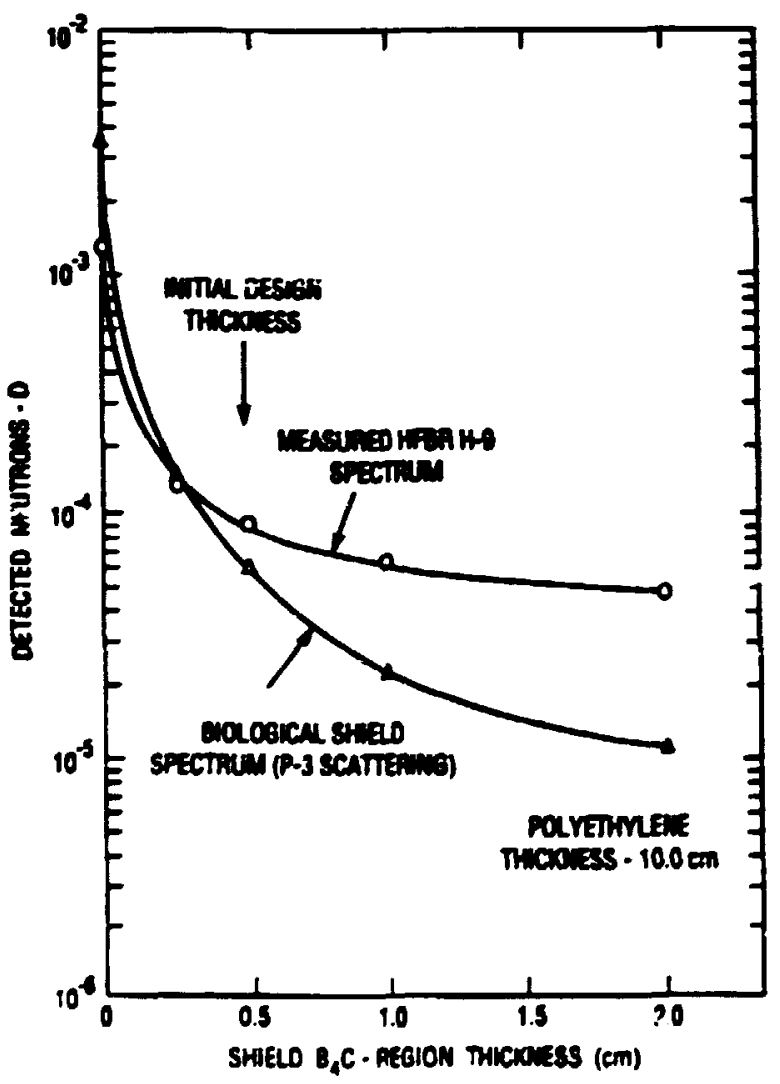

Fiz 210. Detector shielding attencution betors in two specernl ranges for varions thich seaves of B,C sucorter behind $100 \mathrm{~mm}$ of high-denaty polyethyleace moderator.
A substantial sensitivity of the detector response was observed with respect to (1) the shield polyethylene thickness (a factor of about 25 decrease in background for a $50 \%$ increase in thictoness), (2) the incideat neutron spectrum, and (3) the $\mathrm{B}_{4} C$ absorber region thichness (a factor of about 10 increase in background for a $100 \%$ reduction in thickneas). It is also noteworthy that about $80 \%$ of the incident neutrons that entered the shielding leaked out of the system before being absorbed by the shield or the detector.

Typical results are shown in Fig 210, which shows the fraction of neutrons penetrating the shielding $a$ a function of $B_{4} C$ absorber thictness for a fixed amount of polyethylene moderator. These results show that the initial design combination of 100-mm polyethylene and 5-mm $B_{4} C_{\text {, which }}$ was baced on experience, is in fact very good, but that improvement is still possible for the most sensitive experiments. The study confirms the utility of these types of calculations in detector shield design and makes possible a future systematic study of possible new shielding materials, such as boron-loaded alloys.

\subsection{Beam Tube and Guide Design}

The ORNL Solid State group, led by R. M. Moon, is conducting extensive research into optimal beam sizes and geometries. The work has centered on computations for five claseses of instrument: powder diffractometers, single-crystal diffractometers, triple-axis spectrometers, diffuse scattering. and small-angle scattering cameras. The first results indicate that powder diffraction can use the largest beams, $s 0$ recent efforts have concentrated on completing this case. Results are summarized in Table 2.3, which shows optimal parameters for two types of high-resolution (HRPD, AHRPD) powder diffractometers, an equivalent ILL instrument (D2B), a structure refinement instrument (SRPD), and an instrument which 


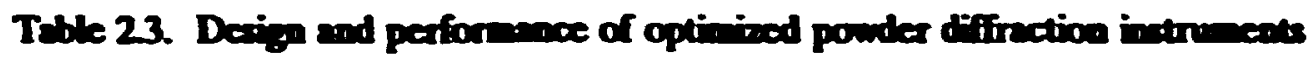

\begin{tabular}{|c|c|c|c|c|c|}
\hline & HRPD & AHRPD & D2B Equiv. & SRPD & RTPD \\
\hline 20_(deg) & 135 & 135 & 135 & 135 & 60 \\
\hline$h_{3}(\mathrm{~mm})$ & 220 & 220 & 220 & 2200 & 140 \\
\hline$L_{0}(m)$ & 11 & 11 & 11 & 11 & 7 \\
\hline$h_{1}(\mathrm{~mm})$ & 109 & 140 & $\mathbf{2 2 1}$ & 267 & 333 \\
\hline$L_{1}(m)$ & 25 & 25 & 25 & 25 & 2.5 \\
\hline$h_{2}(\mathrm{~mm})$ & so & so & so & so & so \\
\hline $\mathbf{R}(\mathbf{m})$ & 1 & 1 & 1 & 1 & 1 \\
\hline$h_{0}(\mathrm{~mm})$ & 44 & 56 & 88 & 107 & 133 \\
\hline$a(d e g)$ & 0.046 & 0.061 & 0.107 & .157 & 0.185 \\
\hline$p(\mathrm{rad})$ & 0.0436 & 0.056 & 0.088 & .107 & 0.133 \\
\hline$W=\Delta 2 \theta($ deg $)$ & 0.077 & 0.103 & 0.193 & 0.281 & 0.33 \\
\hline$\triangle Q Q$ & $28 \times 10^{4}$ & $3.7 \times 10^{-4}$ & $6.9 \times 10^{4}$ & $1 \times 10^{-3}$ & $5 \times 10^{-3}$ \\
\hline Peak intensity & 0.049 & 0.14 & 1 & 3.1 & 10 \\
\hline Integrated intensity & 0.019 & 0.075 & 1 & 4.6 & 18 \\
\hline
\end{tabular}

could undertake real-time studies. The most important numbers in Table 2.3 for our purpose are $h$ and $h_{6}$, which are the beam tube height at the source and monochromator. respectivety. These studies are being continued and extended by both the ORNL and BNL neutron groups using complementary methodologies.

The scoping studies show that elliptical beam tubes $100-\mathrm{mm}$ wide and about $220-\mathrm{mm}$ high would satisfy most requirements. This width is the same as our present reference beam tubes, but the height is substantially larger than the $150 \mathrm{~mm}$ used so far as a reference. Initial 3-D Monte Carlo neutronics calculations by the INEL group, led by J. M. Ryskamp, indicate that beam tubes of this size should be practicable.

\subsection{HOT SOURCE DEVELOPMENT}

The hot source is another planned R\&D activity that has not been initiated due to present funding levels. This task has received low priority because it has been believed that the hot source would be located on the back edge of the reflector tank and would thus have little or no effect on the reactor design. Under this assumption, work on the hot source could be delayed, allowing tight resources to be concentrated on more pressing issucs associated with the reactor development. However, it has recently been determined that if we are to match the ILL hot source flux, our hol source may need to be centered at least $300 \mathrm{~mm}$ inside the reflector. 
This may mean that the hol source would have to be a foxture more like the cold source and thus could have a higher impact on the reactor development than previoushy perceived. Present plans include only minor activities for the bot source in FY 1991. In light of the new information, additional resources may have to be allocated to the bot-source development task

\section{NEUTRON TRANSPORT AND SHIELDING}

The majority of the wort under this task was asociated with (1) the evaluation of heat loads for various components in the core and reflector region, and (2) the reactivity effect of beam tubes and other components in the rellector region.

\subsection{Component Heat Loads}

An analysis was performed during this report period to estimate the neutron and gamma heating londs for various reactor and reflector tank comporents based on the conceptual core. Heat losds for the CPBT, control rods, and inner-fuel side plate were evaluated Neutron and gamma fures were generated using a 2-D coupled neutronl gamma transport calculation (DORT calcuLtion), ${ }^{2}$ and neutron and gamma kerma factors were used to generate heat loads. Statistics in the 3-D Monte Carbo calculations were sufficient to generate average beat bods for componnt sezments as a check of the transport evaluations. The average heat bods obtained for various axial segments of the CPBT and control rods are shown in Figs 211 and 212 Earty discrepancies were traced to poor (n,gamma) cross sections for certain key materials in the transport model. By the end of the report period, beat loads for the control rods were developed that were consistent with the average values generated by the 3-D Monte Carbo analysis.

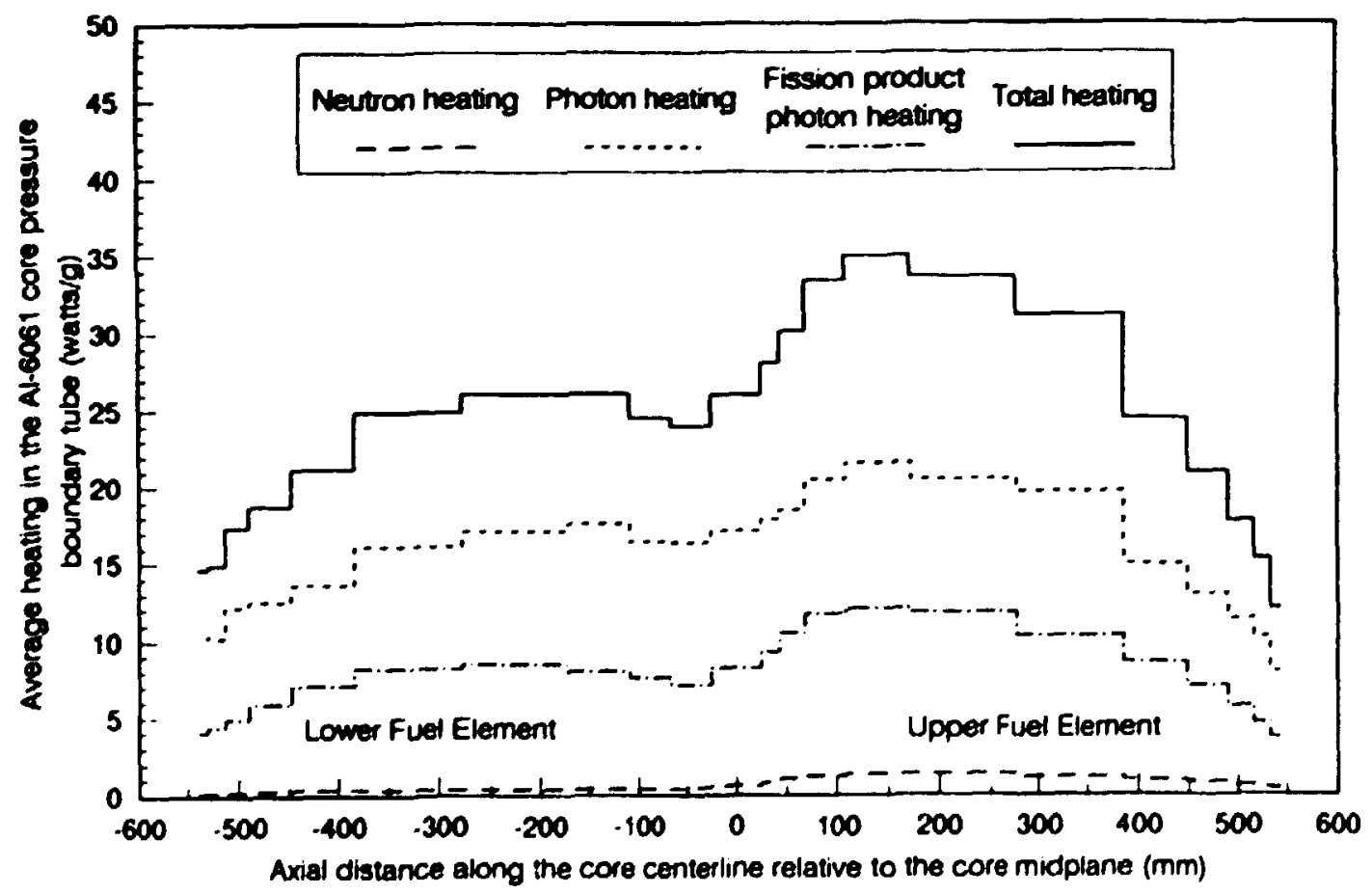

Fig 211. BOC veatiog in the CPBT. 


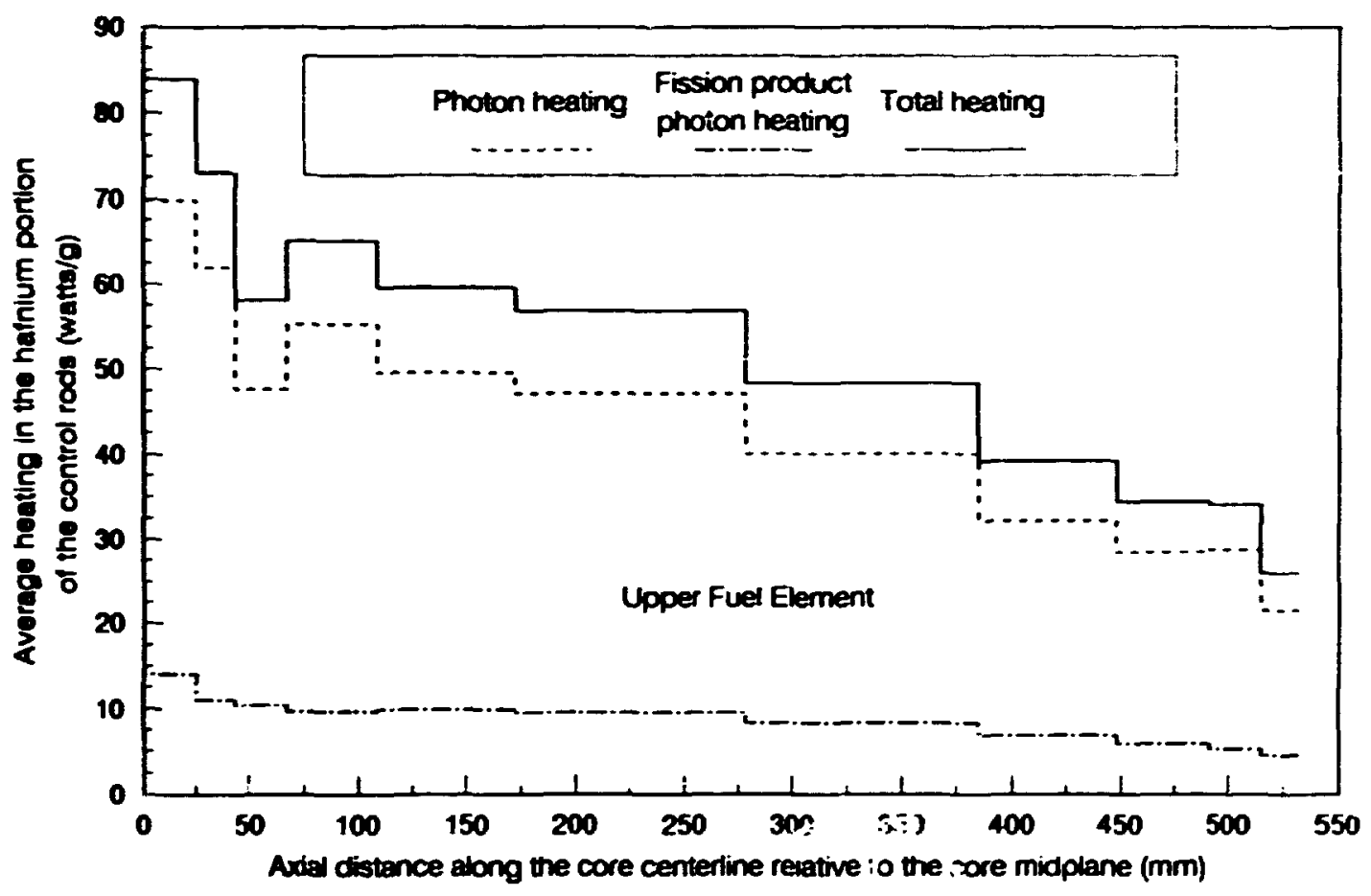

Fig 212 BOC heating in the hafium control rod

\subsection{Reactivity Effect of Beam Tubes and Other Components \\ Seven elliptical beam tubes and a cylindrical through tube have been added to \\ the 3-D MCNP model. The reactivity effects of these additions to the model are summar- ized in Table 24. It should be noted that all the beam tubes used in this analysis are rela- tively large $(220 \mathrm{~mm} \times 100 \mathrm{~mm})$ and corre- spond with the maximum perceived beam}

Table 24. Effect of beam tuber on core reactivity

\begin{tabular}{lll}
\hline Case & $k$ & $\begin{array}{c}\text { Reactivity } \\
\text { change } \\
\%\end{array}$ \\
\hline No beam tubes & $1.0182 \pm 0.0028$ & Reference \\
4 beam tubes & $1.0027 \pm 0.0029$ & -1.53 \\
$\begin{array}{l}7 \text { beam tubes and } \\
\text { through tube }\end{array}$ & $0.9813 \pm 0.0025$ & -3.69 \\
\hline
\end{tabular}

'Elliptical beam tubes, major axis $=220 \mathrm{~mm}$, minor axis $=100 \mathrm{~mm}$.

Cylindrical through tube, radius $=75 \mathrm{~mm}$. All tubes surrounded hy $10-\mathrm{mm}$ thick Al 6061. 
tube size rather than the present reference beam tube size of $150 \mathrm{~mm} \times 100 \mathrm{~mm}$.

Two slant tubes reserved for sample irradiation have ako been added to the 3-D MCNP model. These tubes are positioned approximately opposite each other outside the CPBT. The irradiation capsules extend from the top of the reactor to the core midplane. To simulate exact tube positions, one tube was rotated $16^{\circ}$ about the $x$-axis and the other was rotated $15^{\circ}$ about the $z$ axis and $57^{\circ}$ about the $x$-axis. The reactivity effects of using different sample materiak in the slant tubes is summarized in Table 25. The reactivity effect of the slant tubes without samples is relatively small. However, it is observed that both the solid Hf sample and

\section{I\&C RESEARCH AND DEVELOPMENT}

\subsubsection{Protection and Control Strategy}

The ANS protection system functional requirements have been scoped using the results of dynamic analyses and other considerations. The core is characterized by very high-power density and relatively low heat capacity so that fast response is needec to protect the core against over-power or under-cooling events. Based on years of favorable experience with fast-acting protection systems at the HFIR and other ORNL reactors, the ANS reactor will be designed

Table 25. Reactivity effocts of two shant tubes and various sample materials

\begin{tabular}{lcl}
\hline \multicolumn{1}{c}{ Case } & $\mathbf{k}$ & $\begin{array}{c}\text { Reactivity } \\
\text { change } \\
\%\end{array}$ \\
\hline No slant tubes & $1.0155 \pm 0.0022$ & Reference \\
Slant tubes with void & $1.0116 \pm 0.0027$ & -0.39 \\
Slant tubes with & & \\
following samples: & & \\
a) Hf & $0.986 \% \pm 0.0023$ & -2.86 \\
b) Al-6061 & $1.0070 \pm 0.0028$ & -0.85 \\
c) $25 \%$ SS, 75\% Al-6061 & $1.0075 \pm 0.0029$ & -0.79 \\
d) Graphite with & & \\
Al shroud & $1.0130 \pm 0.0028$ & -0.25 \\
e) Al with Hf shroud & $0.9964 \pm 0.0032$ & -1.90 \\
\hline
\end{tabular}

the 2-mm Hf shroud cases have significant reactivity effects and would be expected to result in reductions in the reactor core life. Other samples examined as shown in Table 2.5 would have substantially less impact. with nominal safety response of $20 \mathrm{~ms}$, with a safety-limit criterion of 30 ms. The principal safety parameters requiring this fast response are power-equivalent flux, rate-ofchange of flux, and the primary system pressure. 
Neutron flux is used as the primary responsive power signal because of its inherently fast response, but the flux signal is adjusted continuously to agree with the core heat power computed from the coolant flow rate and the core differential temperature. This technique combines the a:tributes of high accuracy and fast response to achieve higher performance and more predictable operating margins. To enhance operability and to provide automatic protection for different operating conditiuns, the flux signal is combined with the coolant-flow signal to provide the combined parameter of powerequivalent flux-to-flow ratio. This combination, used in both the control system and the protection system, permits the reactor to be operated at different flow rates while maintaining appropriate power-level control and safety settings for the available flow. This technique was first used in the HFIR and has been adopted by a number of commercial power reactors.

Using the rate of change of neutro: flux as a safety parameter provides enhanced response for very fast transients initiated by unplanned reactivity additions. The signal is deriv: $d$ by taking the pseudo-time derivative of the neutron flux signal. This signal provides superior performance, higher reliability, and less susceptibility for folse action than a reactor period channel.

Reduced primary system pressure results in reduced margin to incipient boiling and critical heat fux so that fast response is nceded for unplanned pressure reduction. The pressure is sensed with fast transducers and controlled at the reactor outlet. This location provides the necessary protection and avoids high system-pressure excursion when the primary coolant pumps are started and the pressure drop across the core increases.

The need for several additional safety parameters with less demanding response requirements is being evaluated as the systems designs progress. These include primary coolant flow, core thermal power, reactor inlet temperature, very low primary coolant flow, coolant fission product sctivity, accumulator heavy-water level, reflector tank: cooling, heavy-water leaks, cold source and experiment parameters, and seismic activity.

The plant heat removal control system is being developed as a hierarchy of multiple levels and multiple loops, using advanced digital techniques to maintain close control of plant parameters under a variety of operating conditions. A simplified controd diagram is shown in Fig. 2:3. The scheme includes both multilevel proportional control of vital parameters and coordinated discrete control of pumps and valves in the multiple primary and sccondary cooling circuits. The top level of control is the demanded reactor power. The second level maintains constant reactor coolant inlet temperature by regulating the heat removed by the primary heat exchangers. The reactor inlet temperature may be programmed for different seasonal conditions or multiple-loop configurations. The primary coolant flow rate nominally is constant, but may vary discretely as the number of operable pumps is altered. The maximum reactor power is limited automatically by the available primary flow. The immediate heat removal rate and the reactor inlet temperature are controlled by adjusting the secondary coolant flow rate.

The next level of conirol in the hierarchy adjusts the cooling tower fans and bypass valves around the cooling towers to maintain the secondary coolant flow rate and the secondary coolant temperature within appropriate programmed limits. The cooling loops normally act in concert with similar conditions in each loop, sharing the load equally when operating at or near design power. However, the control scheme permits isolation of an active loop or activation of an idle loop as conditions require. This may become necessary when failures occur within a loop, such as a pump trip, valve failure, or loop isolation. For extended operation at low reactor power level, it may be more practical to operatc only one loop to achicve more cfficient and stable performance, bringing additional loops on-line as the power level is 


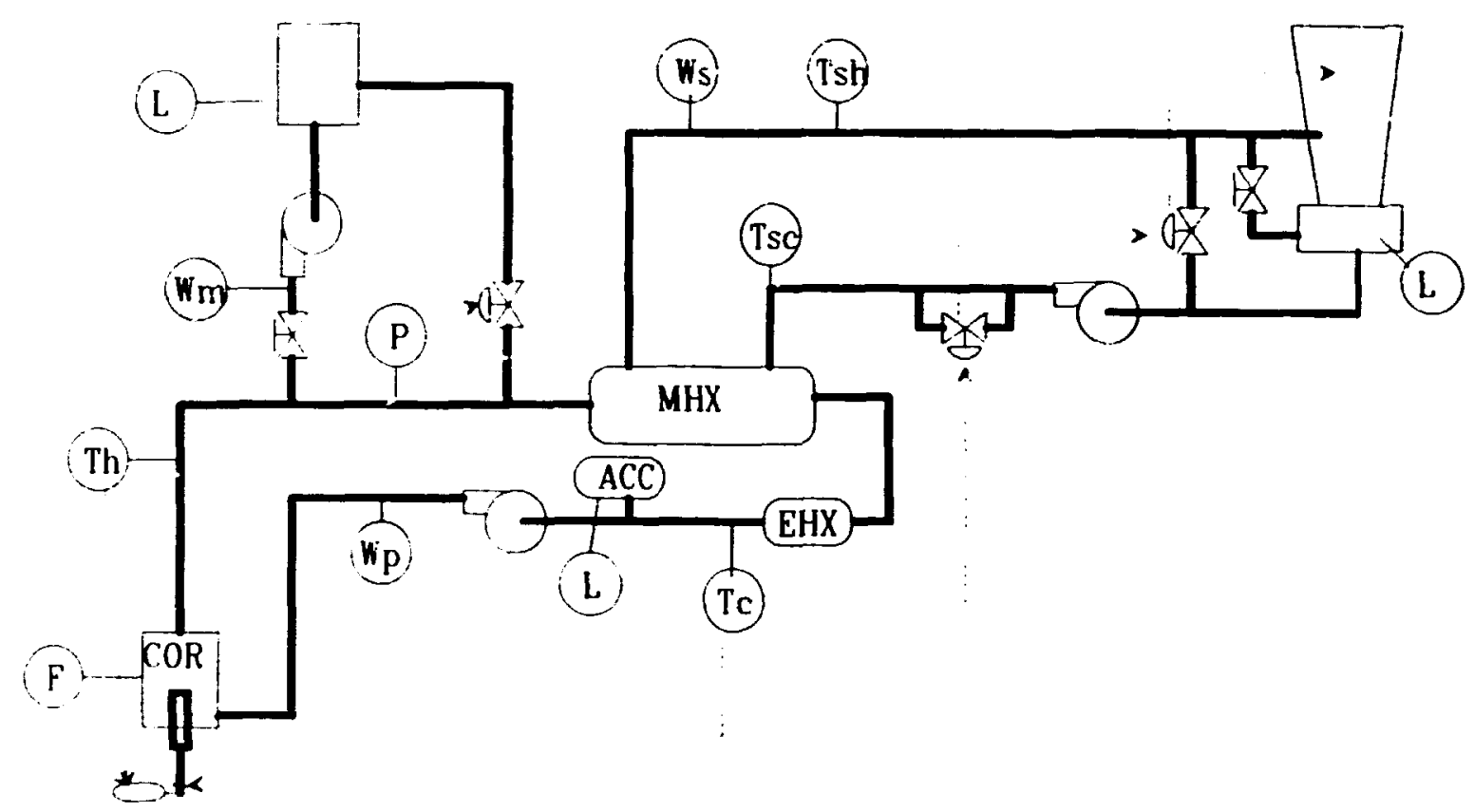

Fig 213. ANS instrumentation and control systems.

increased. It is a design goal of the control system to perform these functions under computer control with a minimum of operator interaction.

\subsubsection{Candidate Protection and Control Systems for the ANS}

Several vendors make control and protection systems that may be appropriate or adaptable for the ANS. These systems comprise digital control and protection, communications networks, ope:a:or workstations consisting of keyboards and video display units, and dedicated safety system controls and displays. A typical integraied syste $n$ is shown in Fig. 2.14. Digital control and protection systems may have many advantages and some disadvantages over analog systems. Advantages of an integrated digital system include system construction and testing prior to installation; cable reduction by multiplexed signals; system isolation through fiber optic cables; self-diagnostics and remote, on-line testing; simplified initial startup; and improsed normal operaticn. A serious disadvantage of available systems is that the scan time of a digital system may not meet the stririgent response time requirement for the ANS reactor protection system (RPS). Because of the fast response time requirements of the ANS, the RPS may have to be a hybrid analog-digital system. The capabilities of digital protection systems to meet the time requirement need further evaluation.

Digital systems that have been reviewed include the Westinghouse AP-600, Combustion Engineering Nuplex 80+, AECL Open Architecture Distributed Control System (OADCS), and the CEGELEC P20 and CHANCE 2000. All but the AECL system are designed primarily for commercial power reactors, although they could be used for rescarch reactors. The OANDCS and CHANCE 2000 are smaller systems that would function for the ANS. All of these systems include safety-qualified protection 


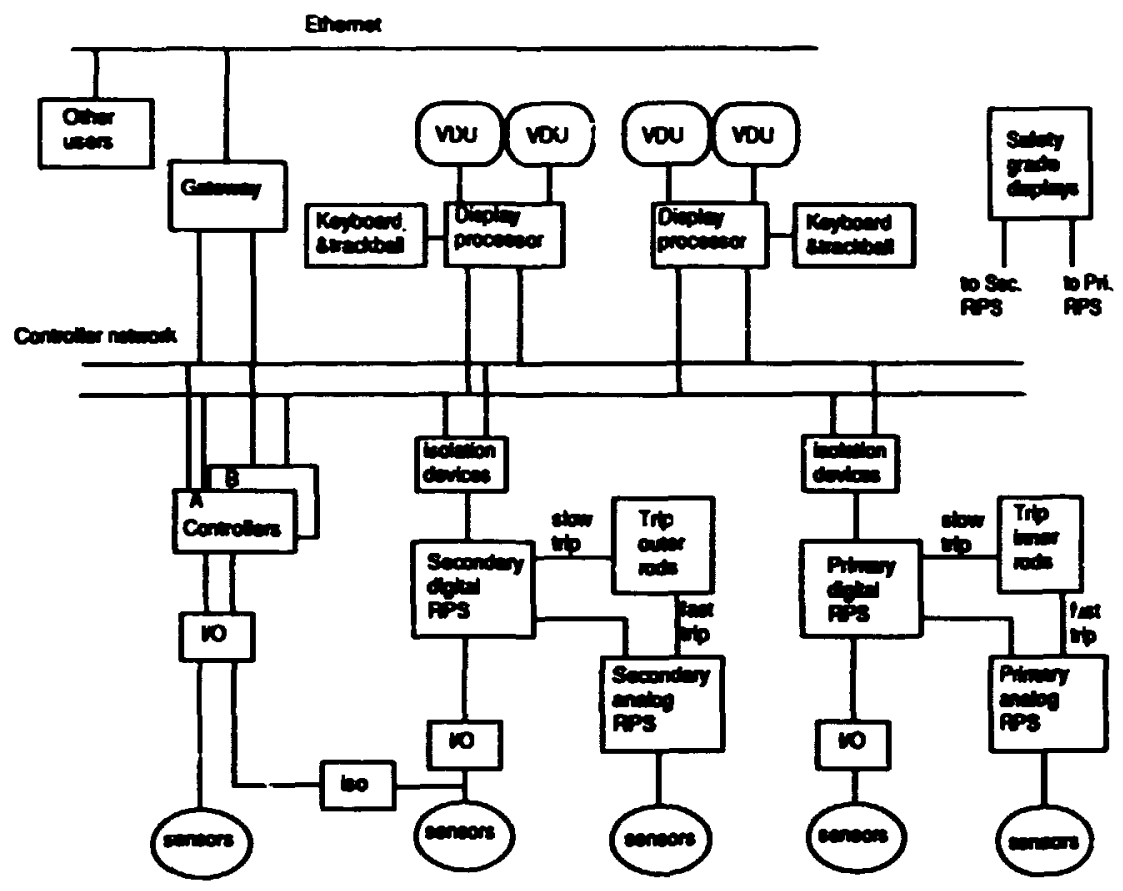

Fig 214. Typical integrated control systen.

systems. Fault tolerance is accomplished with dual redundancy for the networks and some modul z. Included are multiple operator wortstations for control and dedicated safety-grade displays. The safety and RPS systems also are connected to the plant communications network through one-way isolation devices.

The ANS design has two protection systems, each with separate, independent sensors. To reduce the total number of sensors, it is feasible to share the secondary RPS sensors with the reactor control system. Isolation devices would assure that RPS failures would not occur as a result of failures in the control system. Signal validation and selection algorithms (for example, averaging or median select) would provide reliable signals to the control system. The reactor control system would consist of dual or triple redundant digital controllers that position the regulating rod.

The control, protection, data handling. operator displays, and auxiliary computers are integrated by plant networks. Two levels of networks are shown in Fig. 2.14. The con- trol level network is designed to assure that each device on the network can transmit and receive information within a predetermined time, which is necessary for real-time process control to function properly. The top level network (Ethernet in the figure) connects to other machines or other networks for maintenance personnel, managers, engineers, regulators, and experimenters to monitor the plant. Several variations of network topology will be evaluated for the ANS.

\subsubsection{Process Instrumentation}

An initial draft of an instrument application diagram (LAD), Fig. 2.15, has been generated for the primary coolant system. The IAD includes instrumentation for plant protection, diagnostics, and operational requirements. The location of the various sensors are shown on the IAD relative to the major equipment items in the primary coolant system. Most of of the primary piping will be submerged in light-water pools. To facilitate maintenance of the instrumentation and to reduce the consequences of leaks, most of 


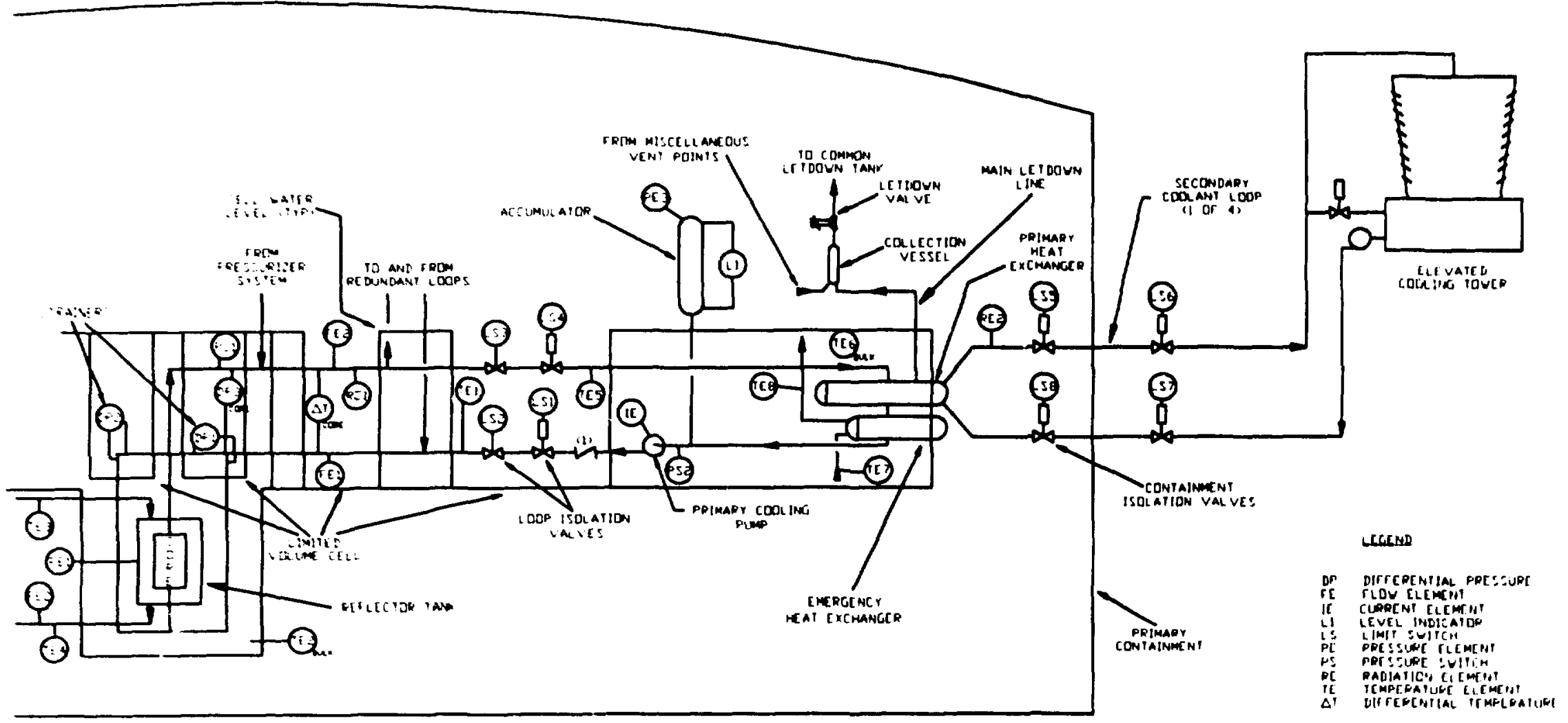

Fig. 215. ANS instrument application dlagram for primary coolant loop. 
the sensors, transmicters, and actuators will be located in lisited-volume (dry) cells which are shown on the IAD.

The primary coolant loop process measurements that are part of the plant protecion system are the primary flow rate, the core outlet pressure, the core inlet temperature, the core inlet and outlet temperature difference, the fission product detection in the primary loop, the accumulator water levels, and the heavy-water leak detectors. The remaining sensors and indicators on the IAD are for operation or diagnostics.

Requirements and design considerations for the process instrumentation have been tabulated. The major criteria identified for most of the measurements are high accuracy, fast time response, radiation resistance, durability, maintainability, and capability for in-situ testing. These criteria often lead to conflicting design solutions; for example, fast time response for temperature measurement requires direct-immersion sensors, but direct immersion creates serious maintenance problems. Other conflicting requircments include maximizing information available to the operators for diagnostics and smooth operation while miniñizing the number of sensors fol reducing maintenance, the number of limited-volume cells, and the risks of heavywater leaks.

Another major requirement that was studied extensively was the need for Class $1 E$ qualification of instrument systems for all safety-related measurements. A vendor survey revealed that there are a limited number of companies supplying Class $1 \mathrm{E}$ instrument systems, that the systems are of $1960 \mathrm{~s}$ vintage, and that many do not mect the ANS functional design criteria. The vendor survey did show that process sensors are available to make all the necessary measurements, but that the ANS project will need to qualify the systems for Class $1 E$ servicc, a nontrivial task.

\subsubsection{Analyses Supporting the Conceptual Design of the ANS Inner Control Rods and Drives}

A report describing the analyses performed to support the conceptual design of the ANS inner control rods and drives has been written and is in the publication process. In addition to describing the analyses, the report includes sample calculations performed using a prototype control rod based on the current control rod design.

Three analyses are described. A dynamic analysis of the control rod was performed to determine the control rod acceleration, velocity, and position during a scram event. This analysis includes a calculation of the coolant drag force and has been used to estimate the required accelerating spring forces, the spring rates, and the force applied to the control rod latch for various coolant velocities and control rod masses.

A force analysis of the latch was performed to estimate the force transfer through the latch muchanism. This analysis is based on a theory-of-elasticity solution for the control rod latch disks and has been checked using finite-clement calculations. The fraction of force applied to the latch by the control rod, which is ultimately supported by the control rod drive magnet, can be calculated for various latch geometries. These results will be useful during the detailed design of the latch.

A static analysis of the control rod drive magnet was performed to relate the magnet and coil gecmetry, coil current, and magnetic material propertics to the developed magnet force. The main result of this analysis is the magnet size required to produce a given force. The combination of the three analyses forms a comprehensive package for examining 
the major mechanical components of the control rod drive system.

\subsubsection{ANS Diagnostic and Surveillance System}

The ANS Diagnostic and Surveillance System is intended primarily as an aid for plant operators but will ako provide data for all of the plant staff. It is being scoped to satisfy the Nuclear Regulatory Commission (NRC) reorirements for a safety parameter display system (SPDS) and an emergency response facility. A prescriptive report is being prepared which could be used as a design document for inhouse development or as a specification for the purchase of a commercial system.

Approximately 900 plant signals have been identified as useful for plant monitoring. The total data acquisition rate is expected to be about 1000 signals per second, and with a reasonable data-logging rate, it is estimated that 40 years of plant operational data can be stored on 160 optical disks (which could be stored in a single cabinet).

Operator support functions in the following categories have been identified: (1) configuration control aids (anticipaie the safety effect of off-line plant compoisente, valve line-ups); (2) SPDS; (3) plant performance evaluation (help the operator determine that the p'ant is performing properly); (4) event handling aids (scram analysis and restart aids); (5) communication (electronic mail); (6) plant data base access (plant information and old data); and (7) training (in conjunction with plant simulation). Functions are planned for plant maintenance also, especially in the area of automated plant equipment testing and sensor calihration.

$A$ variety of standards and requirements have been identified that apply to the monitoring system. There are many companies which could supply part or all of this system. To date, 17 software suppliers have been identifieci. The software ranges from operator data display systems to full monitoring systems. The computer hardvare and operating system should not be a problem. To date, seven hardware vendors or generic computer types have been identified. The leading contenders probably will be VAX/MMS/ELN systems and RISC/realtime-UNIX systems. Very high performance of computers, graphic display systems, networks, and data storage systems is being attained at ever decreasing costs; computer security is being improved; and software is being standardized. Many choices should be available when the time comes to select a particular system.

\subsubsection{Dynamic Model Simulations}

A computer model of the ANS transient behavior has been developed. The main goals of this model are to test different control and plant protection systems schemes and to help specify minimum requirements for safety and control-related instrumentation. The model is valid for single-phase coolant conditions (boiling is not expected in the ANS reactor) and represents the core. hot and cold legs, main and emergency heat exchangers, main circulation pumps, makeup and letdown systems, gas accumulator, incontainment light-water pools, and the secondary-side cooling system that includes hot and cold legs, pumps, and cooling towers. The core is modeled as a single average thermohydraulic channel that feeds back to the neutronics through effective reactivity coefficients. A parallel calculation is performed to determine the hot channel and hot spot conditions by multiplying the average power by predetermined peaking factors that are specified as input to the code.

The model has been used to estimate the performance of the plant protection system. 
An example is presented in Fig. 2.16 that shows the calculated maximum safe reactivity step that the ANS reactor can survive as a function of the control rod initial acceleration and the latch release time. In this context, survival is achieved if critical heat flux conditions are not reached at the bot spot during the transient. Conditions for this study are representative of the CCD core and can be summarized as: $362 \mathrm{MW}$-fission total power with 93\% deposited in the active core, $1700 \mathrm{~kg} / \mathrm{s}$ hot channel flow (87\% of average channel flow), $180.3 \%$ hot channel peak power, $246.5 \%$ hot spot peak power, and the hot spot located $80 \%$ downstream of channel entrance. As seen from Fig. 216, the ANS core should be able to withstand a 1.25 step in reactivity if the latch release time is less than $\mathbf{3 0} \mathrm{ms}$ and the initial acceleration is greater than $60 \mathrm{~m} / \mathrm{s}^{2}$.
Even though the dynamic model was developed primarily for control and plant protection system studies, it has been used extensively to test the reference cooling system design for proper operation under off-normal conditions. An example of this use is presented in Fig. 2.17, which shows a containment isolation transient under natural circulation conditions for different sizes of emergency heat exchangers. The performance of the emergency heat exchanger is crucial to transfer heat to the in-containment light-water pook during isolation events, but this performance cannot be judged from steady-state calculations because of the nonequilibrium nature of the flow and temperature corditions during the event. For this transient, the goal is to maintain the coolant temperature below saturation at the point of lowest pressure in the !oop: if boiling

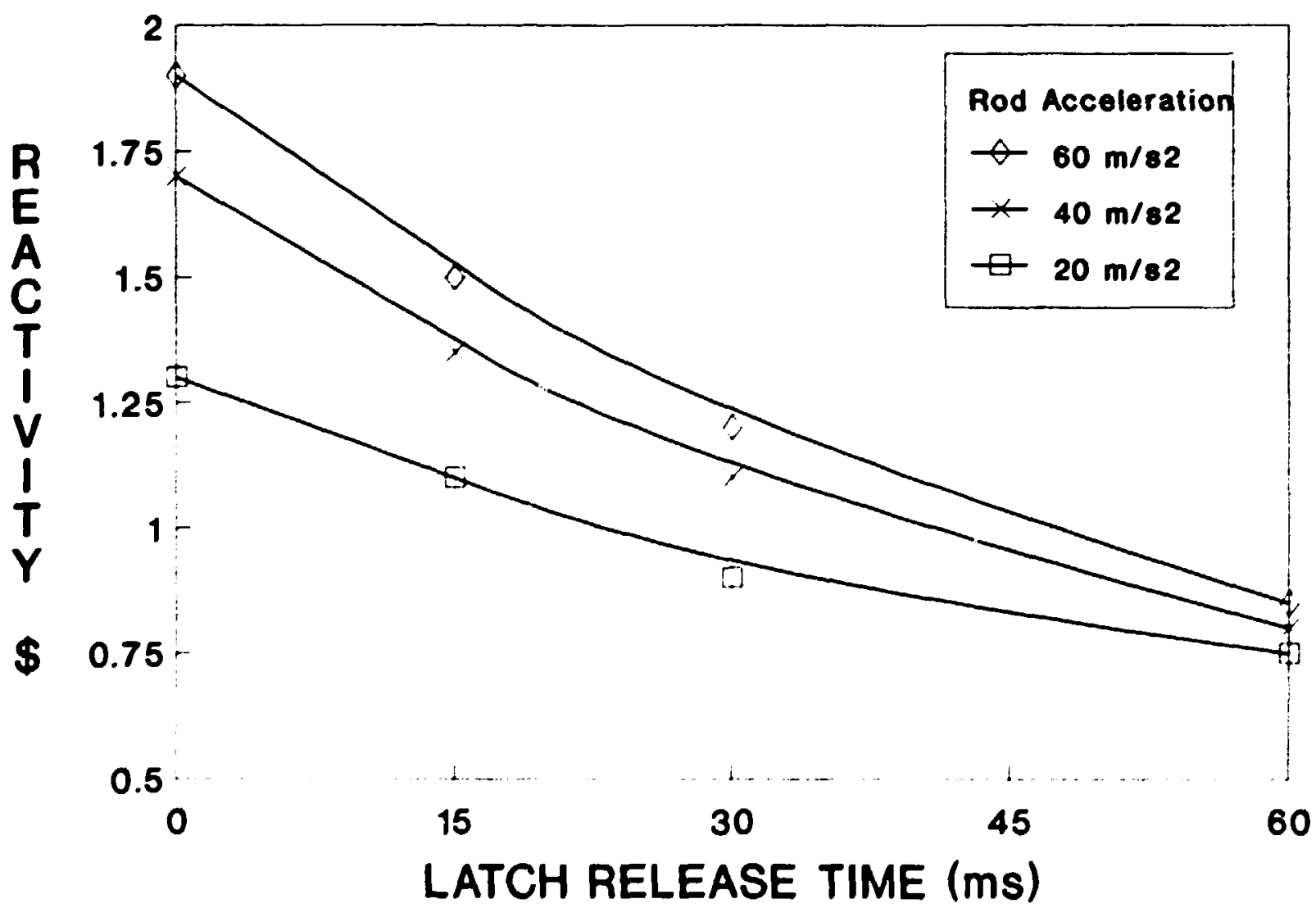

Fig 216. Maximum safe reactivity step as a function of latub relcasc time. 


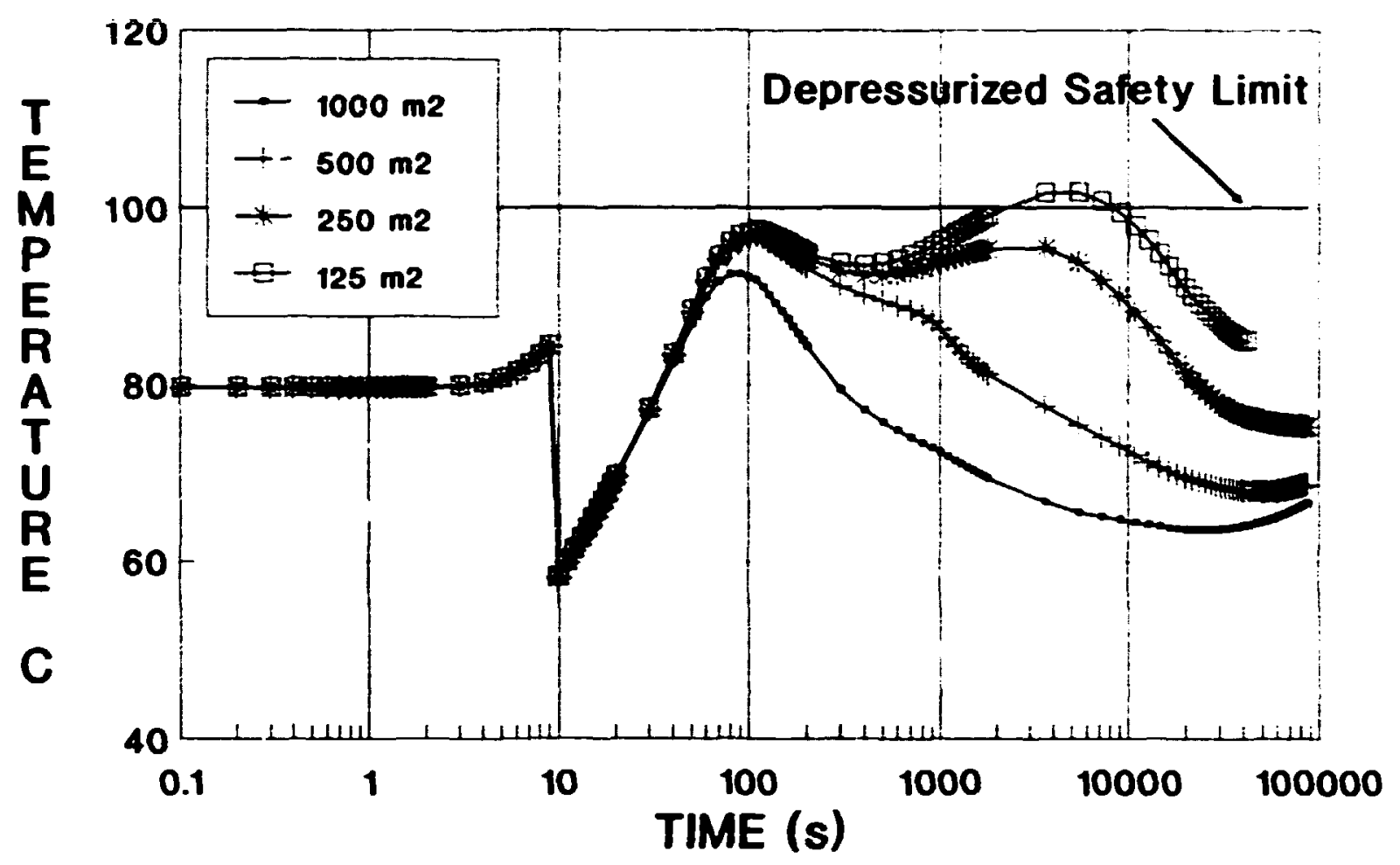

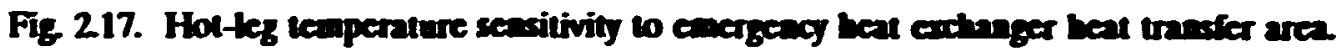

occurred, a vapor lock would form in the top of the loop, and natural circulation would be inhibited, leading to core failure. As seen in Fig. 2.17, the emergency heat exchanger must have a heat transfer area greater than $125 \mathrm{~m}^{2}$ to survive this transient.

\subsection{R\&D FACILITY CONCEPTS}

There has been some effort to identify the test facilities needed to support the reactor systems design activities. Those facilities identified are a seal-test facility, a reflector vesel and core flow-test facility, and a reactor engineering mockup.

\subsubsection{Seal Test}

The seal-test facility will be used for two different functions during its life. First, the facility will be used to evaluate different seal configurations and/or scals from different vendors; second, the facility will be used to verify the final seal design selection. This facility must be able to perform screening tests under conditions that simulate the actual operation and maintenance conditions expected in the reactor. The test will evaluate leakage characteristics, durability, special assembly techniques required, compatibility with remote maintenance philosophies, and leak detection methods.

The preliminary evaluation test will be performed using full-scale seaks with components to simulate full-size hardware. The diameters of all the joints will be full scale, but the lengths will not. The facility will be designed to take into account axial thermal expansions of the full-scale hardware. Initial tests are expected to evaluate different seal and different flange configurations. Therefore, the facility must be designed to accommodate different test pieces without major modifications. The differences in the teat pieces may include differences in fastening methods (for example, bolted vs lock ring). 
The candidate seal will be installed onto the test hardware according to the manufacturer's specification. The test hardware will be installed into the test fixture that simulates the installation manipulator. The test hardware will be joined using forces and alignment conditions forecast for the reactor. Once the joining of the mating pieces has been accomplished, the forces required for the joining and any difficulties will be recorded. The system will be pressurized with water to the operation pressure of the reactor. The seals will be monitored for leaks. The initial test may not include thermal cycling, but later tests will. Even though thermal cycling may not be a condition imposed on the early test, any relative motion due to thermal expansion will be simulated and the effects monitored.

The design verification test will simulate as accurately as possible the actual operation conditions of the reactor for the design configuration selected as the final design. The parameters monitored will be leakage characteristics of new seals, seals that have been irradiated, seals that have been installed more than once, and irradiated seals that have been installed more than once. All of these tests will include pressure and temperature cycling, as well as relative motion cycling if that is expected to be part of the test.

\subsubsection{Reflector Vessel and Core Pressure Boundary Tube Tests}

The reflector vessel and core flow tests facility will provide flow distribution and flow velocity data for the design configuration of the interior of the reflector vessel and the interior of the CPBT. This facility will use two different test setups; one will use scale models of the reflector vessel and the com. ponents mounted in the vessel, and the other will use a scale model of the interior of the CPBT with actual geometry of the different flow channcls and obstructions.

\section{Refloctor Vesed Tex}

The purpose of this test is to determine Dow patterns, flow velocities, and heat transfer characteristics within the reflector vessel. This test will be run on a half-size scale model where the geometry and surface finish of the interier sur faces of the rellector vessel and the surface components inside the reflector vessel that are exposed to reflector vessel coolant will be accurately modeled. The surfaces of the components will be instrumented with temperature and pressure sensors to provide dynamic llow measurement of the cooling water. There will be provisions for inserting movable pitot-tubetype probes within the reflector vesel so that flow mapping can be performed. The reflector vessel model will have view ports, and there will be provisions for injecting dye or vapor bubbles for flow visualization testing.

Flow will be established in the reflector vessel, which will be scalable to the operating conditions of the full-size reactor. The flow charactcristic will be measured at locations of interest using the thermal and pressure sensors installed for this purpose. The temperature of the test fluid will be set to provide measures of heat transfer at the different locations. If necessary, dye or bubbles will be injected and high-speed movies made to determine flow patterns in critical areas.

\subsection{Core Pressure Boundary Tube Teat}

The purpose of this test is to determine the flow distribution of the cooling water through the core region of the reactor. Of primary interest is how much flow passes through cach fuel element and how much is bypassed cither through the core region, around the control rods, or between the fuel element assembly and the CPBT. The wetted surfaces of the components in the interior of the CPBT will be accurately modeled for geometry and surface finish. The fuel elements will be modeled as a flow restriction, and the exits from the fuel element region 
will be modeled to scoount for the flow characteristic around the irradiation sample ascemblies. The exit streams of coolant from the upper and the lower fuel elements will be kept separate so ikn: low-rate measurements can be made.

The wetted surfsces within the CPBT will be instrumented to provide data for determining the tow and heat transfer characteristics of the cooling water.

\subsubsection{Reactor Mockup}

The reactor mockup will be a full scale engineering model of the reactor system. It will provide an accurate representation of the reactor components from a geometry, weight, and interface standpoint. This mockup will be used to asess carefully the ability of the reactor to be assembled, disasembled, and remotely maintained. It will be used for training, development and lesting of procedures for maintenance, and certain operation functions. Research equipment and instrumentation hardware can be developed on the mockup in an efficient manner with a high degree of confidence that the hardware will be capable of being installed.

The reactor mockup will be full scale, but the components will not necessarily be made of the same materials as the reactor components unless that is necessary for the function of a particular test or training objective. For components to be used for remote maintenance or assembly and disasembly operations, it may be necessary that the weight of the components be the same as the actual component. In some cases, it may be required that duplicates of the actual reactor components be used. In all caser, the geometry of the components must be the same as the actual hardware.

The mockup must have provisions for visual observation of key operations not readily visible in the reactor itself. For this reason, the reflector vessel may be represented by a skeletal framework or something similar. Design decisions of this type will be made as the requirements for the mockup are generated and refined. 


\section{3 \\ Design}

\subsection{SYSTEMS NTEGRATION}

\subsubsection{Plant Design Requirements}

The preparation of the PDR document progreased to the point of an initial issue in July 1990.2 This document defines the plantlevel requirements for the design, construction, and operation of the ANS. It also defines and provides input to individual system design description (SDD) documents. Together, the PDR and SDD documents will define and control the baseline configuration of the ANS.

The top-level requirements specified in the PDR include those developed to meet the ANS user-community needs as defined by the National Steering Committee for the Advanced Neutron Source; those defined in DOE orders applicable to the design and construction of DOE-owned reactors; other federal and state agency regulations, standards, and guidelines; national codes and standards that are applicable to the ANS; and those specific requirements identified in the design, safety, and environmental studies conducted as part of the ANS Project. As the project progresses, the safety and environmental studies will be fully documented in the Preliminary Safety Analysis Report, the Final Safety Analyzis Report, a Probabilistic Risk Assessment (PRA), the Environmental Report, and the Environmental Impact Statement. The PDR has been established at this time to identify lop-level goals and requirements. Its implementation provides the basis for conceptual design studies of the plant's systems and major components, with subsequent incremental additions following through to preliminary and final decign and ultimately to construction and operation of the plant.

It is important that the PDR clearty distinguish between design goals and design requirements so that features and characteristics that are cssential are clearty distinguished from thoue tinat are only desirable. The PDR is a living document, and the subsequent releases will add content to other sections as the dexign is developed.

\subsubsection{Systems Engineering Management Plan}

A draft of the project's Systems Engineering Management Plan (SEMP) was issued in April 1990.23 This document prescribes how systems engineering will be implemented for the ANS Project. The SEMP must define specific deliverables (a plan, an anabysis, a report) that are required by DOE Order 4700.1 and Energy Systems' engineering procedures.

Each major section of the plan includes a specified output along with identification of the work breakdown structure elements that define the particular portion of the project's work where:

1. The deliverable item is to be produced. This is the element of work where a particular individual (or organization) has been assigned responsibility for producing the required product.

2. The deliverable item will be controlled. 
This is the element of work where a particular individual (or organization) has been assigned responsibility for management control of the produced item. This would include review and approval.

3. The deliverable item interfaces with other areas within the project. This element of work is related to integration and interface control, with responsibility for this aspect assigned to a particular individual (or organization).

The SEMP ako describes systems engineering activities structured to ensure that project definition, design, and verification are conducted on a total-system basis and that engineering activities and project management efforts are coordinated and integrated. The content of the SEMP includes sections to

1. define the scope, purpose, and applicability of technical planning and control;

2. describe the systems engineering process to be used in ANS project implementation;

3. define the integration activities required for engineering specialty activities;

4. provide systems engineering requirements, which must be followed by all other project participants in order to adequately control the implementation of the project; and

5. provide preliminary schedule and cost estimates for the tasks described berein.

\subsubsection{Project Planning}

The project has once again been replanned to accommodate changes in planned funding and in the overall strategy for proceeding with design and construction. Figure 3.1 indicates the major project schedule components and milestones. The summary data illustrate the time spans associated with design and construction leading to operations, along with work activities related to environmental and safety documentation.
The work breakdown structure (WBS) section includes identification of the key design, procurement, construction, and testing times planned for each level 2 element of the WBS.

\subsection{REACTOR SYSTEMS}

\subsection{Core Pressure Boundary Study}

A tey design decision task was initiated last year to address the seak and connections at the lower and upper ends of the removable CPBT. Issues evaluated in this study included the method of providing physical support for the CPBT and the core assembly as supported by the CPBT, both under static and dynamic conditions, and how the primary coolant pressure and inventory is sealed from the reflector heavy water.

This year's activities concentrated on the various sealing concepts generated by the task team, with the objective of arriving at a reference-design recommendation.

A workshop was held on February 12, 1990, to discuss potential CPBT seal configurations. The lower connection of the CPBT was identified as posing particular problems in designing the connection to allow withdrawal of the CPBT up through the overall assembly, in satisfying the requirements of Sect. III, Class 1 of the ASME Code, and in developing a test and inspection plan for ensuring the quality of the connection during operation.

The purpose of this workshop was to present the requirements, design options, and concepts for the CPBT seal configuration; to solicit input as to whether the options investigated were the appropriate options and as to whether the investigations were sufficient to support a decision on which configuration to pursuc as a bascline conceptual design; and to provide input to the list of elements comprising the decision matrix. Prior to the workshop, several 


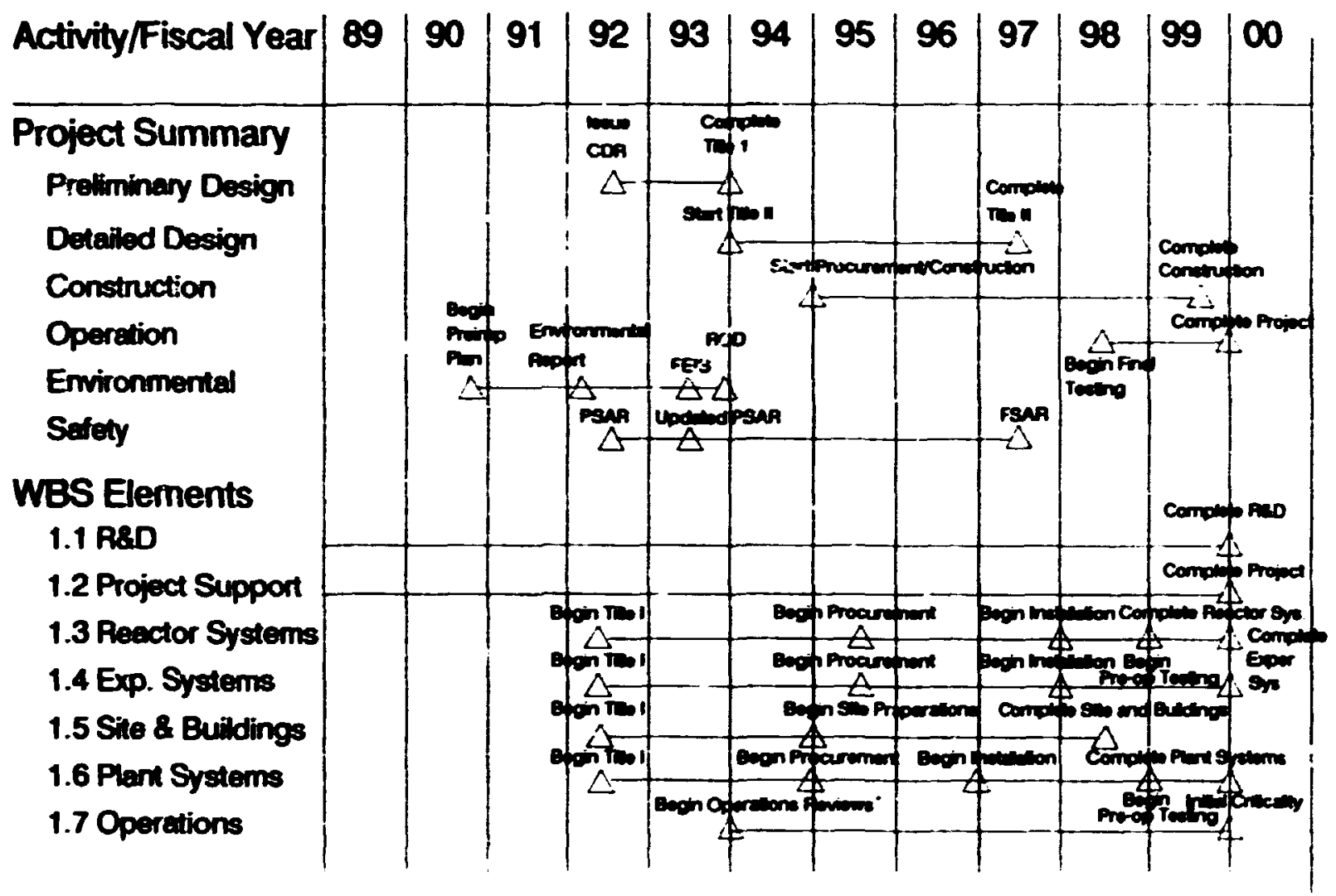

Fiz 3.1. ANts major projoct schedule components and milestones.

months of work by the task team resulted in the generation, presentation, and review of a set of requirements and options. These were summarized in the set of presentations given at the workshop.

Activity on the CPBT following the workshop has centered on the configuration which appeared to be the most conservative-an arrangement with both ends of the CPBT bolted to face seal-type flanges. This configuration has required new concepts for the fuel element support assembly. Where the previous design could incorporate the support as an integral part of the CPBT, the new concept requires access to the bolts at the bottom of the CPBT which, in turn, means that the support must be removable. The requirement to torque the holts at the bottom of the CPBT also requires special equipment. Several concepts of bolt torquing devices have been developet, and contacts have been made with vendors who supply gang-bolt torquing equipment for the automotive industry. These contacts have said that the concepts being evaluated are within available technology.

The design team's evaluation of the workshop's five concepts also determined that work should continue to develop a configuration with radial seals at the bottom of the CPBT. Figure 3.2 shows details of the arrangement with bolted CPBT flanges.

\subsubsection{Refueling Study}

The design team working on the refueling task continued to refine two refueling concupts, one utilizing a self-contained refueling machine and another using a refucling stack-and-tunnel configuration. The refueling machine concept is one in which the spent fuel is withdrawn into a transporter 

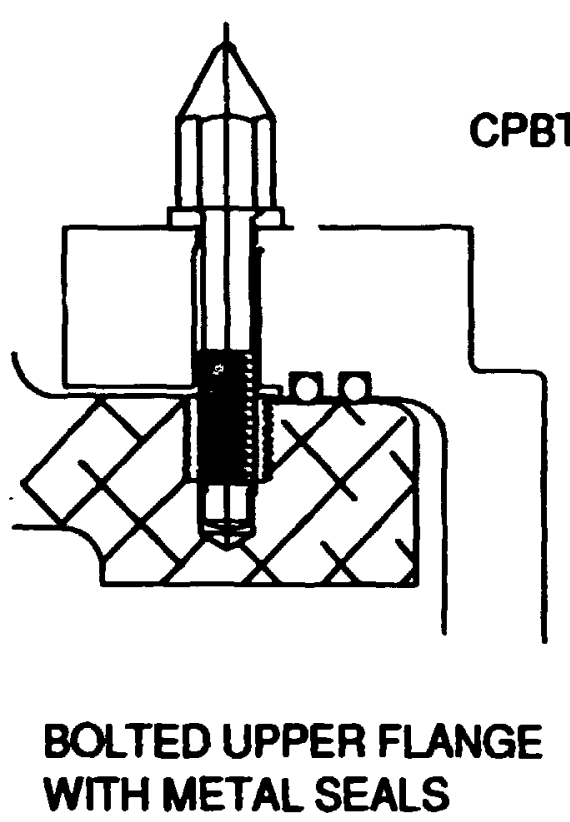

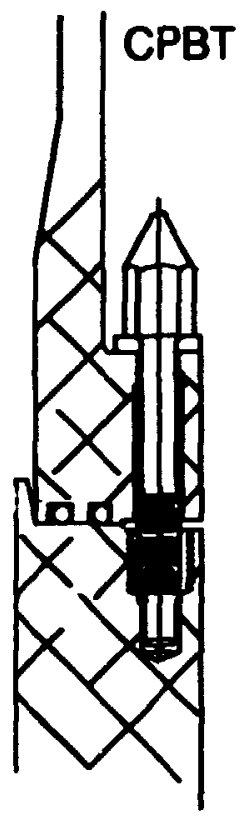

\section{BOLTED LOWER JOINT WITH METAL SEALS}

Fiz 3.2 CPBT arrangenent will bolted fanger.

filled with heavy water and transported to a transfer cell. All the necessary manipulation equipment, which is needed to open the pressure containment and to remove the fuel element and components that must be removed to access the fuel element, is contained within this refueling machine/ transporter. The stack-and-tunnel concept employs a stack filled with heavy water that extends from the free surface of the lightwater pool to the interface with the reactor system. Midway between the reactor system and the upper erit of the stack is a horizontal tunnel which provides a passageway from the stack to a transfer cell. The upper end of the stack is sealed with an appropriate air lock arrangement but allows the lifting and manipulaticn equipment to be operated from the reactor hall.

A detailed sequence of operations was developed for both concepts. The time required for each operation was estimated, and an overall time line for the refueling operation was generated for each concept. The required downtime for the refueling operation was within the desired $72 \mathrm{~h}$ for the stack-and-tunnel concept but was in excess of $80 \mathrm{~h}$ for the rcfueling machine concept.

The stack-and-tunnel concept akso offers more design options for handling the instrumented in-core irradiation sample arcemblies. If a set of samples is to be irradiated for more than one fuel cycle, the instrument leads, which include gas cooling lines as well as electrical wires, can remain connected during the refueling operation. For the refueling machine concept, these leads must be disconnected before the refucling machine can dock with the react.ur system pressure boundary iriterface. 


\subsection{Component Thermal and Stress Analysis}

The ability to cool components near the core is crucial to the successful operation of the reactor. Thermal modek of the CPBT and the inner control rods have been generated to assure that the design configurations can be adequately cooled. The models have gone through several iterations where the thermal response has indicated a need for more cooling or changes in geometry.

An initial 2-D axisymmetric model of a section of the control rod was prepared with PATRAN. The thermal analyses were done with the P-Thermal software, and the results were post-processed on a Silicon Graphics 4D-20 workstation with the NISA Display II software.

The control rod was modeled as two concentric tubes, with an inner tube of aluminum having an inner radius of $9.85 \mathrm{~mm}$ and a thickness of $2 \mathrm{~mm}$. The outer tube was hafnium with a thickness of $5.8 \mathrm{~mm}$. A $180-\mathrm{mm}$ length of the control rod was modeled, corresponding to the section: of the rod exposed to the highest heating rate. The heat rates were assumed to be $100 \mathrm{~W} / \mathrm{g}$ in the hafnium and $123 \mathrm{~W} / \mathrm{g}$ in the aluminum. It was also assumed that the coolant velocity would be $15 \mathrm{~m} / \mathrm{s}$ on both the inside and outside surfaces.

Initial results indicate the maximum temperature in the hafnium was $382^{\circ} \mathrm{C}$. The maximum aluminum/hafnium interface temperature was approximately $177^{\circ} \mathrm{C}$. Since the temperature of the hafnium was 12 degrees higher than the maximum allowed, another model was run with the hafnium thickness reduced to $5.0 \mathrm{~mm}$. The maximum hafnium temperature was lowered to an acceptable $304^{\circ} \mathrm{C}$. The aluminum/hafnium interface temperature, however, is $158^{\circ} \mathrm{C}$, which is 9 degrees above the maximum allowable. This indicates that the hafnium thickness in this section of the control rod will have to be reduced to below $5.0 \mathrm{~mm}$.

The simple 2-D axisymmetric model was modified to include the inner tube of zircal- loy and the clearance gaps between the material interfaces. As in the previous case, the 2-D control rod model was prepared with PATRAN and analyzed with the P-Thermal heat transfer code.

For this analysis, the control rod was modeled as three concentric tuber. The inner tube was zircalloy with an inside radius of $9.85 \mathrm{~mm}$ and a thickness of $2 \mathrm{~mm}$. The middle tube consisted of 6061 aluminum with a thickness of $8.25 \mathrm{~mm}$, and the outer tube was hafnium with a thickness of $4 \mathrm{~mm}$. A $180-\mathrm{mm}$ length of the control rod was modeled corresponding to the section of the rod exposed to the highest beating rate. Heating rates were axsumed to be $50 \mathrm{~W} / \mathrm{g}$ for the zircalloy, $123 \mathrm{~W} / \mathrm{g}$ for the aluminum, and $100 \mathrm{~W} / \mathrm{g}$ for the hafnium. Also included in the model was a $0.65-\mathrm{mm}$ gap between the zircalloy and aluminum and a $0.25-\mathrm{mm}$ gap between the aluminum and hafnium. It was assumed that the coolant velocity would be $15 \mathrm{~m} / \mathrm{s}$ on the ou'side surface and $1 \mathrm{~m} / \mathrm{s}$ on the inside surface. The maximum allowable temperatures are $370^{\circ} \mathrm{C}$ for the hafnium and $177^{\circ} \mathrm{C}$ for the aluminum.

The preliminary results indicate that the aluminum and hafnium interface temperature will be in excess of $770^{\circ} \mathrm{C}$. This far exceeds the maximum allowable temperature for both the aluminum and bafnium, indicating a need for design changes in the control rod configuration.

Stress analyses of the CPBT were performed to determine stress levels due to pressure and temperature in a CPBT with conventional flange connections. The design modeled was a $494-\mathrm{mm}$ diam by $3.954-\mathrm{m}$ long bell-mouthed tube with a large, external upper flange and small, internal lower flange. Both flanges use metallic c-ring seak. The shell and flange material is 6051-T6 aluminum. An internal design pressure of $\mathbf{4 . 1 2 5}$ $\mathrm{MPa}$ is assumed, and temperature distribution was obtained from a thermal analysis.

Pressure-induced stresses in the middle and at the ends of the tube are presented in Table 3.1. A 2-D axisymmetric finite clement analysis was performed using ADINA 
Table 3.1. C.PBT stress due to internal presure.

\begin{tabular}{|c|c|c|c|c|c|}
\hline Section & Thickness & Loading & $\begin{array}{l}\text { Prin ipal stress } \\
\text { analy,tic soiution }\end{array}$ & $\begin{array}{l}\text { Stress intensity } \\
\text { FE model results }\end{array}$ & $\begin{array}{l}\text { Design stress } \\
\text { intensity }\end{array}$ \\
\hline Uppcr & $93 \mathrm{~mm}$ & $\begin{array}{l}289 \mathrm{kN} / \mathrm{m} \\
\text { radial } \\
\text { constraint } \\
94 \mathrm{kN} \text {-m } \\
\text { end moment }\end{array}$ & $\begin{array}{l}\sigma_{\mathrm{ma}}=23 \mathrm{MPa} \\
\sigma_{\mathrm{ke}}=0 \\
\sigma_{\mathrm{md}}=0\end{array}$ & $\mathrm{~S}=30 \mathrm{MPa}$ & $\begin{array}{l}77 \mathrm{MPa} @ 150^{\circ} \mathrm{C} \\
50 \mathrm{MPa} \text { (welded) }\end{array}$ \\
\hline Middle & $125 \mathrm{~mm}$ & $4.125 \mathrm{MPa}$ & $\begin{array}{l}\sigma_{\mathrm{ma}}=82 \mathrm{MPa} \\
\sigma_{\mathrm{lom}}=0 \\
\sigma_{\mathrm{nd}}=0\end{array}$ & $\mathrm{~S}=89 \mathrm{MPa}$ & $\begin{array}{l}92 \mathrm{MPa} @ 100^{\circ} \mathrm{C} \\
54 \mathrm{MPa} \text { (welded) }\end{array}$ \\
\hline Lower & $19 \mathrm{~mm}$ & $\begin{array}{l}314 \mathrm{kN}-\mathrm{m} \\
\text { radial } \\
\text { constraint } \\
24 \mathrm{kN} \text {-m } \\
\text { end moment }\end{array}$ & $\begin{array}{l}\sigma_{\mathrm{wa}}=71 \mathrm{MPa} \\
\sigma_{\mathrm{bod}}=0 \\
\sigma_{\mathrm{rdd}}=0\end{array}$ & $S=75 \mathrm{MPa}$ & $\begin{array}{l}96 \mathrm{MPa} @ 50^{\circ} \mathrm{C} \\
55 \mathrm{MPa} \text { (weldeci) }\end{array}$ \\
\hline
\end{tabular}

and showed good correlation with analytic results. Stress intensities are rompared to the $A S M E$ Code design-stress intensities at she maximum temperature in each region.

Calculations were made to determine the optimum wall thickness in each section using the design equations of the Code, Sect. III, Appendix A A computer program was developed to calculate stress-intensity values over a range of wall thicknesses. Resu!'s indicate that the required thickness for pressure loading is 49 to $54 \mathrm{~mm}$ in the upper flange region, 11 to $14 \mathrm{~mm}$ in the middle, and 17 to $19 \mathrm{~mm}$ in the lower flange region. The calculation is based on allowable stress intensity values between 50 and $150^{\circ} \mathrm{C}$. The program is being modified to include the Harge design equations of the Code, Sect. III, Appendix $\mathrm{XI}$ for the end regions.

A second inite element analysis was performed using pressure and thermal loading as shown in Table 3.2. Circumferential bending stress away from the ends was found analytically to be atoui $\pm 50 \%$ of the pres- sure induced stress; however, this effect is not readily seen in the finite element model results because of the coarse mesh. The finite element analysis did reveal a peak stress intensity of $268 \mathrm{MIPa}$ in the upper lange, due to the large radial temperature gradient.

Present conclusions from this analysis are that stress margin: due to pressure and temperature are adequate and that the hub thickness in the upper flange can be reduced. This would reduce thermal stresses significantly, and the thermal analysis is beir.g updated to reflect the current design.

\subsection{EXPERIMENT SYSTEMS}

\subsubsection{Irradiation Facilities}

Most of the design efforts on irradiation facilitics during the last year have focused on developing a better definition of the reflector tank components. There have been no significant changes in the concept for five 
Table 32. CPBT stress due to pressure and temperature effects.

\begin{tabular}{|c|c|c|c|c|c|}
\hline Section & $\begin{array}{l}\text { Thermal } \\
\text { loading }\end{array}$ & $\begin{array}{c}\text { Stress } \\
\text { pressure }\end{array}$ & $\begin{array}{l}\text { Thermal stress } \\
\text { analytic }\end{array}$ & $\begin{array}{l}\text { Stress intensity } \\
\text { FE model results }\end{array}$ & 3S $\mathbf{n}$ limit \\
\hline $\begin{array}{l}\text { Upper } \\
@ 150^{\circ} \mathrm{C}\end{array}$ & $49-150^{\circ} \mathrm{C}$ & $\begin{array}{l}\sigma_{0 u}=23 \mathrm{MPa} \\
\text { radial gradient } \\
\text { in flange }\end{array}$ & $\begin{array}{l}\sigma_{\mathrm{lon}}=0 \\
\sigma_{\mathrm{rdd}}=0\end{array}$ & $\mathrm{~S}=54 \mathrm{MPa}($ hub $)$ & $\begin{array}{l}231 \mathrm{MPa} \\
\text { (268 MPa peak in } \\
\text { flange) }\end{array}$ \\
\hline $\begin{array}{l}\text { Middle } \\
@ 100^{\circ} \mathrm{C}\end{array}$ & $65-95^{\circ} \mathrm{C}$ & $\begin{array}{l}\sigma_{\mathrm{m}}=82 \mathrm{MPa} \\
\text { near core }\end{array}$ & $\begin{array}{l}\sigma_{u 2}= \pm 38 \mathrm{MPa} \\
\sigma_{100}=0 \\
\sigma_{\mathrm{mad}}=0\end{array}$ & $\begin{array}{l}\mathrm{S}=120 \mathrm{MPa} \\
\sigma_{\mathrm{lod}}=-27 \mathrm{MPa} \\
\sigma_{\mathrm{md}}=0\end{array}$ & $276 \mathrm{MPa}$ \\
\hline Lower & $\begin{array}{l}49^{\circ} \mathrm{C} \\
\text { uniform }\end{array}$ & $\begin{array}{l}\sigma_{\mathrm{um}}=71 \mathrm{MPa} \\
\sigma_{\mathrm{ba}}=0 \\
\sigma_{\mathrm{rdd}}=0\end{array}$ & & $\mathrm{~S}=75 \mathrm{MPa}$ & $288 \mathrm{MPa} @ 50^{\circ} \mathrm{C}$ \\
\hline
\end{tabular}

instrumented and five non-instrumented capsules within the CPBT as shown in Fig. 3.3. Also unchanged is the conceptual design for the transplutonium production targets within the CPBT.

Conceptual drawings for two large slantirradiation facilities just outside of the CPBT were developed in sufficient detail to verify the mechanical feasibility of installation and assembly. There are concerns, however, that these facilities may have an unacceptable impact on the thermal neutron flux at the beam tubes. To evaluate the effects of these and other reflector tank components, a 3-D Monte Carlo model is being developed based on the current hardware layouts.

Isotope production is supported by four hydraulic rabbit tubes located in regions of neutron flux ranging from 25 to $100 \%$ of the peak thermal flux, along with seven vertical holes near tice outer perimeter of the reflector tank. The locations of the vertical holes were sclected to provide high thermal fux $\left(>10^{19} \mathrm{~m}^{-2} \cdot \mathrm{s}^{-1}\right)$ and low fast flux and a gamma heating ratc less than $1 \mathbf{k W} \cdot \mathbf{k g}^{\cdot !}$.
Conceptual layouts for the hydraulic tubes were developed and preliminary heat transfer calculations performed to estimate the coolant flow requirements.

The analytical chemistry in-tank facilities for activation analysis are being revised. Layouts were developed for three pneumatic rabbit tubes as previously proposed. These had capacities of $200 x c, 40 c c$, and $1 c c$, with heat loads somewhat less than $1 \mathrm{~W} / \mathrm{g}^{-1}$. A review of these facilities by the analytical chemistry community (including NIST and internal reviews) has led to a number of suggestions. Because this reactor is so well suited to nuclear analytical chemistry, an expansion in the number of pneumatic tube and support facilities has been recommended. Additionally, it is felt that the heating rates should be low $\left(<0.1 \mathrm{~W} / \mathrm{g}^{-1}\right)$ and that the large tube should be replaced by several smaller ones. A request was also made for two pncumatic tubes in the lightwater pool. These recommendations will be investigated by the project over the next ycar. Four pneumatic tubes capable of 


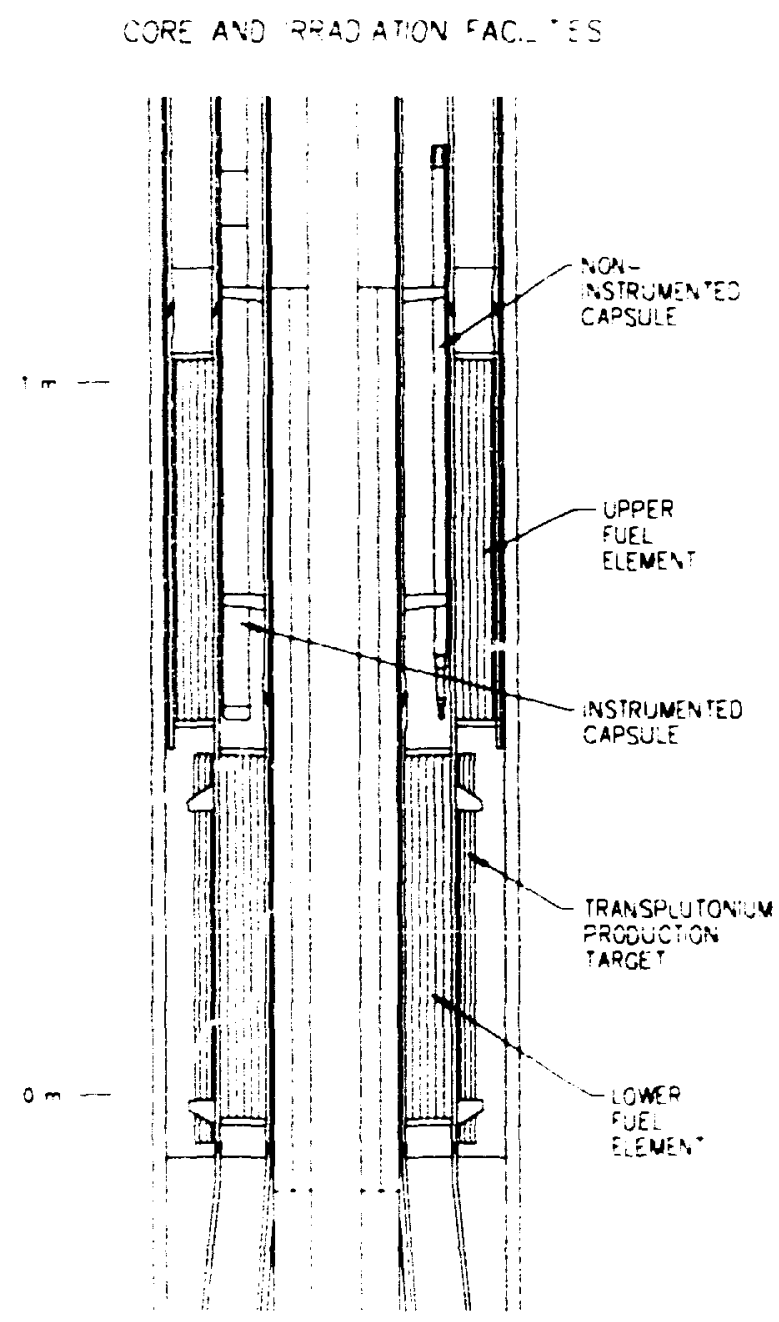

Fig 33. Reactor core showing CPRT and irradiation facilitica.

handling a $40 \mathrm{cc}$ rabbit will be provided in the heavy water reflector along with one with a 1 ce rabbit capacity. Additionally, two pneumatic tubes will be located in the lightwater pool.

\subsubsection{Second-Floor Beam Transport and Research Facilities}

Figure 3.4 shows the current conceptual layout for the second floor. A number of modifications have been made during the year. The area available for experiment systems has been defined based on a more com- plete estimate of the space requirements for the cooling and reactor systems as shown. A second slant-cold guide has been added so that each cold source has the same arrangement of one very cold guide and one slantcold guide. One slant-cold guide is foreseen for a depth profiling station with the second providing a station for future expansion.

The instrumentation arrangement has been changed to provide better access and also to incorporate a more realistic estimate for the space requirements of the on-line isotope separation device, based on the Lohengrin installation at the ILL Figure 3.5 shows an elevation view of this instrument and the slant-thermal beam. This facility will need a small hot cell for target handling. The beam tube penetrates to a position of less than peak thermal flux because the targets in Lohengrin are already at close to maximum heat load. Some additional space will be needed to allow incorporation of a sniall ion-beam accelerator for ion implantation studies.

Layouts have been completed for the highly-curved, very-cold neutron (VCN) guides with a critical wavelength of 6 to $7 \mathrm{~nm}$. One VCN guide will be used to feed an ultra-cold neutron source.

\subsubsection{Main Floor Beam Transport}

A concept has been developed for a standard beam tube and biological shield plug, as shown in Fig. 3.6. The heavy-water seal is at the outer boundary of the lightwater pool. This allows double-walled containment but minimizes the window thickness. It also permits straightforward beam tube replacement without draining the lightwater pool. No mechanical operation is closer to the core than the inside of the biological shiclding.

The plug itself would contain a rotating collimator with a beam stop and three open channels. Al either end of the collimator is a rotating thermal-ncutron mask. This arrangement would allow the heam shape to be 


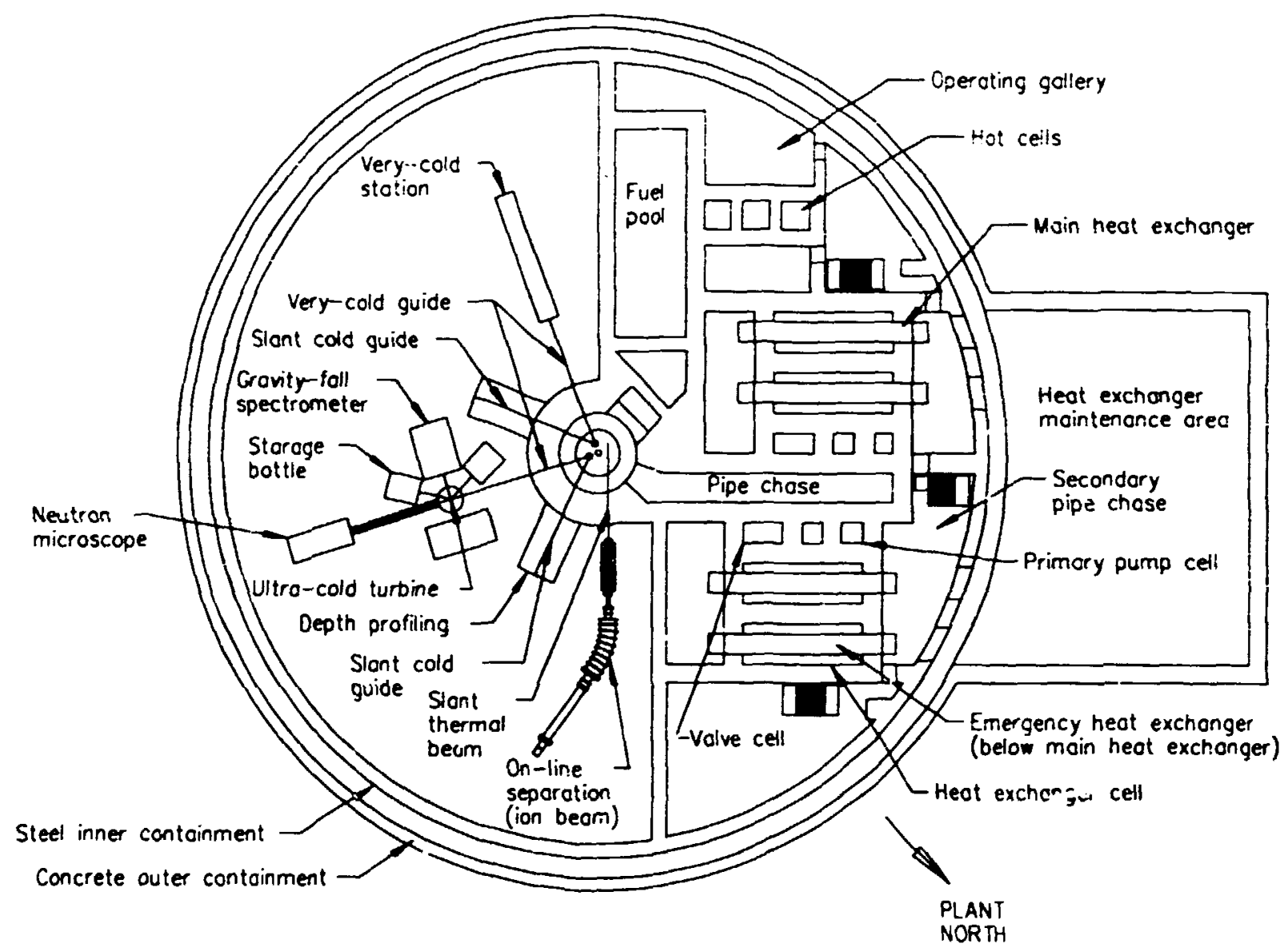

Fig 3.4. Lyout of failitics on the second foor of the reactor building

tailored in a number of different ways. Two fast-acting gate valves are just inside the biological shield to prevent heavy water from leaking into the beam room in case of a beam tube failure in the tank.

Only minor changes have been made in the arrangement of the thermal beam tubes and cold guides from previous layouts. Instrument layouts are being developed for the beam room to maximize the utilization of the beams. Thermal guides will be used in some locations where there would otherwise te overlaps between adjacent instruments. Recent advancements in the development of supermirrors make this type of arrangement more attractive. As this effort progresses, it is likely that some rearrangement of the beam-line locations will be desired.

\subsection{SITE AND BUILDINGS}

\subsubsection{Preliminary Site Characterization}

A preliminary field investigation was conducted on a proposed ANS reference site to obtain general information about subsurface conditions, to determine the general engineering characteristics of the subsurface materials, and to present preliminary recommendations regarding the geologic suitability of the site.

The initial exploratory program consisted of nine borings located in the vicinity of the proposed reactor building. Three of the borings were cored $9 \mathrm{~m}$ (30 ft) into bedrock, 


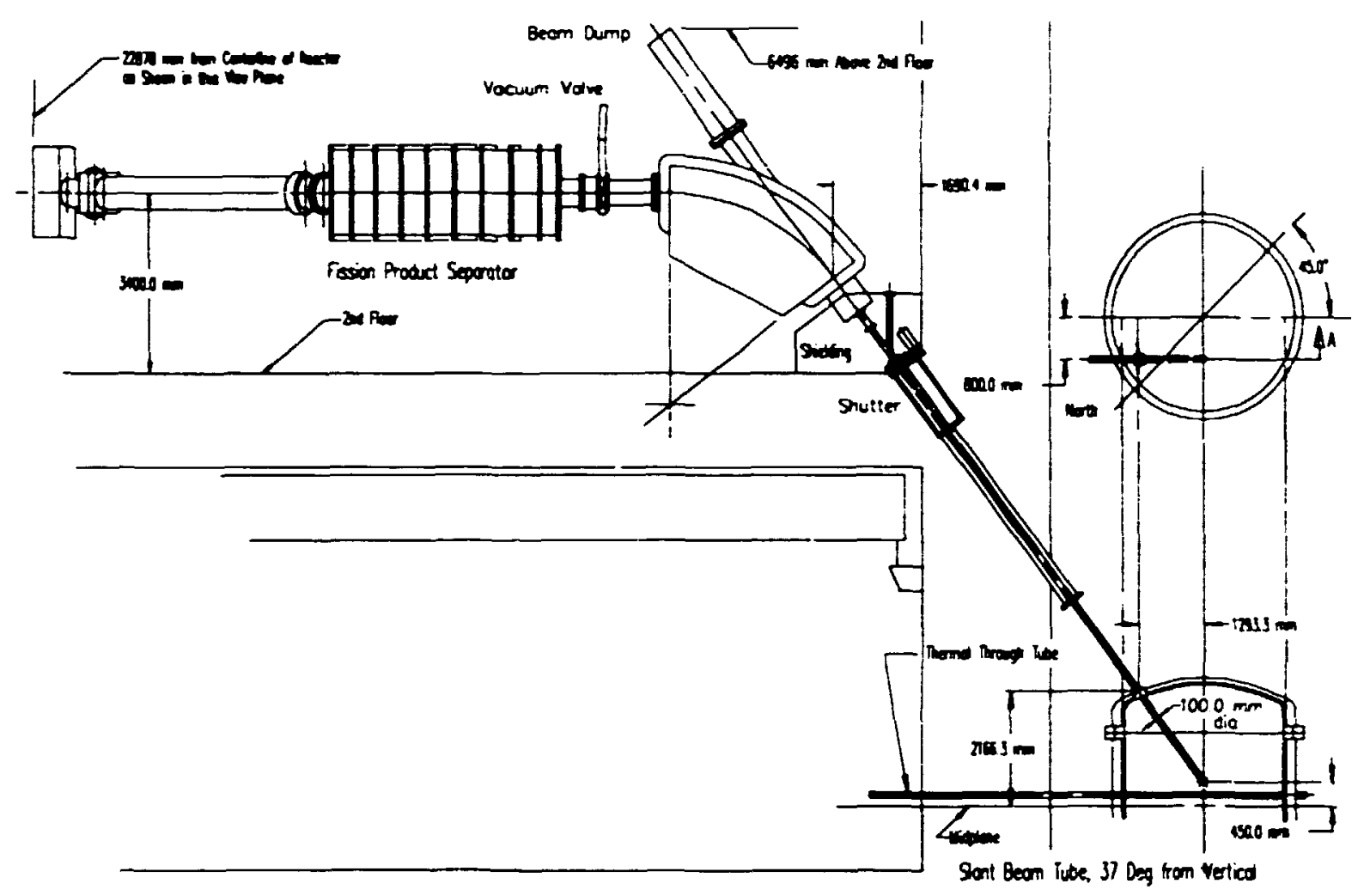

Fig 3.5. Elention view of the isorope separation on-line fecility.

and one boring, directly under the proposed location for the reactor, was cored $30 \mathrm{~m}$ (100 ft) into rock. The soil and core samples obtaired during the exploration were classified and tested. Also, all borings were monitored for the presence of ground wr:er. The results of the drillings and testin? activities were documented by the contractor, ERC/EDGe, Knoxville, Tennessee. ${ }^{24}$

The findings revealed a rock mass of relatively uniform composition and consistency with a very low potential for bedrock dissolution. The bedrock does not appear to be severely weathered to significant depths and should be able to sustain foundation loads in the range of 0.5 to $1.5 \mathrm{MPa}$ (10 to $30 \mathrm{kjps} / \mathrm{ft}^{2}$ ) depending on the degrec of wcathering. Spread foundations bearing directly on bedrock should provids adequate support for the primary structure'.. If local decp foundations are required, drilled piers should be relatively casy to install. Only a small amount of settlement induced by large spread foundations is anticipated, and most of this will occur during construction. Most rock excavation can be accomplished with large earth-moving equipment with only a modest amount of blasting anticipated. While important structures will probably require support on the bedrock, the excavated soil should make very good engineered fill when properly placed and compacted. In conclusion, although the amount of subsurfacc data is very limited, no "red flags" have been identificd to preclude further study.

\subsubsection{Architectural Workshop}

A site and facility planning task has been initiatcd to focus on the functional and organizational layout of the principal buildings on the sitc. This task will involve the reactor building, the reactor and opcration 

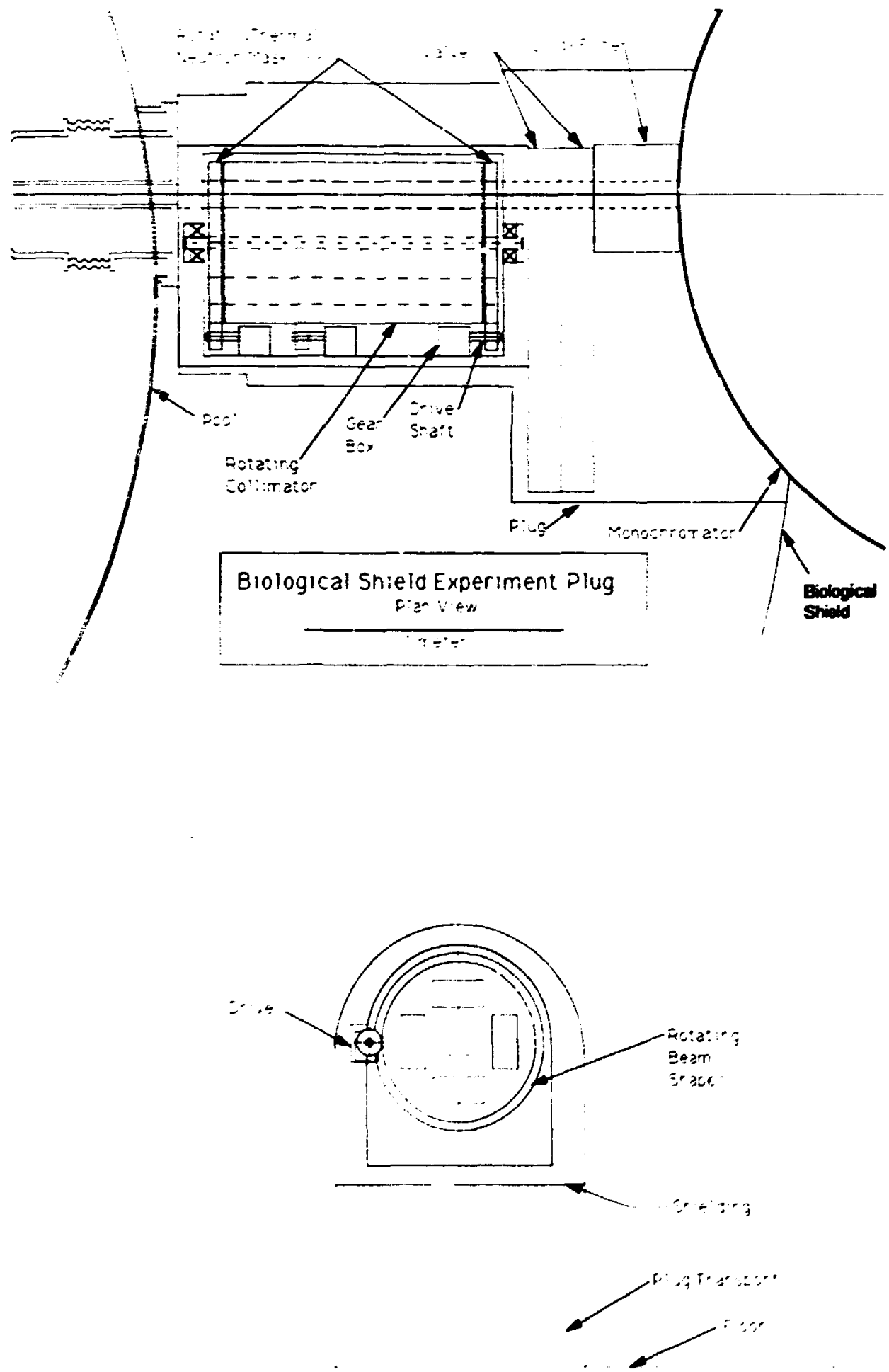

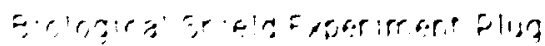

Fie 36 Standard bean twbe and biological shield plog. 
support buildings, the guide hall and research support buildings, the main office building, the area between the buildings, and the arrangement of these and other buildings on the site.

A Site and Facility Planning Workshop was held on October 18-19, 1989. The purpose of the workshop was to gather under the same roof not only the multidisciplinary design team but also experimentalists, representatives from laboratory regulatory and support offices, and operators of existing reactor facilities. The workshop was divided into six sessions: plenary, users/clients, general support and site, systems issues, interface, and wrap-up and conclusions. Sixty-five people attended the workshop and the intense discussions that followed the presentations. During the three days of discussions, important information-crucial to the planning of the ANS-was generated and shared by the participants. This information was then reviewed and compiled into a computer data base for use in development of a criteria document.

A first draft of this ANS Site and Facility Criteria Data Base document was circulated for comments in July 1990. The document, based on the information generated by workshop participants, was discussed, modified, clarified, and recompiled into the computerized data base. This data base also provides a list identifying all spaces in the facility, as well as an expanded description of each, including general, architectural and structural criteria, electrical, HVAC and experimental systems, security, safety, ALARA, and industrial hygiene. Figure 3.7 depicts a portion of an example record. For some functions, much information is already entered in the records, but for others the record still appears in the form of an unanswered questionnaire.

In conjunction with the effort to develop the facility requirements, work was initiated to identify site critcria. An cffort to determine the characteristics of the soil, slope orientation and stecpness, soil hydrology, and other characteristics was begun late in FY 1990. This information will be incorporated into the criteria document being prepared and will form a basis on which to develop the ANS site plan. This effort is important because it influences such issues as cost of excavation, elevations of facilities and accommodation of entrances at various leveks, radiation shielding by a partially buried or mounded earth structure, equipment elevations affecting natural circulation of cooling water, and many other requirements.

\subsection{PLANT SYSTEMS}

\subsubsection{Reactor Cooling Systems}

Definition of the conceptual design for the reactor cooling system was one of the most important accomplishments during the fiscal year. This work was accomplished by a deticated task team, with the involvement of others both on and off the project team. A key step in obtaining review of the cooling system design options was a workshop held February 15-16, 1990, in which participation was sought from inside and outside the project íboth from others at Energy Systems and from participants from other national laboratories and universities). ${ }^{25}$

The ANS reactor cooling system reference design shown in Fig. $3 \%$ provides cooling water flow up through the core, utilizing four separate and independent primary and secondary loops employing passive means to maintain coolant flow (natural circulation for decay heat removal), pressure (accumulators), and inventory (pools and flooded equipment cells) during emergency conditions. Three of the four loops are required for full power operation (one out for maintcnance). A minimum of only onc is required for all emergency design-basis events.

Each primary loop includes, in scrics, a main heat exchanger, an emergency heat cxchanger, a two-specd pump, and loop maintenance valves. The pumps' higher speed is 


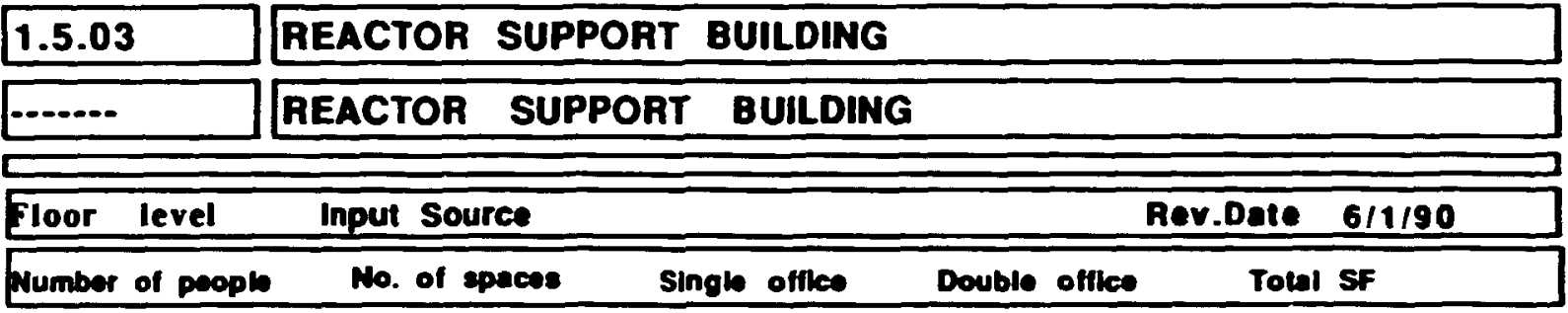

General Criteria Description

The reactor suppon building will be a seismic class I faciliy capable of withstanding all classified natural events with minimial damage and capable of continued operation following such an evert. The tuiding will house the critical equipment and operations functions that control reactor operations. The control room and its suppont requirements, reactor support equipment, containment equipment, and other critical equipment will be housed in this facilty. Also contained within the facitity wit be health physics and security functions that indirectly support operation and control of the reactor.

\section{Architectural and Structural}

\section{Conveying Systems}

\section{Electrical Systems}

All offices will need computer terminal hard lines. Special oulbts for power for computers shall be provided from uninterruptible sower supplies to provide fittering and transient protection for computer usage.

Fif 3.7. A portion of the sample form for the sits and facility criteris data base element

used for normal operation and the lower speed (10\% of high speed) for shutdown conditions. Each pump has an uninterrupt. ible power supply for low-speed operation with a minimum mission time of at least 30 min. The heat exchangers have the heavywater coulant on the shell side to facilitate tube inspection and maintenance activities. To enhance natural circulation, the heat exchangers are clevated with respect to the 


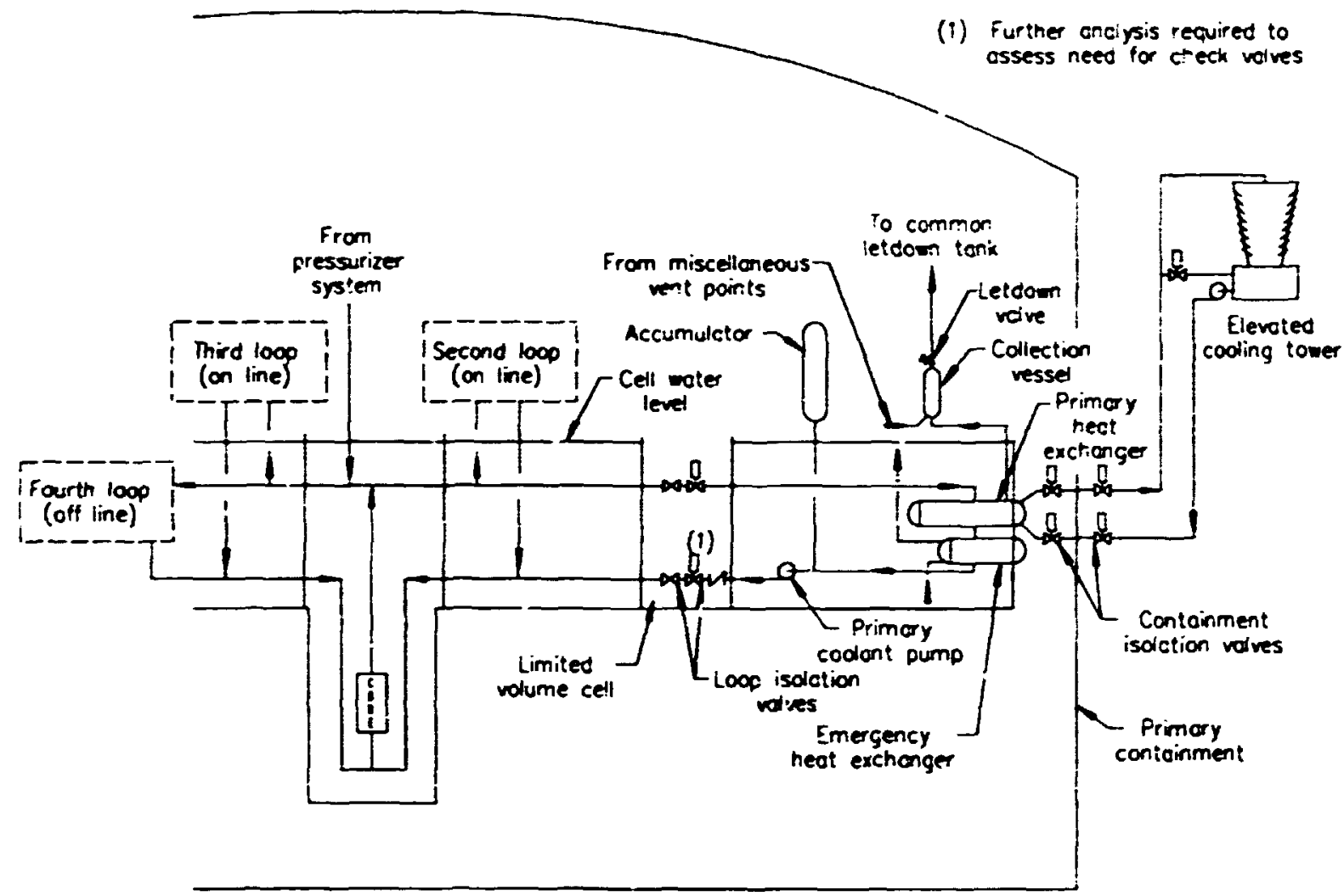

Fig 38. Fonsheet of the reactor cooling sostem

core, and the loops are simple in shape with only one high point and one low point. To obtain passive inventory control, all primary piping and equipment are located in either flooded or limited volume cells (cells with a volume less than the capacity of the accumulators). All primary coolant system equipment is located within the primary containment structure.

Each secondary system for the main heat exchangers includes a forced-draft cooling tower, cooling tower basin, pump, containment isolation valves, and tower-bypass valve. The tower basins and the piping between the main heat exchangers and cooling towers are designed for all design-basis events. Flow under normal conditions is by forced circulation; however, the tower basins are clevated with respect to the main heat exchangers to enhance natural circulation for emergency conditions. Each tower basin has sufficient heat capacity to provide adequate shutdown cooling for $3 n \mathrm{~d}$. Makeup water would then be required to replace evaporation loses.

The emergency heat exchangers are located in flooded cells having sufficient heat capacity to provide adequate shutdown cooling for at least $\boldsymbol{7 2} \mathbf{h}$. The secondary system includes the flooded cell water, piping, and maintenance values, with flow provided by natural circulation.

The pressure control system utilizes a feed-and-bleed system coupled with passive accumulators. The control parameter is the reactor coolant outlet pressure. The ketdown points are through the high-point collection tanks on each loop while the makeup is supplied by pumps to the hot leg. An accumulator is located in each primary pump suction leg to protect the core and the primary coolant pumps by maintaining higher core outlet and pump suction pressures during transient 
depressurization scenarioc. The sccumulators will also provide a sufficient amount of prinary coolant inventory to flood any single limited volume cell in the cvent of a pipe break within that cell and will provide diverse protection against core melt for total loss-of-power scenarios.

The selection of the reactor cooling system design concept was made just prior to the thersaal-hydraulics review beld at ORNL on Biarch 29-30. That review provided a furiner opportunity for feedback from experts ai universities and at other national laboratories. Although concerns were expressed over the ability to predict natural circulation Low patterns in a multi-loop system, the reviewers clearty endorsed the overall concept.

\subsubsection{Reactor Containment Systems}

Selection of a reference concept for the ANS reactor containment system is another of the key conceptual design decisions undertaken during the facal year. Although not all aspects of the system were fully clarified by the end of the reporting period, selection of the basic concept had been made. As with the reactor cooling system, the work was undertaken by a decicated team, in consultation with other project participants and outside experts. A wortshop on the requirements and design options for the containment system was held August 23$24,19900^{26}$

The ANS reactor is designed in accordance with the defense-in-depth concept, in which succeeding layers of safety are built into the design and operations of the facility and excessive reliance upon any one element is avoided. The reactor containment system provides the third level of this defense-indepth concept. The containment systems function to provide personnel protection for the ANS site population, the population of the Oak Ridge Reservation, and the general public against the effects of severe sccidents. ANS site personnel include the operating and experimental personnel beated within the containment building.

The reactor containment building (Fig 3.9) is a duai-containment structure

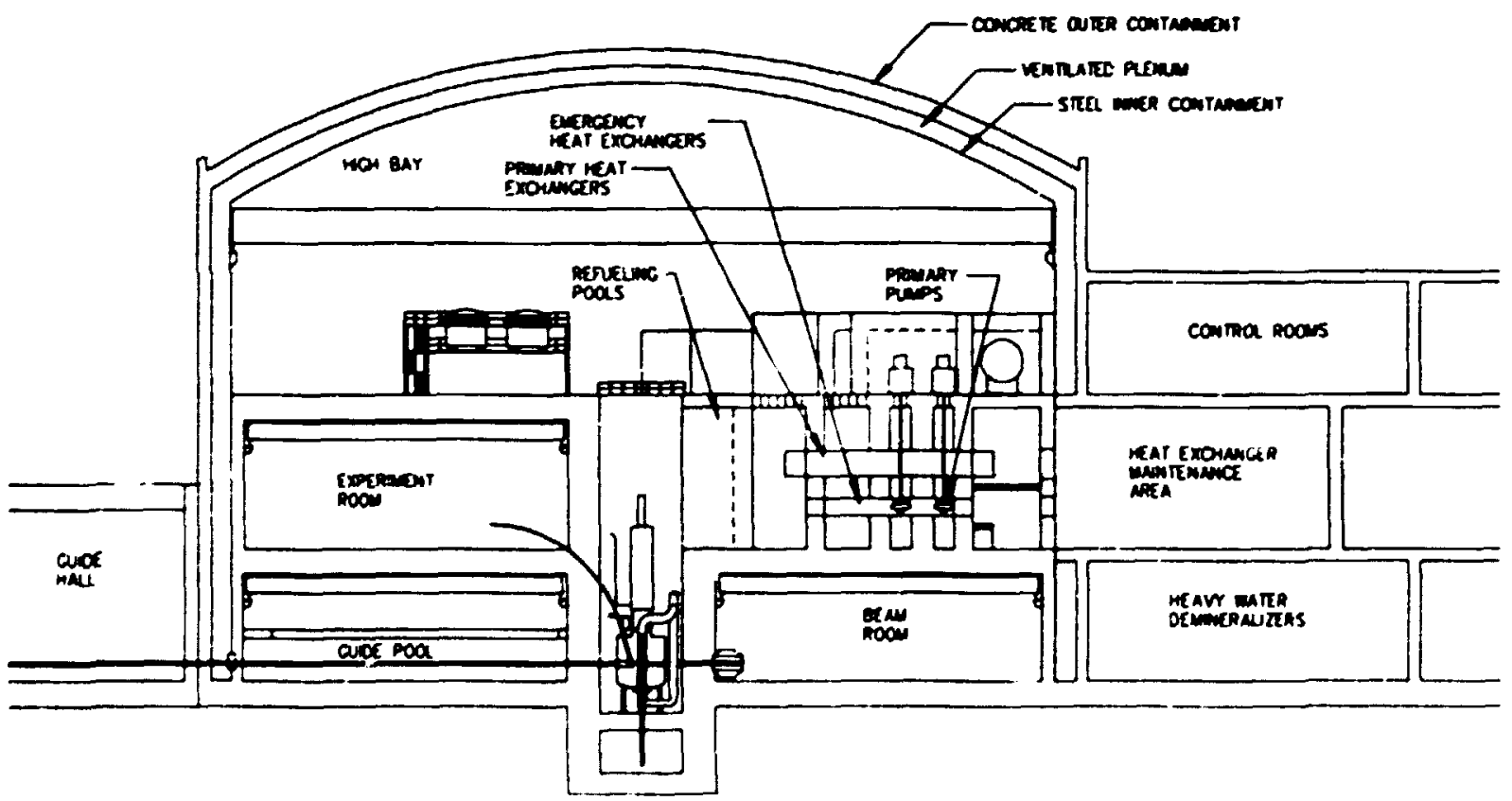

Fie 3.9. Elevation view of the reactor building 
consisting of an inner steel containment vessel, which limits the leakage of any fission products that may be released into the internal containment atmosphere, and an outer concrete structure, which provides for collextion and subsequent treatment of fission products that leak from the inner barrier. The concrete shell also provides protection for the inner stcel vescel against the external environment and acts as a radiation shiekd for any radioactivity between the inner and outer barriers that may be present during a severe accident. The barrier also incorporates isolation values installed on all penetrations through the steel vessel. The reactor containment building is ako divided intu separate operating and experimental areas. The normal HVAC systems for these areas are separated so that any radioactivity released into one area is not spread into the other, except in the most severe accidents.

The fission product-control system provides a means to limit or delay the release of fission products in order to permit the safe evacuation of all on-site and off-site personnel. Fission product control inside the containment is provided by locating the reactor primary fluid boundary in either water or airfilled pooks or cells and by isolation values installed on all pool or cell wall penetrations. Fission product control is provided by a fission product-treatment system that maintains a negative pressure relative to the outside air presure in the annulus, the space between the inner steel containment vessel and the outer concrete structure, and removes the fission products that would leak into the annulus space during severe accidents (Fig. 3.10). The combination of the inner primary containment leak rate, on the order of $0.5 \%$ volume per day, and the annulus fission product-treatment system, having an iodine decontamination factor on the order of $\mathbf{4 0 0}$, satisfies the Environmental Protection Agency's Protection Action Guidelines limits for the ANS boundaries. This is true even for ground level releases during severe accidents, including up to a $100 \%$ release of roble gases and iodine into the inner containment atmosphere.

Heat removal for severe accidents is provided by the inherent containment building heat sinks and by passive beat transfer through the inner steel containment vessel and outer concrete wall. Inherent combustible gas control is provided by the large containment volume that, with adequate mixing assures that concentrations are less than combustible limits.

\subsubsection{Heavy-Water Management, Cleanup, and Detritiation}

Careful management of $\mathrm{D}_{2} \mathrm{O}$ is necessary to insure adequate reactor core activity and minimal (ALARA) worker radiation exposure with economical treatment processes. The ANS design has proceeded on the basis of separate cooling circuits for the primary coolant and the reflector tank.

Chemical cleanup of the primary coolant involves a low-pressure sidestream providing degassing, particulate removal, and ion exchange removal of dissolved impurities. Targets of this system are radiolysis products; particles eroded from fuel cladding and valve parts, together with similar diseolved metals; remnants of the $\mathrm{pD}$ arjustment chemicals; and degradation products of the ion $\mathrm{ex}$ change resins. A similar cleanup system will be needed for the rellector circuit. Degassing may be a necessary step for the rellector circuit also.

Tritium accumulates in the heavy-water coolant and reflector streams as a result of neutron absorption in deuterium. Because of the large high flux volume in the reflector tank, along with the smaller volume of reflector water, the tritium concentrations increase faster in the reflector water than in the primary coolant. Core reactivity declines as protium atoms accumulate in the $\mathrm{D}_{2} \mathrm{O}$ in the core and the reflector. ${ }^{n}$ Such buildup occurs due to unavoidable mixing of the $\mathrm{D}_{2} \mathrm{O}$ in the primary coolant, the reflector coolant, 


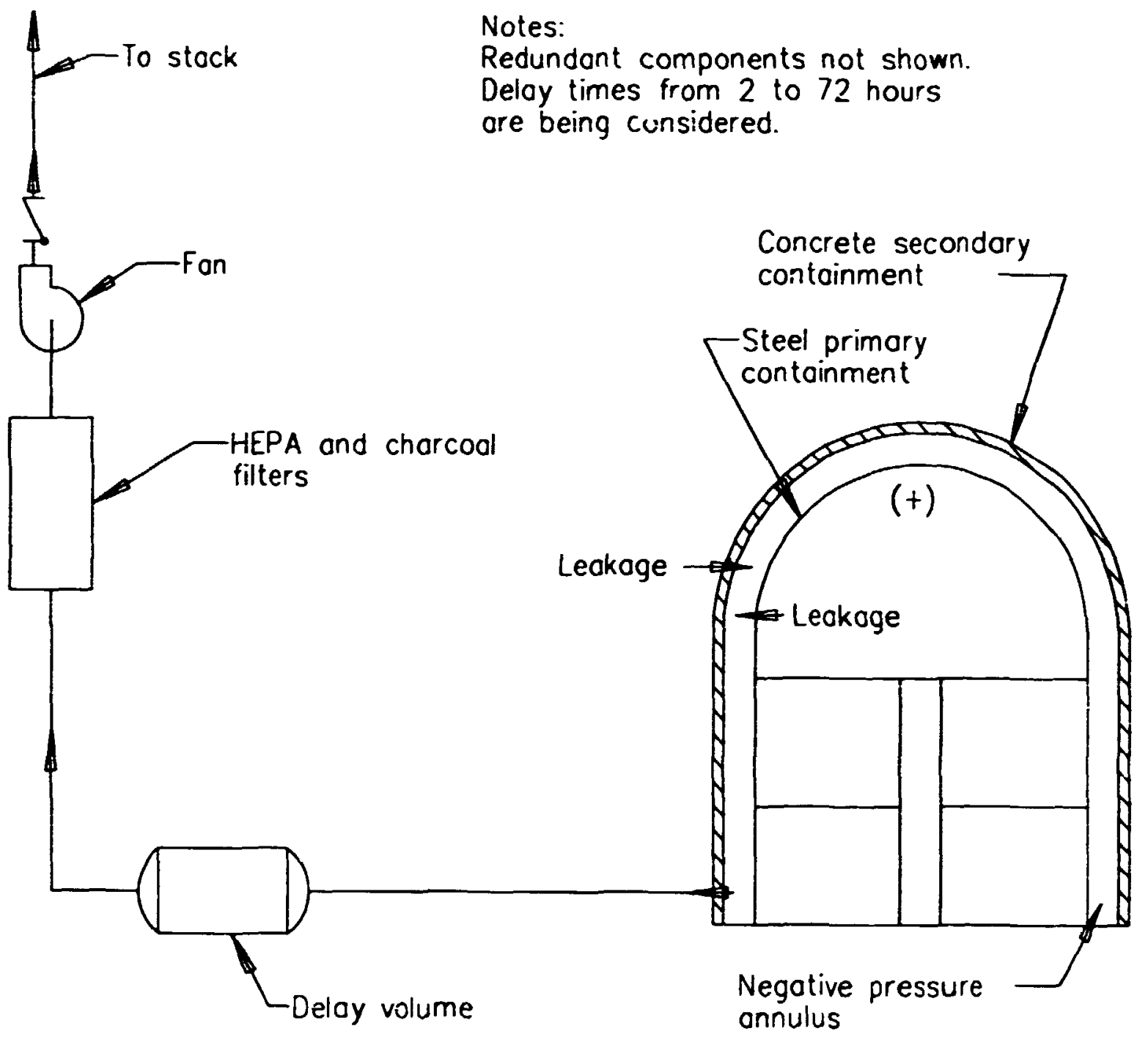

Fig 3.10. Fonsheet of the annelos edhand and treatment gystem

and the r'el transfer pool, with the $\mathrm{H}_{2} \mathrm{O}$ in the reactor shield pool during change-out of the CPBT. The transfer pool $\mathrm{D}_{2} \mathrm{O}$ may also capture some atmospheric moisture $\left(\mathrm{H}_{2} \mathrm{O}\right)$ at its surface during the anticipated 20 refuelings performed each year. The adulterated transfer pool water then mixes with the primary coolant during refueling $A$ small amount of protium may also be iniroduced with ion exchange resins and with the nitric acid and caus.ic, which are used for pD control.

Removal of tritium and protium from heavy water requires sending a separate, smaller sidestream to a detritiation and upgrade facility. Sizing the $\mathrm{D}_{2} \mathrm{O}$ flow to this facility was investigated this year. A detritiation unit can achieve the same detritiation factor with any feed tritium concentration, which means that the unit size is theoretically smaller if it is fed with reflector water rainer than mixtures involving primary coolant. Unfortunately the protium, which is relatively more prevalent in the primary coolant, must also be removed.

If the primary coolant and the reflector were mixed and treated together, a larger detritiation unit would be needed. If they 
were treated individually, separate campaigns would be needed. The prediction of the required annual removal capacity for protium is more difficult than that for tritium. It is expected that use of a liquid phase catalytic exchange process would improve the capability of protium removal over that of the vapor phase catalytic exchange system used at ILL.

The design team worked to ensure effective communications betwren the ANS project and other North American sites encountering similar problems with heavy-water handling. In particular, team members visited the Savannah River site, and one member attended the Safe Tritium Handling Course at Ontario Hydro and Chalk River Nuclear Laboratories, Ontario, Canada.

\subsubsection{General Equipment Data Base}

Work was begun on an equipment data base, providing not only a listing of equipment items, but also key performance and utilities requirements for all equipment in the plant system WBS. This data base will complement the site and facilities data base discussed in Sect. 3.4.2. An initial description of the structure of the equipment data base was prepared over the summer by a student assigned to the projact. 27 
The ANS safety program supports the overall project objective of completing the conceptual design in 1992. The major safety program goals are twofold: to participate in the conceptual design process to help design a safe reactor, and then to produce a safety analysis report (SAR) and a Level 1 PRA during 1992. ANS safety analysts have, as documented in three previous progress reports, ${ }^{1,622}$ performed analyses and studies as necessary to guide the evolving design, while at the same time developing the analytical capabilities and data base necessary to produce the requisite SAR and PRA.

Safety activities during 1990 centered on PRA, transient thermal-hydraulics, and severe accident analysis. In the sections below, each of the task leaders summarizes the activities in his area over the past rear: R. R. Fullwood (BNL) in PRA, G. L. Yoder for transient thermal-hydraulics, and R. P. Taleyarkhan on severe accident analysis. It should be realized that each of these is a snapshot of activities and results completed at some point in the year. The safety analyses are being rapidly advanced as necessary to keep up with the evolving conceptual design. For example, Fullwood is working to complete failure-modes effects and criticality analyses (FMECAs) of major systems and will, when this activity is complete, update the core damage probabilities presented in Sect. 4.1. Similarly, the preconceptual RELAP5 model discussed in Sect. 4.2 is currently being modified to reflect the reactor core and the new conceptual primary coolant system designs adopted during the year and will be utilized to provide valuable feedback to designers durirg the upcoming year.
Before moving on to the progress summaries of each safety analysis discipline, it is appropriate to consider overall progress in the ANS nuclear safety posture. During the past year, the ANS conceptual design effort has been very actively pursued by enginéering, R\&D, and safety analysis personnel; developments have been very positive for nuclear safety. Consider, for example, the release in July 1990 of the ANS PDR specification (see also Sect. 3.1.1). The PDR section on safety goals embraces and designates as project policy the goal that the ANS be licensable and specifies stringent risk limitation goals that are responsive to the DOE safety objectives policy, as outlined in DOE's policy statement on nuclear safety objectives for DOE facilities, revised draft of February 15, 1989, and to the NRC Nuclear Safety Goals Policy. ${ }^{29}$ Similarly responsive not only to the DOE policy but also to the NRC Advanced Reactors Policy ${ }^{30}$ is the PDR requirement that ANS safety-related systems be designed with the maximum practicable degree of inherent and passive safety.

In two major conceptual design efiorts (sec Sect. 3.5), spucific design decisions were made that enhance nuclear safety and that put into practice the goals promulgated by the PDR specification. The reactor cooling systems were redesigned to enhance natural circulation decay heat removal and to provide passive heat sinks for in-containment dissipation of decay heat without active circulation components or off-site power. Gas accumulators were added to enhance the ability of the primary coolant system to undergo pipe breaks without fucl damage; RELAP5 calculations (sce Sect. 4.2.2) have 
confirmed the accumulator size requirements. The number of coolant loops-thiee normally running and one on standby-was chosen by PRA scoping analyses to support the PDR fuel damage risk limitation goal $\mathrm{o}^{-} 10^{5}$ core damage events per year.

Defense-in-depth was significantly enhanced when the containment design team chose a very leak-tight, moderate-pressure primary containment surrounded by a lowleakage secondary containment building. Severe accident analyses were performed during the containment design effort to provide estimates of the pressures that primary containment would need to withstand (See Sect. 4.3.3). Both the reactor cuoling system and the containment system design efforts culminated in workshops that gave the design teams the chance to get feedback from objective, experienced professionals selected from both inside and outside of Energy Systems.

\subsection{PROBABILISTIC RISK ASSESSMENT}

The year began with the completion of a scoping PRA for ANS based on the HFIR PRA, with modifications for currently planned design differences between the two plants. The results, summarized in Table 4.1, show that the design changes are significantly reducing the risks. However, this scoping analysis is now obsolete in that it was based on the ANS preconceputual design. The scoping PRA drew heavily on HFIR data ${ }^{31}$ without giving full credit to ANS features such as the dual independent scram systems, accumulators, and improved pressure control. The results from the scoping ANS PRA are considered to show qualitatively the effects on the ANS design but are too uncertain to use for prioritizing work toward more accurate assessment of the ANS risk. The HFIR

Table 4.1. Comparison of core damage frequencies: HFIR PRA results and scoping ANS PRA.

\begin{tabular}{|c|c|c|c|}
\hline \multirow[b]{2}{*}{ Initiator } & \multicolumn{2}{|c|}{ HFIR } & \multirow{2}{*}{$\begin{array}{c}\text { ANS } \\
\text { Frequency/y }\end{array}$} \\
\hline & Frequency/y & $\%$ Contribution & \\
\hline Flow blockage & $1.1(10)^{4}$ & 35.7 & $7.2(10)^{6}$ \\
\hline Loss of off-site power & $6.4(10)^{-5}$ & 20.5 & $7.7(10)^{-9}$ \\
\hline Large pipe break & $3.3(10)^{.5}$ & 10.5 & $<3(10)^{-7}$ \\
\hline $\begin{array}{l}\text { Manual scram, inadvertent } \\
\text { scram, or control element drop }\end{array}$ & $2.6(10)^{-5}$ & 8.4 & $2.8(10)^{-9}$ \\
\hline Degraded primary flow & $2.2(10)^{.5}$ & 7.1 & $1.9(10)^{8}$ \\
\hline Failure of instrument air & $1.7(10)^{-5}$ & 5.4 & $4.6(10)^{9}$ \\
\hline *Small pipe break & $1.6(10)^{-5}$ & 5.1 & incomplete \\
\hline Reactivity transient & $1.3(10)^{-5}$ & 4.1 & $6.6(10)^{-7}$ \\
\hline Pressurizer/controi failure & $6.4(10)^{6}$ & 2.0 & $2.2(10)^{-7}$ \\
\hline Beam tube failure & $2.1(10)^{6}$ & 0.7 & incomplete \\
\hline Degraded secondary flow & $2(10)^{6}$ & 0.5 & $2.1(10)^{8}$ \\
\hline TOTAL (" kas) & $3(10)^{4}$ & 94.2 & $<8.4(10)^{6}$ \\
\hline
\end{tabular}


prioritization by the rank ordering indicated in Table 4.1 was used for that purpose.

\subsubsection{Failure-Modes Effects and Criticality Analysis}

From the beginning of the ANS project, PRA has been considered a risk assessment tool for guiding designers. The current state of ANS design does not support detailed PRA analysis, and communication with the designers through fault trees and event trees is ineffective. For these reasons, the more design-effective procedure of FMECA has been used this fiscal year for evaluating the ANS design evolution.

Flow blockage has the first rank in the HFIR PRA Because the ANS PRA used data from the HFIR PRA, it also has the first rank in the ANS PRA. To improve this analysis, the flow obstructions must be identified. The major obstructions identified in the HFIR PRA originate externally, from outside the primary coolant system envelope, either during refueling or during inspection and maintenance. The frequency of refueling (about 17/year for ANS) identifies this as a possible entry route. Lacking details of the process for refueling and for replacement of the CPBT and control rods, a conceptual design of the equipment and procedures wrs prepared to show that these steps can be safely performed in an expeditious manner. Because the refueling machine is prepare 1 off-line under low stress and under administrative control, the entry of foreign objects $b_{j}$ this route can be prevented. This conclusion focuse attention on inspection and maintenance as a possible entry route, but further analysas are deferred unti! those processes are tetter defined.

The HFBR PRA, conducted at BNL, ${ }^{32}$ identified beam tube rupture as a riskdominating accide $n t$ at the facility, thus drawing attention to the situation at ANS. Beam tubes and beam guide; were analyzed for accident potential, but brcause ANS beam tubes or guides do not enter the primary circuit, this mode of accident initiation is less significant for ANS than it is for the
HFBR or HFIR If labyrinth seak are used to seal the ANS CPBT, the effects would be similar, but the magnitude of the effects for ANS would be less. The FMECA for beam and guide tube failure is currently under review.

The development of the reference ANS coolant system design enabled a re-examination of the pressurizer pumps as an accident initiator. The pressurizer pump, accumulator, and letdown systems were analyzed by FMECA to determine if improvement could be made over the HFIR design. As a result, it was shown that by proper sizing and constant-speed operation of the pressurizer pumps, an over-pressurization accident could be eliminated. This work identified an accident potential uniquely associated with accumulators - the possibility of introducing gas into the primary coolant system during the gas-charging operation. Special controls on the addition of gas into the accumulators will be necessary to eliminate this risk.

A major improvement over HFIR will be ANS's dual scram system. The conceptual ANS control rod drive system was analyzed by FMECA. No major defects were found, although concerns were expressed regarding scramming against the fluid drag for the inner scram system and scramming against gravity in the outer scram system. Other concerns involve the possibility of loose parts blocking the scram mechanism and possible common-mode failure mechanisms associated with manufacturing or maintenance.

\subsubsection{Pipe Break Probability}

The PRAISDPD (PRAISe Discrete Probability Distributions) model of pipe failure that was developed in FY 1989' was applied to the conceptual design of the ANS primary piping. As illustrated by Fig. 4.1, the system was detailed as 83 pipe sections, 191 welds, 32 elbows, 12 tecs, 12 valves, and 6 check valves. The time dependence of the leak and break frequencies makes interpretation difficult (PRAISDPD output is in terms of years since startup). Accordingly, the geometric mean averaging of the frequencics 


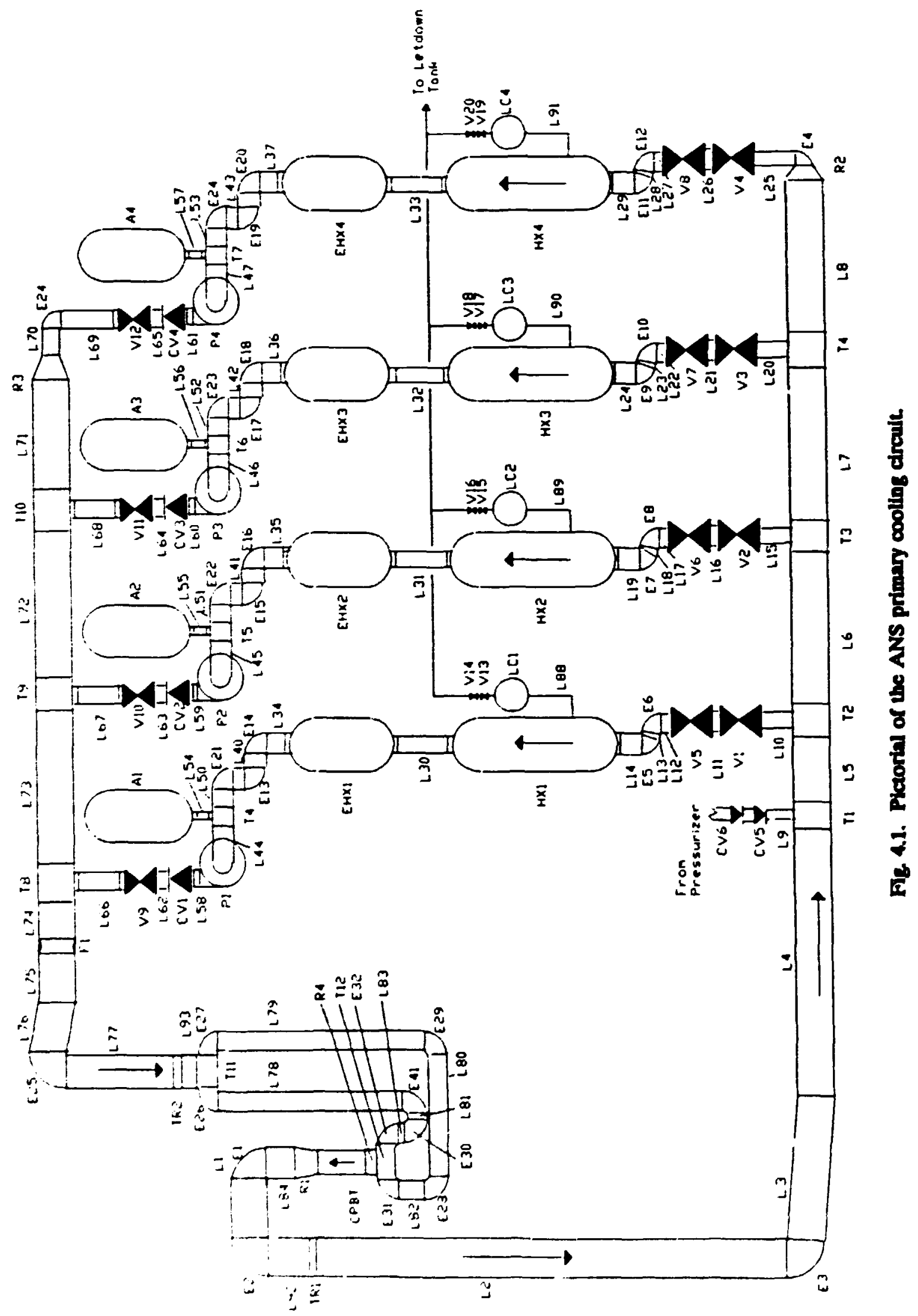


over 40 years (expected life of ANS) was calculated. Table 4.2 shows these mean leak and break frequencies grouped by pipe sutside diameter. The right-hand column includes the effects of leak-before-break by utilizing the probability of $22(10)^{-2}$ for detection of a leak before it grows to be a break. Table 4.2 shows the leak and break frequencies but does not include the additional modeling necessary for pipe-breakinitiated fuel damage frequency predictions as provided in Table 4.1. formed pipe break calculations, while ORNL performed station blackout calculations and planned for future RELAP5 validation experiments. It should be noted that the RELAP modeling and accident analysis calculations reported here apply to the preconceptual ANS coolant system design. Major improvements bave resulted from the coolant system workshop held in March 1990. These modifications are currently being incorporated into a RELAPS model but have not reached a state of completion sufficient for inclusion in this progress report.

Table 4.2 Geometric mean primary pipe leak and break frequenciea

\begin{tabular}{|c|c|c|c|}
\hline Pipe diam $m$ (in.) & Leak frequency $(y)$ & Break frequency $(y)$ & Break inc. $\operatorname{LBB}(y)^{\circ}$ \\
\hline $0.61(24)$ & $7.7(10)^{-7}$ & $4.9(10)^{6}$ & $1.1(10)^{-9}$ \\
\hline $0.36(14)$ & $1(10)^{-4}$ & $7.1(10)^{6}$ & i.6(10) $)^{-7}$ \\
\hline $0.152(6)$ & $1.8(10)^{-5}$ & $1.6(10)^{6}$ & $3.5(10)^{2}$ \\
\hline $0.076(3)$ & $3(10)^{-6}$ & $1.7(10)^{-7}$ & $3.7(10)^{-9}$ \\
\hline $0.051(2)$ & $1.8(10)^{-5}$ & $1.5(10)^{6}$ & $3.3(10)^{2}$ \\
\hline ALL & $1.4(10)^{-4}$ & $1.1(10)^{-5}$ & $2.4(10)^{-7}$ \\
\hline \multicolumn{4}{|c|}{ "LBB = Leak-befo;e-break } \\
\hline
\end{tabular}

\subsection{TRANSIENT THERMAL HYDRAULICS}

Work continued during FY 1990 to improve RELAP5 as a tool for predicting ANS transient thermal-hydraulic behavior and to develop a better understanding of the transient response of the ANS reactor (ANSR) to accident conditions. This activity involved cooperation between ORNL and INEL. INEL improved the RELAP5 model that was assembled during FY 1989 (based on ORNL/ANS/INT -1, Preliminary Description of the Advanced Neutron Source) and per-
The RELAP series of codes was originally developed by INEL for NRC for transient thermal-hydraulic analysis of commercial pressurized water reactors (PWR). As such, the code contains many features common and useful to ANSR: single- and twophase piping analysis, single- and two-phase pump performance characteristics, kinetics and heat transfer calculations, as well as many others. However, it is also recognized that some features of the ANS, such as a highly subcooled primary coolant system with plate fuel geometry, are dissimilar to those of commercial PWRs. The former implies that 
RELAP must perform calculations during rapid depressurization transients and at low system pressures (atypical of PWR analysis), while two-phase behavior within the plate geometry is expected to be much different from that in rod geometry.

Because of questions such as these, activities have been initiated to identify ANS-specific code development needs and to lay out a plan to validate the code for research reactor and ANS-specific conditions. Initial code development needs were identified and implemented during the last reporting period, while a new task was initiated during FY 1990 to plan for RELAP5 validation experiments. The plan recommends experiments that examine core thermal behavior under accident conditions and identifies other experimentation needed because of the subatmospheric pressure reached by the primary system in pipe-break accidents.

To provide the design team with an early cstimate of transient accident response capabilities of the ANSR, several accident scenarios have been investigated. Initially, modifications to the FY 1989 RELAPS model were made to improve the accuracy of the model and to allow parametric evaluations of ANSR accident performance. Revisions included an improved pump model, a revised power distribution, improved reactivity feedback coefficients, and the addition of an accumulator. Calculations were performed with the model to examine the system response to several pipe-break sizes and locations, some station blackout. scenarios, and a parametric evaluation of accumulator performance.

\subsubsection{Planning for RELAP5 Experimental Validation}

Four investigations are planned to support analysis of the safety-related performance of the ANSR using the RELAPS thermal-hydraulic system simulation code. The need for these experiments was established based on deficiencies identified in some resident model in the code when applied to the ANSR. The experiments are structured to allow formal verificaticn and validation, following NQA-1 standards, of these aspects of RELAP5. Thermal-hydraulic testing is expected to be initiated in FY 1991 and will continue through 1993.

\subsection{Inmodinte Reaponse}

The thermal limits in the fueled region of the reactor earty in transients following breaks in the primary system must be wellmodeled Experiments to establish these limits will be conducted in a loop (the THTL), which is to be built to establish the thermal limits of the fuel during normal operation. The experiments will be conducted using an electrically heated aluminum test section with a prototypical coolant gap (1.27 mm) and channel length (507 mm). A further description of the facility to be used for these tests can be found in Sect. 24, Thermal-Hydraulic Loop Test." Three types of experiments are planned to examine a mass flux range from $3,000 \mathrm{~kg} / \mathrm{m}^{2}$ s to $30,000 \mathrm{~kg} / \mathrm{m}^{2}$. The first experiment will examine the subcooled boiling pressure drop characteristics of the cooling channels in the fuel. These studies will be conducted in well-instrumented test sections under controlled mass flux conditions. A model for the subcooled boiling pressure drop, as a function of local conditions in the channel, will result from these studies. It will allow the prediction of the initiation of excursive instability (that is, Ledinegg flow excursion leading to flow redistribution) in the fueled region of the reactor. These experiments will be conducted in such a manner that the test section is not destroyed.

A second set of experiments is planned in which the channel pressure drop is maintained constant and the channel is allowed to 
go through the flow excursion transient, leading to burnout. These experiments will allow a validation of the subcooled boiling pressure drop models implemented in RELAPS.

A third set of experiments will investigate the thermal limits associated with flux peaks due to the fuel grading and so-called hot spots due to manufacturing defects in the fuel. These experiments will also be conducted in well-instruminted test sections under controlled mass flux conditions.

\section{Long-Term Response}

The thermal limits in the fuel assembly late in transients or during refueling (when the decay heat and mass flux values are low) must ako be established. This work will also be accomplished in the THTL However, significant modifications will be necessary to accommodate the low mass flux, low pressure, and positive quality flow situations that will be encountered. The test section to be used in these tests will be constructed with a prototypic heat capacity and span width to simulate the thermal response of an ANSR fuel plate. This is necessary because flow instabilities, and associated temporal variations in the mode of heat transfer, will occur in these situations.

\section{Pump Response}

The head developed by the main circulating pumps during coastdown carly in transients affects the cooling flow provided to the core. Therefore, the performance of the main circulating pumps during potential accidents must be very well characterized. Tests are planned to establish the behavior of the main circulation pumps during cavitation and during two-phase ingestion.

\subsection{Choking}

The high mass flux in the fuel elements and in the primary system make internal choking a possibility after vapor generation in loss-of-pressure cvents. The critical mass flux in the fuel assembly must be known for low-pressure flashing flows and for subcooled boiling flows; data can be taken in the apparatus used for parts 1 and 2 An additional test facility may be needed if the possibility of critical flow in the hot leg of the primary loop after low-pressure flashing remains an issue. However, the design of the primary system, along with more realistic pump cavitation modek, may prevent flashing and choking in the hot leg of the primary loop during credible transients.

\subsection{Flow Blockage}

Partial blockage, by debris in the primary system, of flow entering the fuel assembly of the reactor system is an important accident initiator. However, this cvent is not amenable to analysis using RELAPS. Other codes, such as TEMPEST, will be examined to determine their applicability to this problem. Experiments are planned to establish the type of blockage necessary to initiate fuel damage during normal operation. Adiabatic experiments are planned to examine the flow field downstream of a blockage. These results can be used to establish the vapor generation point in a heated channel. A heated channel experiment is planned in which flow blockages are introduced upstream of a heated channel. These experiments would be conducted using the same facility as the tests described in Sects. 4.2.1.1 and 4.2.1.2. However, a unique test section would be required. Partial flow blockage may lead to structural failures due to flowinduced vibrations or fuel plate buckling. Experiments to address these issues can be conducted in conjunction with experiments already planned to examine the stability of the fuel plates in high velocity flow (that is, Task 1.1.7.2.4). 


\subsubsection{RELAP5 Transient Calculations}

\section{RELAPS Moded}

The ANS RELAPS model developed in FY 1989 was modified to incorporate the most recent and accurate ANSR information, including a revised core power distribution based on the E8 fuel grading. To provide for manufacturing uncertainty, the hot channel coolant gap is assumed to be $1.14 \mathrm{~mm}, 90 \%$ of the nominal value. $A 1.14$ multiplier on the bot channel power densities represented the hot channel combined uncertainty factors.

In addition, a bot stripe representing hot spot heat structures was added, incorporating an uncertainty factor of 1.31 for hot spots within the core. Fuid density reactivity feedback coefficients were revised to reflect more recent calculations. These revisions tended to reduce the reactivity insertion resulting from decreases in fluid density. The nominal pressurizing system flow was reduced from $0.0252 \mathrm{~m}^{3} / \mathrm{s}$ to $0.0126 \mathrm{~m}^{3} / \mathrm{s}$ based on the pressurizer flow rates utilized at the HFIR.

A nitrogen-charged accumulator was added to the RELAP5 system model. The modeled accumulator is a $10-\mathrm{m}^{3}$ tank assumed to be nitrogen charged and heavywater filled, with the fluid initially at the pool water temperature. The accumulator aspect ratio is 3, with an initial gas volume of $0.25 \mathrm{~m}^{3}$ and an initial liquid volume of $9.75 \mathrm{~m}^{3}$. The initial gas volume was such that the tank would not empty were the system depressurized to atmospheric pressure. The reference accumulator model is connected to the cold leg distribution header, but a hot leg connection was also investigated. The surge line is assumed to be 3-m long with an elevation drop of $1 \mathrm{~m}$ from the tank bottom to the cold leg and a flow area of $0.2495 \mathrm{~m}^{2}$ (three times the area of one heat exchanger loop cold leg). A schematic of the RELAP5 model used in this analysis is presented in Fig. 4.2.
The ANS RELAPS model has been applied to different types of hypothetical events, from extremely unlikely pipe break events to more likely events such as station blackout. The pipe break events were examined first in order to help answer pressing design configuration questions, such as the need for accumulators. The station blackout analyses were then run to check the beneficial effects of accumulators on more likely events. For this reason, the pipe break events are presented first.

\section{Pipe-Breal Anlyais}

Brief results and analyses for representative RELAPS pipe-break calculations are presented in this section. Small, medium, and large breaks that open instantly in the main coolant pump discharge, puinp suction, and hot-leg piping were investigated. The small, medium, and large break sizes were defined by round holes with diameters of $58 \mathrm{~mm}$, $152 \mathrm{~mm}$, and $325 \mathrm{~mm}$, respectively. The double-ended break of a pressurizing line ako was investigated. For this break, the pressurizing system was assumed to be connected to the primary coolant system through two or more 76-mm diam pipes with a check value in each line (the system design in this region is incomplete). The pressurizing line break therefore assumed a circular hole in the cold-kg pipe, with the same diameter as one pressurizing line. All pipe breaks were assumed to discharge into a light-water filled space that is simulated by a constant-pressure condition. Calculated results are presented in Figs. 4.3 and 4.4 for a representative small break at the main coolant pump discharge without an accumulator in tice system. (The reference coolant system design did not include an accumulator at the beginning of the reporting period.)

Because the primary coolant system is liquid-filled, when the break opened the primary system pressures declined rapidly over the first $6 \mathrm{~s}$ of the sequence, as shown in Fig. 4.3. The declining core inlet pressure 


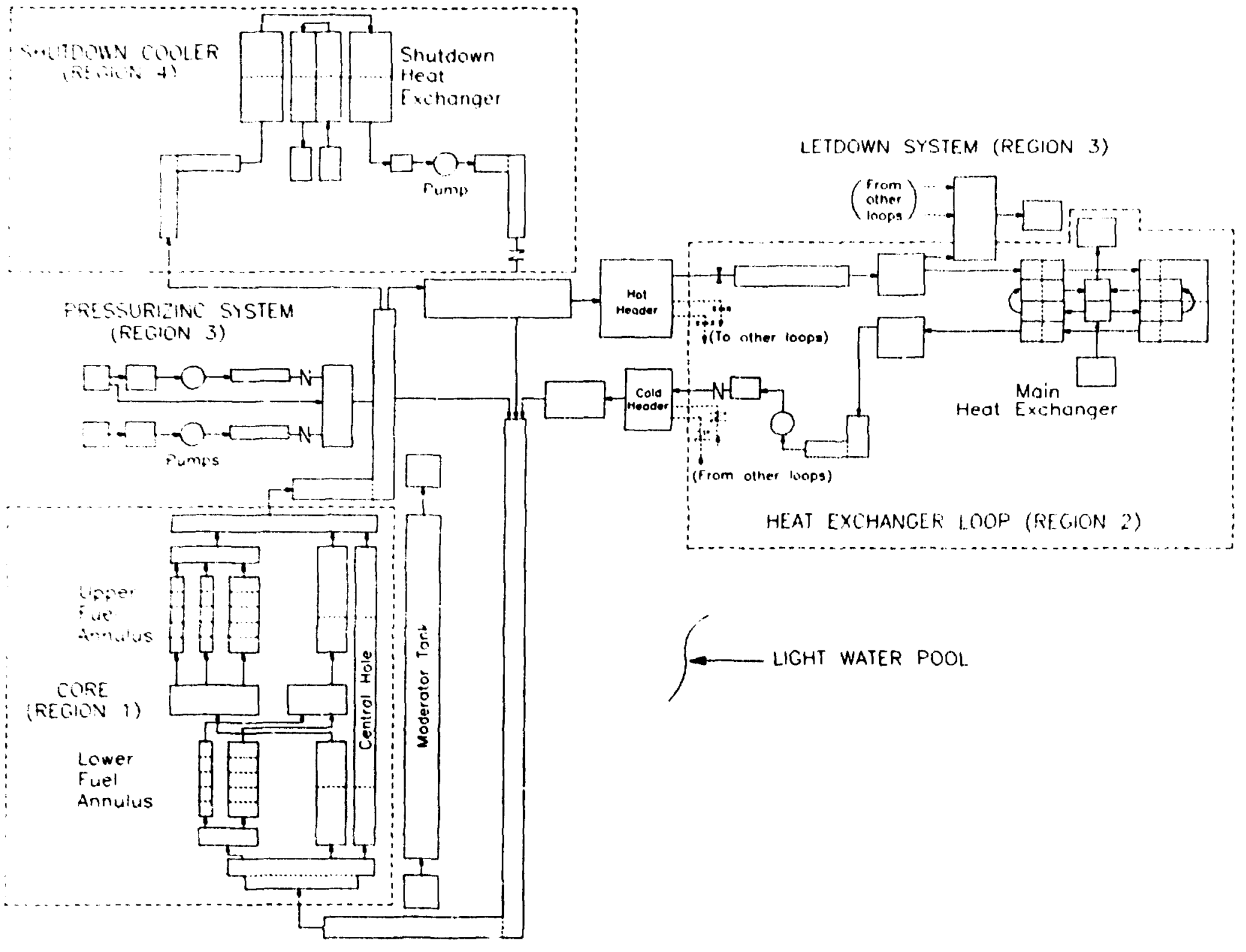

Fe. 42 Nodilintion of ANS REI APS gyted model 


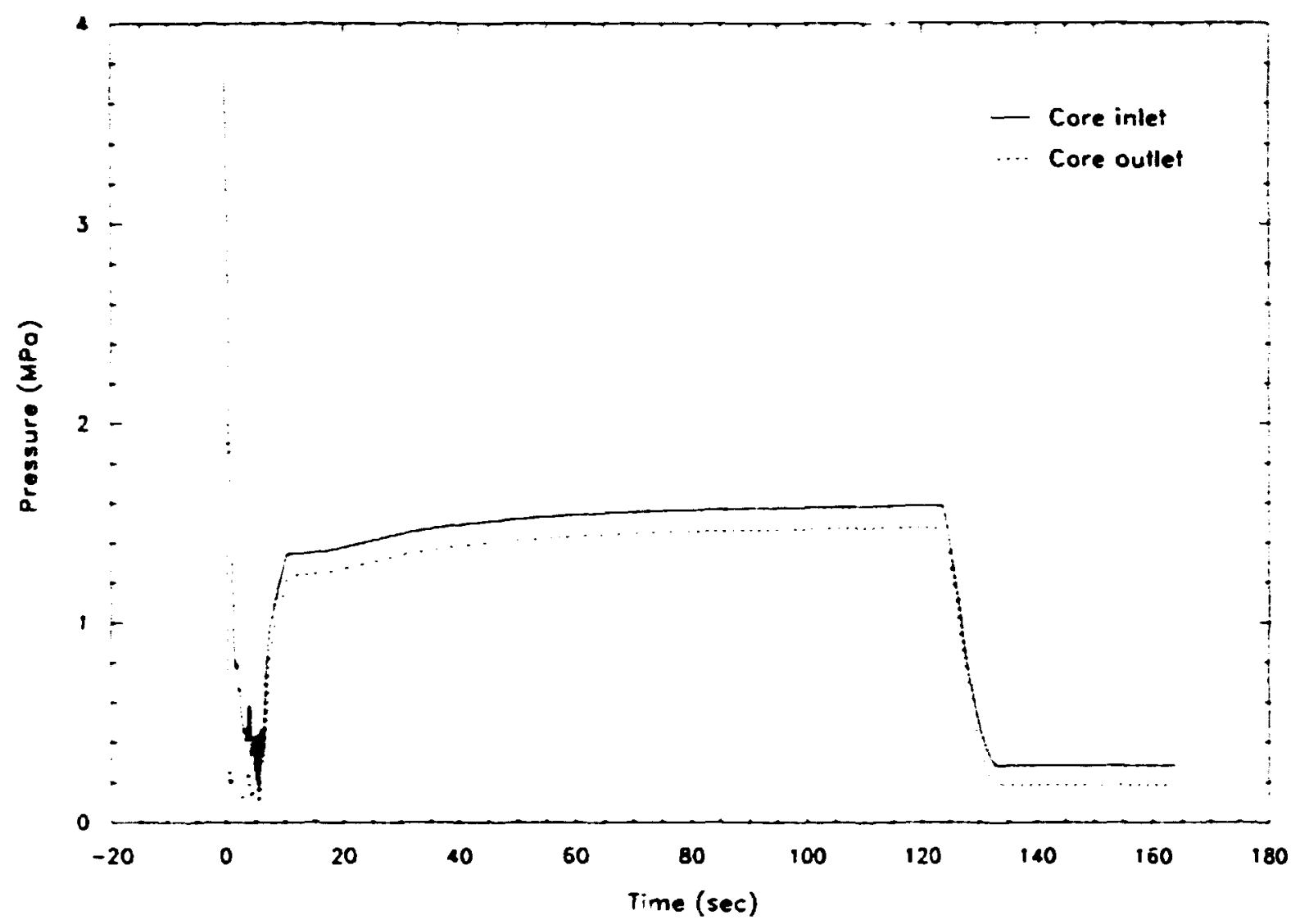

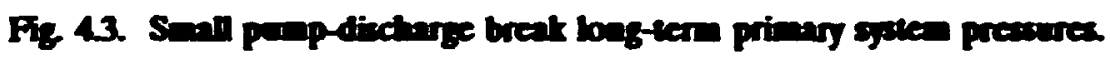

first resulted in letdown flow isolation and a control signal to start the standby pressurizing system pump.

Next, the low pressure reactor trip condition was reached; then $-0.4 \mathrm{~s}$ was required to insen the scram rod. As the depressurization continued, the main coolant pumps were tripped and their 9-s coast down to the pony motor speed began. The primary coolant pump main motors were tripped on low inlet pressure to prevent subatmospheric pressures.

Representative fuel plate centerline temperature responses are shown in Fig. 4.4 for the first 10 s of the sequence. No fucl plate heat-up was calculated in any of the hot stripe, hot channel, or average channcl heat structures. Following reactor trip, the fuel plates were quickly cooled.
The break flow fell and the injection flow rose as the primiry coolant system depressurized. The primary coolant system inventory that had been previously lost through the break was replaced by the pressurizing system injection flow, the primary coolant system was refilled and repressurized. The repressurization began at about $6 \mathrm{~s}$ when the volumetric injection rate, minus the rate of fluid contraction due to cooling. exceeded the break volumetric flow rate.

Analysis of the medium (152-mm diam) break at the pump discharge showed that when the break opened, a depressurization wave traveled around the primary coolant system, starting at the piping nearest the break, then traveling to more remote locations around the coolant loop. Without an accumulator, the depressurization was almost 


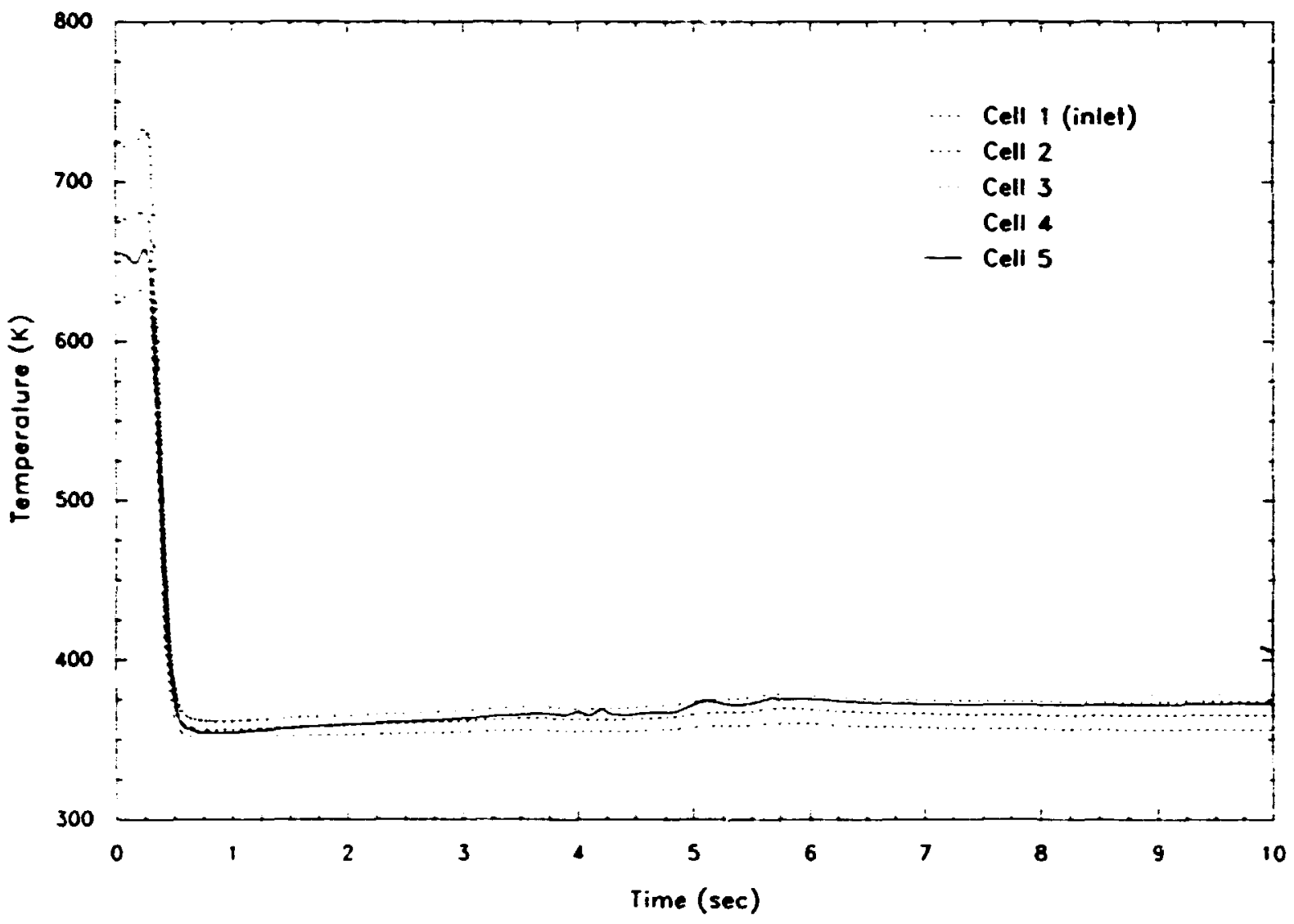

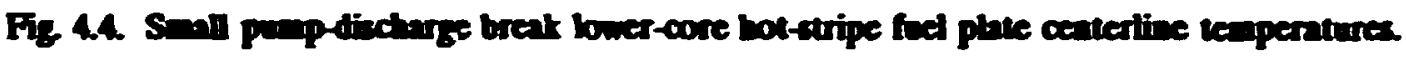

immediate at the pump suction, but was delayed by about $0.022 \mathrm{~s}$ at the core inlet and outlet. This delay is in fair agreement with the 0.028 s required for a wave to travel the $40.5 \mathrm{~m}$ from the break location to the core inlet and outlet at the $1448 \mathrm{~m} / \mathrm{s}$ sound speed.

As was the case for the small break, the declining core inlet pressure resulted in letdown flow isolation and in control signals that initiated the standby pressurizing pump, a reactor trip, and a main coolant pump trip. However, unlike the small break transient, the medium break injection flow was only a small fraction of the break flow, and primary system repressurization did not occur.

Fuel plate centerline temperature responses indicated that the hot stripe and hot channel heat structures experienced fuel plate heat-up starting at about $0.06 \mathrm{~s}$. No fuel plate heat-up was calculated in any of the average channel beat structures. Once heat-up began, the fuel plate temperatures rose very rapidly due to the low thermal capacitance of the aluminum plates, reaching the aluminum melting temperature (858 K) by about 0.09 s. The fuel plate heat-up and damage were caused when the critical heat flux fell to the local fuel plate heat flux. Negative reactivity insertions due to fluid density and core tuel plate expansion effects were minor, resulting in a slight but noticeable downward core power drift prior to scram rod insertion. The core inlet flow rate was also declining, but only slightly 20 , during the early portion of the calculation.

However, because of the extreme incompressibility of the primary coolant system, its pressure declined rapidly, and the critical 
heat fur dexlined with it. Fucl damage resulted because the depressurization rate was so high that departure from nucleate boiling occurred before the scram rod reactivity insertion could become effective.

The major implication is that for the ANSR design proposed at that time, fuel damage may be expected for medium and larger breals due to the incompressibility of the primary coolant system and the resulting extremely rapid depressurizations.

By increasing the overall compressibility of the primary coolant system through addition of an accumulator, the depressurization rate during a pipe break may be reduced. To evaluate the fuel-damage-prevention capabilities of increasing the coolant system compressibility in this manner, a series of RELAPS simulations was performed with an accumulator added to the ANS model. For these accumulator studies, the medium pumpdischarge break was selected as a base case.

With the $10-\mathrm{m}^{3}$ accumulator model connected at the cold leg distribution header, virtually all the fuel plate damage was eliminated for the medium pump-discharge break. Only the top heat structure of the lower core hot stripe experienced a heat-up. Next, the effect of increasing the size of the accumulator by $50 \%$ was evaluated by changing the model to reflect a $15-\mathrm{m}^{3}$ total tank volume with an initial bubble size of $0.375 \mathrm{~m}^{3}$. With this larger accumulator connected at the cold leg distribution header, all fuel damage was eliminated for the medium pump dischar ${ }_{6}$ break. Finally, relocating the $10-\mathrm{m}^{3}$ accumulator to the hot leg distribution header was evaluated; no fuel plate damage was calculated with this arrangement either. A summary of all cases examined is presented in Table 4.3, and a more detailed account of these calculations can be found in ref. 33. As of the end of this reporting period, the reference design included an accumulator in each coolant loop.

\subsection{Station Blackout Analycis}

A station blackout accident refers to a loss of all on-site ac powcr. During this accident, the following events are assumed to occur simuitancousiy: (ij) the main circuiation pumps trip and coast down to pony motor speed, (2) the main and standby pressurizing pumps coast to a stop, (3) the shutdown cooler system pumps coast to a stop. and (4) the secondary coolant flow is lost.

In the system without accumulators, the calculation results reveal that (1) there is a rapid depressurization until flashing occurs at the highest cells of the heat exchanger in the shutdown cooler system, (2) there is no core heat-up, and (3) there is no pump cavitation. The core inlet and outlet pressure transients are shown in Fig. 4.5. Without the accumulator, there is an initial stabilization of system pressures due to the pump bead reduction (1.3 s), a very rapid depressurization due to cool down and water shrinkage after reactor scram (3.5 s), and a final coast down of the pump (9 s). The inclusion of a $10 \mathrm{~m}^{3}$ accumulator at the cold leg distribution header causes a delay in reactor scram, lessens the primary coolant depressurization rate, and suppresses void at the highest cells in the shutdown cooler system heat exchanger. The significant improvement in depressurization rate is included in Fig. $\mathbf{4 . 5}$ for comparison.

Calculations with an accumulator installed at the hot leg distribution header show two advantages of this location. First, the gas expansion ratio is reduced by half; hence, the accumulator size can be reduced by half (to $\left.5 \mathrm{~m}^{3}\right)$. Second, because of its close proximity to the core exit, where fuel damage is more likely to occur, the accumulator becomes more effective in depressurization mitigation.

A RELAP5 model was assembled that included an accumulator in each flow loop to study the behavior of smaller accumulator volumes, as well as loop interactions. A concern of this geometry is flow oscillation caused by the interaction between accumulators in different loops. When calculations were performed, such phenomena were expected but were not predicted by RELAP5 because an implicitly built-in check valve within the accumulator model prevented the interaction. Coding changes are planned to resolve this problem. 
Table 43. Summary of REIAPS ANS pipe break anabsea.

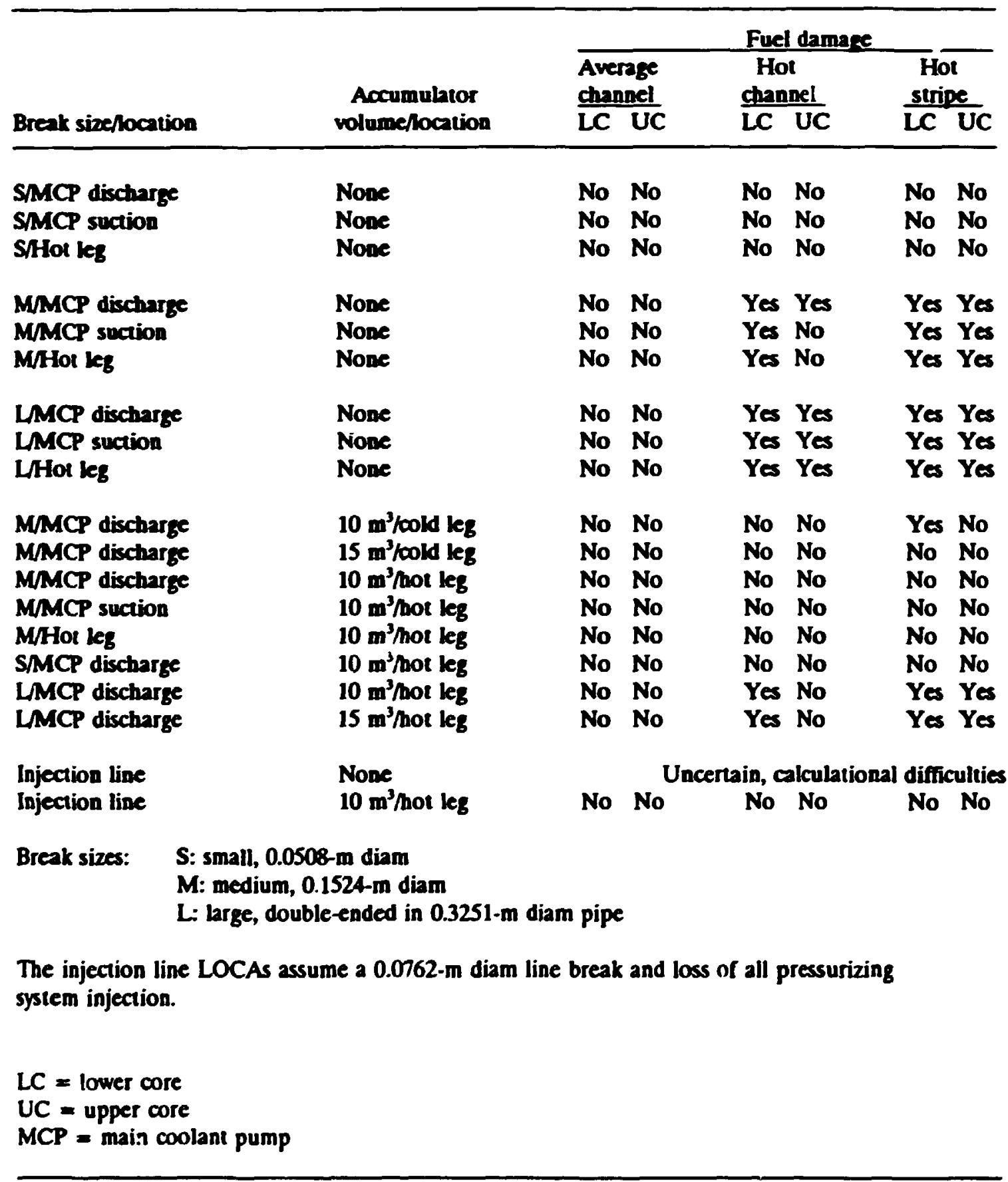

In summary, no co:e cocling problems are predicted with or without accumulators for the st..tion blacko':t accidents studied. An accumulator sited at the hot leg distribution header is recommended because of its smaller size and therefore smaller $\mathrm{D}_{2} \mathrm{O}$ inventory, and because it is more effective in depressurization mitigation. Additional information about these transients, such as the sequence of events, the hot spot surface 


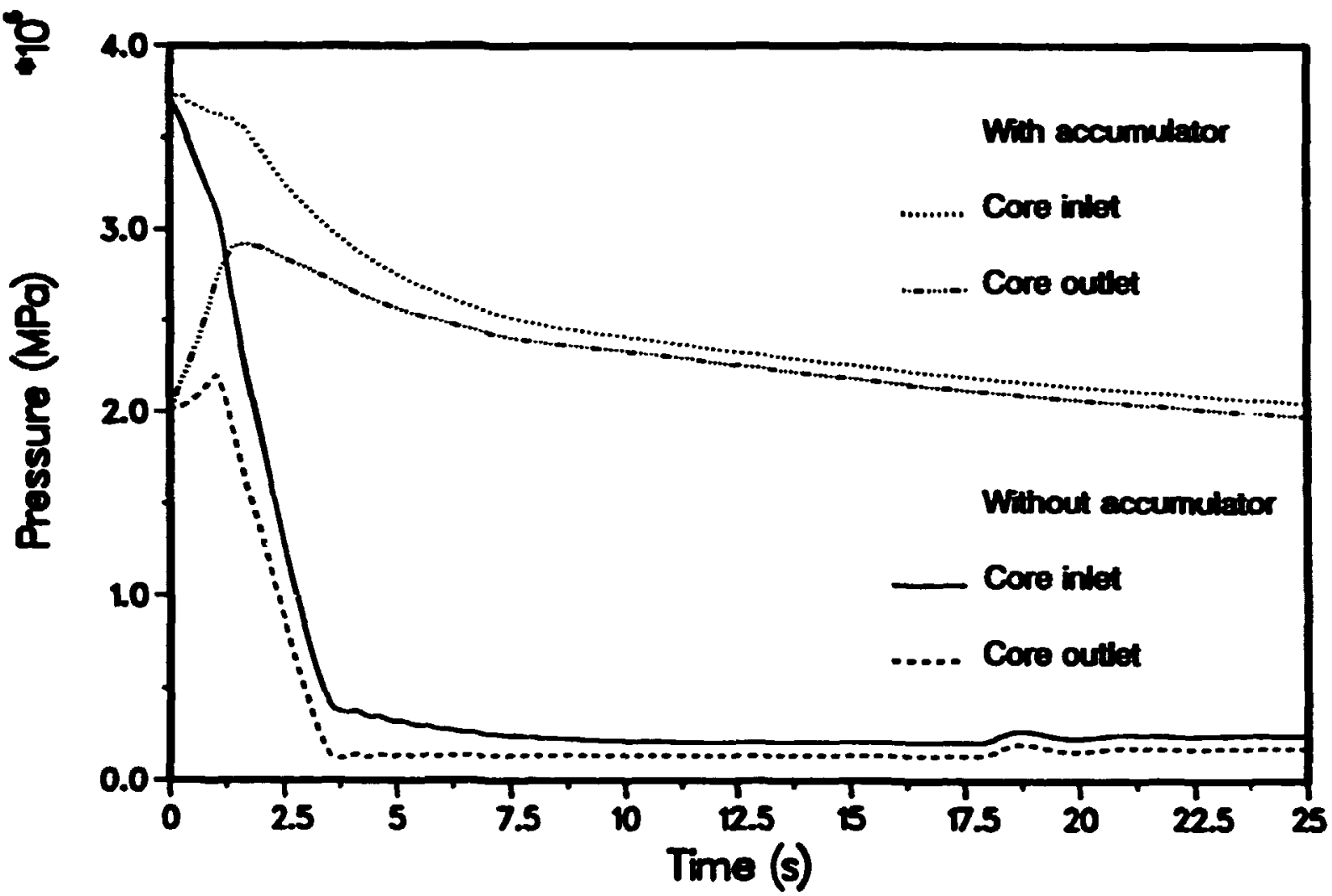

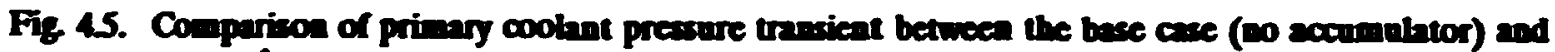

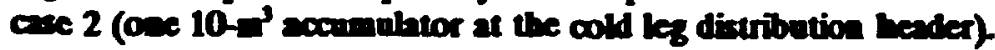

temperature, the heavy-water bulk temperature, and the vapor fraction was reported in ref. 34.

\subsection{SEVERE ACCIDENT ANALYSIS}

A severe accident is defined as one that proceeds beyond the design basis and, therefore, has the potential for releasing significant quantities of fission products out of the fuel-cladding matrix. For the ANS, considerablc efforts have been made to introduce various safety features so as to make severe accident occurrences a low probability event. Notably, the ANS reactor cooling and protective systems are being designed to achieve a severe core-damage risk limitation goal of $10^{-5}$ core-damage events per year.
Despite the fact that the ANS is being designed to have an extremely low probability of core-damage events, severe accident analysis and related technology development efforts have been introduced early in the design phase. This was done to (1) aid in designing a sufficiently robust containment for the retention of radionuclides in the event of a severe accident, (Z) provide deterministic best-estimate Level 2 PRA supporting analyses, (3) provide a means for satisfying on- and off-site regulatory requirements on dose allowances, (4) provide the best possible understanding of the ANS under such hypothetical accident conditions and finally, (5) provide insights for the development of strategies and design philosophies for accident mitigation, management, and emergency preparedness. This approach 
is utilized in response to the defense-indepth safety philosophy adopted by the ANS Project.

Past activities in the area of severe accident analysis included scoping studies on hydrogen explosion loadings, fuel-coolantinteraction (FCI) and debris-recriticality safety analyses, and preliminary CONTAIN code evaluations for containment pressurization. The results of these studies have beer. reported in a previous ANS Project progress report.' Several follow-on efforts have been made to assist in resolving issues highlighted from these studies. For example, a task team has been organized at the national level to resolve FCI issues jointly. The task team consists of participants from other DOE laboratories with U-Al-fueled research, test, or production reactors. Several meetings have taken place, and plans are being formulated for the definition and development of appropriate aralyses.

During the current reporting period, scoping studies on core-melt progression, fission product release, and molten-coreconcrete-interactions (MCCI) were conducted; preliminary containment designrelated response evaluations (from several hypothetical severe accidents) using the MELCOR code ${ }^{35}$ were initiated. The results of these activities are summarized below.

\subsubsection{Core-Concrete Interactions}

The study of MCCI represents an important phase of any hypothetical severe accident that has progressed to the point of core debris relocation outside the primary system onto a concrete surface such as the floor of the subpile room in the ANS. Experience with severe accident analyses for power reactors has shown that several consequences of MCCI must be evaluated when considering the response of the containment during severe accidents. First is the direct attack and ablation of concrete. A second aspect deals with the potential generation of combustible and noncombustible gases that origi- nate from the thermal decomposition of concrete upon interaction with hot core debris. These gases may cause sufficient pressurization from combustion and direct compression to lead to significant leakage from the containment. Finally, a major aspect of MCCI is related to the generation and release of aerosols into the containment atmosphere, which potentially also provides a mechanism for release of radioactive fission products from core debris. The production of aerosols is tied to the stirring action of gases passing through the debris and the vaporization/ entrainment of MCCI materials into these gases.

Extensive experimental and analytical MCCI research has been sponsored by NRC for several years with regard to power reactor severe accident anlayses. The result of this research has been the development of the CORCON ${ }^{36}$ code, which has been used extensively as part of the NRC's source-term code package to evaluate and study several aspects related to MCCI. Over the past several years, the Savannah River Laboratory (SRL) has been conducting research into the MCCI issue in relation to their production reactors. As part of inis research, SRL has also sponsored the development of appropriatc modifications to the CORCON code so that it is applicable to the analysis of U-A fuel-concrete interactions. A version of the code has been developed that enables prediction of concrete ablation and generation of combustible and noncombustible gases for MCCI events involving U-Al fuel. Predictions from the modified CORCON code were compared to SRL-sponsored experimentally observed values for concrete ablation rates, and good agrcement was obtained (personal communication with Dave Bradley at SRL). The aspects of modeling U-A fuel-specific aerosol generation and fission product chemistry are still under development. This version of the CORCON code was obtained from the sponsors and set up on ORNL's CRAY-XMP for ANS MCCI anailysis. 
In the event of a severe accident in the ANS, molten core debris may relocate to the base of the corcrete reactor pool or to the floor of the subpile ronm. It thus becomes necessary to judge the potential concrete ablation and related consequenses in terms of excess gas generation, timing, amounts, and resulting containment pressurization. The following paragraphs summarize some of the salient aspects of the work conducted by C. R. Hyman and R. P. Taleyarkhan of ORNL, documented in detail in Characterization of Core Debris/Concrete Interactions for the Advanced Neutron Source, ORNL TM-11761 (to be published).

The scopiag study included a background description of recent MCCI research along with comparison of CORCON code predictions against experimental observations. For ANS-specific analyses, a parametric study was conducted. Parameters addressed include initial debris spreading radius, concrete rebar fraction, concrete type, concrete ablation temperature, magnitude of debris internal heating, initial debris inventory, and the effect of an overlying water pool. A limited analysis was also conducted to evaluate the mitigative effect of very-high-meltingtemperature alumina concrete. Calculations were initiated $60 \mathrm{~s}$ after scram.

Sample results for several concrete types are displayed in Table 4.4 for the assumption of $100 \%$ decay heat retention in the debris (that is, no fission product volatilization or gamma eriergy escape) and no water pool. As seen under such conservative anditions, about 1 to $2 \mathrm{~m}$ of concrete ablation is predicted, and about $10^{4}$ moles of combustible gases are gencrated for all three cases. In general, it was found that the primary factor controlling the production of the combustible gases was the rebar fraction assumed for the concrete. Again, concrete ablation was primarily affected by the anount of

Table 4.4. CORCON results as a function of concrete type. These results are cumulative at $16.9 \mathrm{~b}$ and assume a spreading radius of $1.1 \mathrm{~m}$, a concrete rebar fraction of 0.10 , and no overlying water pool

\begin{tabular}{|c|c|c|c|}
\hline & \multicolumn{3}{|c|}{ Concrete type } \\
\hline & Basaltic & $\begin{array}{l}\text { Limest } \\
\text { sand }\end{array}$ & Limestone \\
\hline Ablation depth, $m$ & 2.2 & 1.1 & 0.94 \\
\hline $\begin{array}{l}\text { Gas release, } 10^{4} \text { moles } \\
\mathrm{H}_{2} \\
\mathrm{CO} \\
\text { Moles of } \mathrm{H}_{2}+\mathrm{CO}\end{array}$ & $\begin{array}{l}5.1 \\
0.6 \\
5.7\end{array}$ & $\begin{array}{l}0.6 \\
2.3 \\
3\end{array}$ & $\begin{array}{l}0.3 \\
2.1 \\
2.5\end{array}$ \\
\hline $\mathrm{H}_{2} \mathrm{O}$ & 4.6 & 3.3 & 3.7 \\
\hline $\mathrm{CO}_{2}$ & 0.4 & 5 & 7.8 \\
\hline TOTAL & 10.7 & 11.3 & 14.0 \\
\hline$\%$ Combustible & 53 & 26 & 17 \\
\hline Ablation temperaturc, ${ }^{\circ} \mathrm{C}$ & 1180 & 1780 & 1480 \\
\hline
\end{tabular}


debris decay heating. In Table 4.4, the case considering limestone common sand concrete is referred to as the base case for ANS analysis.

It was found that ANS MCCI could be significantly reduced in one of two ways. First, regardless of concrete type, if the internal debris heating rate was reduced to about $20 \%$ of the whole core decay beat (e.g., by escape of gamma radiation or fission product volatilization), axial concrete erosion could be mitigated. Second, the combination of alumina concrete and the presence of an overlying water pool were shown to reduce concrete erosion significantly even at conservatively high debris heating levels. These aspects are clearly noted in Fig. 4.6. Note that for ANS fuel, much of the volatile fission products contributing about $45 \%$ of the decay power can be expected to leave the fue; over a period of time at the elevated temperatures characteristic of $\mathbf{M C C l}$.

Further, gamma energy escape from the debris will reduce the decay heat level from its nominal value. Hence, the values of ablat on and combustible gas release amounts shown in Table 4.4 should be considered conservative upper-bound estimates.

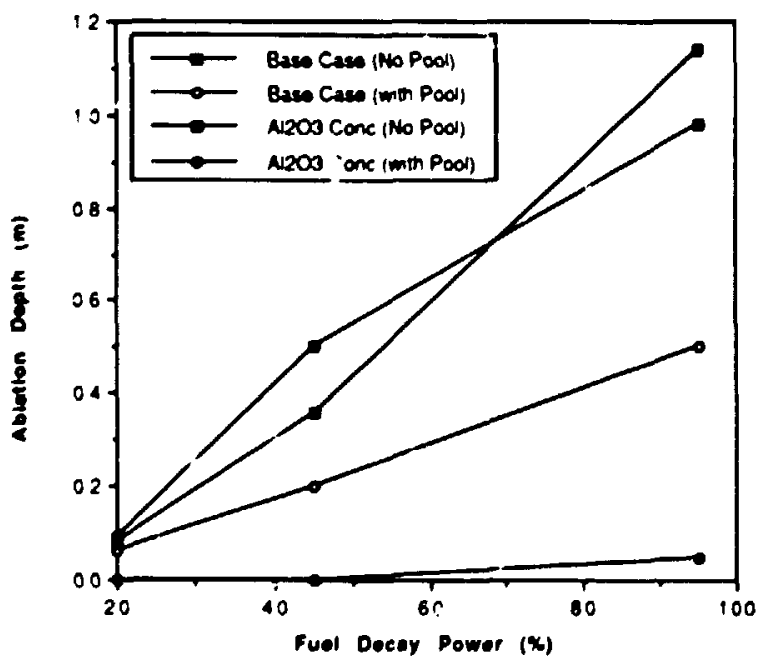

Fig. 4.6. Variation of ablation depth with concrete type, debris power, and water pool.
Scoping estimates were made for the base case to evaluate the effects of combustible gas deflagration. Due to the large containment volume for the ANS, deflagration levels cannot be reached if the combustible gases are uniformly dispersed. If these gases were concentratcd in the subpile room, it is estimated that a third of the combustible gases released would be sufficient to exceed the deflagration limit. Based upon simple hand calculations that did not account for structural heat sinks, the heat generated from complete combustion of combustible gases was found to raise the high bay containment volume pressure by more than $34 \mathrm{kPa}$ (5 psi). More detailed MELCOR code calculational results, which include the effect of heat absorbing structures, are prescnted later in this chapter.

\subsubsection{Core Melt Progression and Fission Product Release Considerations for the ANS}

The study of core-melt progression and fission product release addresses the most fundamental aspects of severe accident analysis. It pertains to the issues th $-t$ relate to core heat-up, melting, and relocasion, with simultaneous release and transport of the available radinnuclide inventory. The core region construction and operation for the ANS are radically different from that of power reactors. Such radical differences make it prudent to conduct a scoping study in order to judge which aspects of the heat-up and melting processes require further attention. It is alsu prudent to conduct methodsdevclopment efforts and investigate safety concerns that can be addressed by proper system design. In the following paragraphs, salient aspects of work conducted by $R$. P. Taleyarkhan are documented in detail from a report entitled Core Melt Progression and Fission Product Release Considerations for the Advanced Neutron Source Reactor at ORNL. An Issue Paper, ORNL/TM-11764 (to be published). 
The scoping study included an overview of the extensive budy of work on core-melt progression for power and, to a lesser extent, for UAl-fueled reactors. For these reactors, it was found that considerable debris dispersal can occur upon grain boundary melting, if melting occurs in a flowing medium. A mathematical model was developed and an analysis conducted. The model and analyses give extimates of when to expect fuel plate slumping and of how to estimate particulate size distributions if dispersion and entrainment occurs in a flowing medium. Comparisons against SRL data gave good overall agreement.

The study ako provides a perspective overview and analysis of volatile fission product relsase data obtained for UA: reactur fuels $\mathrm{UAl}_{2} \mathrm{U}_{3} \mathrm{O}_{8}-\mathrm{Al}, \mathrm{U}_{3} \mathrm{Si}_{2}-\mathrm{Al}$, and $U_{3} S i-A$. Particular attention was given to the aspect of fission product release from $\mathrm{U}_{3} \mathrm{Si}_{2}-\mathrm{A}$ fuel since it is the reference fuel for the ANS.

Communication was established with the Japan Atomic Energy Research Institute (JAERI) where fission product release data from $\mathrm{U}_{3} \mathrm{Si}_{2}-\mathrm{Al}$ fuel have been obtained. ${ }^{37}$ This data base has been kindly provided to the project by JAERI. It was iound that considerably lesser amounts of volatile fission products can be expected to be released from silicide fuels at a given temperature (close to melting conditions) than from alloy fuels. This same conclusion was reached for the rclease of noble gases. The release was found to be strongly dependent on the ambient atmosf:.ere, burn-up level, fucl type, and, finally, the time of release. An extensive library of correlations and methods for predicting release rates for each individual volatile fission product specics from the various fuels was developed based upon analysis of characteristic data trends, phenomenological aspects, and regression analysis. The relcasc rates vary with time, as well as with other parameters such as ambient environment, burn-up, and temperature. A comparison of correlation predic- tions against measurements resulted in an overall mean value and standard deviation of 1.04 and 0.31 , respectively. These statistucal indicators improve considerably to 1.00 and 0.1 if the $\mathrm{HEDL}$ data taken for $\mathrm{U}_{3} \mathrm{O}_{8}-\mathrm{A}$ fuel specimens (which displayed considerable experimental data scatter) are excluded.

A preliminary analysis was conducted to evaluate debris coolability and structural ablation in relation to hypothatical ANS severe accident scenarios. Phenomena such as debris thermal-power reduction from fission product release, gamma energy escape, eutectic formations, and chemical energy releases from potential fuel-aluminum and aluminum-water interactions were considered. Finally, the impact of transuranic target rods on core-melt progression was evaluated. It was found that volatile fission product release, energy associated with gamma rays, and exothermic aluminum-water reactions can significantly affect debris thermal-energy content and, therefore, coolability evaluations. The impact of transuranic target rods and energy addition from exothermic $\mathrm{U}_{3} \mathrm{Si}_{2}-\mathrm{Al}$ reactions was found to be negligible.

Parametric ANS debris coolability evaluations were conducted to bound varying degrees of debris dispersion by modeling the debris as a slab-like gcometry (of different thicknesses and interfacial areas) on structures. For the conservative case of debris relocation to the bottom of the CPBT (corresponding to a dispersion area of $0.35 \mathrm{~m}^{2}$ ) in the first few hours after scram, the debris may overheat and cause structural steel ablation to occur. For higher dispersion areas, it was found that the debris would remain coolable and structural ablation would be highly unlikely or would proceed at a slow pace. For early meltdown and relocation cases (that is, $<100 \mathrm{~s}$ after scram), the debris may be noncoolable and lead to structural ablation even with dispersion areas as .jigh as $3.5 \mathrm{~m}^{2}$. It was found that the debris may be coolable in an air medium only at very low thermal power levels. 
Preliminary evaluations were conducted to evaluate structural ablation rates at different debris thermal-power levels and dispersion areas. For the conservative case of debris relocation to the bottom of the CPBT, it was found that substantial and rapid steel ablation may occur if the debris thermal power is high enough. Such ablation may cause the ANS core debris to be discharged to the subpile room (which is still part of the primary containment system). For cases with greater debris dispersion, the degree of structural ablation decreases correspondingly. The effect of potential debris dilution may cause the ablation rate to decrease substantially with time.

The principal sources of uncertainty in debris coolability and structural ablation evaluations are (1) the impact of potential nonhomogeneous distribution of the various debris-structure constituents, (2) cutectic formation rates during high temperature melt attack on structures, and (3) crust formation. In order to eliminate or at least reduce such uncertaintics, materials data on cutertics and guidance from small-scale experiments using simulant materials are needed. This scoping study confirmed the importance of considering core-melt progression aspects during the design phase of the ANS Project.

\subsubsection{ANS Containment Response Evaluations}

The MELCOR severe accident analysis code was used to produce conservative estimates of containment pressurization for a variety of simulated hypothetical severe accidents. These evaluations were performed to provide support to ongoing containment design efforts. This st ation describes the salient aspects of work performed by $B$. W. Patton and R. P. Taleyarkhan.

A preliminary MELCCR input deck was set up with control volumes to represent the subpile room, reactor pool, first floor, second floor, and high bay containment areas. All the major heat absorbing structures such as concrete walls and steel linings were represented. The large containment dome area was represented along with an annulus cavity between the steel and the outer concrete strurture. The outside environment was defined as a separate control volume. $A$ set amount of leakage was permitted between the inner containment and the annulus region. A separate pool control volume was used for evaluation of cases where steam production may occur from water heat-up from debris decay heat production. It was conservatively assumed that the pool cooling system would not be functional. Again, the evaluations were performed assuming no atmosphere cooling capability (for example, from fan coolers).

Several test cases were run with the preliminary MELCOR model representation; selected unes are described. The base case considered a hypothetical accident where the ANS core debris had relocated to the subpile room floor and had undergone an MCCI event [that is, thermochemical reaction of core debris material with concrete (see Sect. 4.3.1)]. CORCON code evaluations for combustible and noncombustible gas generation were programmed as input loading functions for MELCOR evaluation. Based upon the fission product release characteristics of $\mathrm{U}_{3} \mathrm{Si}_{2}-\mathrm{Al}$ fuel, it was determined that about $50 \%$ of the decay heat would be associated with the volatile fission products. Thus $50 \%$ of the debris decay heat was sourced into the containment atmosphere, and the remaining $50 \%$ of debri decay heat went into coreconcrete interaction progression. For these conditions, MELCOR's best-estimate calculations determined that a containment with low to moderate design pressure would be able to withstand the pressurization loads, which reached a maximum value of $24 \mathrm{kPa}$ (3.5 psi) above atmospheric pressure about $24 \mathrm{~h}$ after the transient began and decayed off almost to atmospheric pressure after $72 \mathrm{~h}$.

Another case dealt with the hypothetical instance where all the core fission products 
are volatilized and are transported to the containment atmosphere. A conservative assumption was made thai the fission products would remain in the atmosphere indefinitely. This was necessary since the radionuclide package in MELCOR was not exercised in this model. The code input for this case was changed so that containment atmosphere included only the volume under the containment dome, leaving out the substantial mass and energy dissipation that would have been provided by the first- and second-floor volumes. This led to MELCOR predicting a peak containment pressure increase of about $79.3 \mathrm{kPa}$ (11.5 psi) $5 \mathrm{~h}$ into the transient, with gradual reducing thereafter.

The case of debris dispersal into a water medium that causes containment pressurization from steam production was also modeled. Two parametric runs were made. In conformance with the site suitability source-term specification, it was assumed that $25 \%$ of the decay hea: would go into the containment atmosphere, and the remainder would go into heating water pools of $100 \mathrm{~m}^{3}$ and $300 \mathrm{~m}^{3}$, respectively. The volume of $100 \mathrm{~m}^{3}$ was chosen to represent approximately the volume of the primary loop. The volume of $300 \mathrm{~m}^{3}$ was arbi! : arily chosen to be three times the base amount to evaluate the effect of increased water availability, as would be the case if the water in the large reactor pool were to become available. Once again, the first- and second-floor volumes were not included in the code input for these evaluations. MELCOR predictions indicated that the containment pressure would rise by about $110 \mathrm{kPa}$ (16 psi) or $62 \mathrm{kPa}(9 \mathrm{psi})$ depending on whether the pool volume assumed was $100 \mathrm{~m}^{3}$ or $300 \mathrm{~m}^{3}$. The maximum pressures occur after $10 \mathrm{~h}$ and $35 \mathrm{~h}$, respectivaly, into the transient. The benefits of increased pool volume and the importance of steaming events in causing significant contairment pressurization were evident from these evaluations.

It should be noted that duc to time and scheduling constraints, it was not possible to include the modeling of radionuclide transport phenomena. From this perspective, the MELCOR evaluations performed so far lack a sense of physical realism, since they only look for thermal-hydraulic effects. In reality, strong physical removal mechanisms (such as aerosol deposition from a variety of phenomena such as Brownian motion, gravitational settling, thermophoresis, and fission product vapor condensation on cold structures) can be expected to lead to significant amounts of heat-generating firsion product removal from the containment atmosphere. Thus, the values of containment pressurization in actuality can be expected to be ronsiderably lower than that predicted with current Mr.LCOR evaluations. It is thus planned that the physical attributes of radionuclide transport, and other features such as inclusion of engineered safety features, will be included in the current MELCOR model in the coming fiscal year. The results from those evaluations will be reported in next year's progress report. 


\section{References}

1. D. L. Selby, R. M. Harrington, and F. J. Peretz, Advanced Neutron Source (ANS) Project Progress Report, ORNL-6574, Martin Marietta Energy Systems, Inc, Oak Ridge Natnl. Lab., April 1990.

2 J. F. Briesmeister, ed, MCNP - A General Monte Carto Code for Neutron and Photon Transport, LA-7396-M, Rev. 2, Los Alamos Natnl. Lab., Los Alamos, N.M., 1986.

3. G. L. Copeland, et al, Advanced Neutron Source Final Preconceptual Referer :e Core Design, ORNL/TM-11234, Martin Marietta Energy Systems, Inc., Oak Ridge Natnl. Lab., 1989.

4. C. J. Pfeifer, PDQ-7 Reference Manual II, WAPD-TM-947(2), Westinghouse Atomic Power Division, 1971.

5. J. Rest and G. L Hofman, Mechanistic Interpretation of an Observed Rate Dependence of Low Temperature Swelling of Irradiated Uranium Silicide Dispersion Fuek, " Proceedings of the ISth ASTM Symposium on Effects of Imadiation on Materials, Nashville, Tenn., June 17-21, 1990 (to be published).

6. D. L. Selby, R. M. Harrington, and F. J. Peretz, Advanced Neutron Source (ANS) Project Annual Repor (April 1987 - March 1988), ORNL/M-10860, Martin Marietta Energy Systems, Inc., Oak Ridge Natnl. Lab., February 1989.

7. B. H. Montgomery, R. E Pawel, and G. L. Yoder, The Advanced Neutron Source Test Loop Facility," Trans. Am. Nuc. Soc. 57, 300, (1988).

8. J. C. Griess, H. C. Savage, and J. L. English, Effect of Heat Flux on the Corrosion of Aluminum by Water. Part IV. Tests Relative to the Advanced Test Reactor and Correlation with Previous Results, ORNL-3541, Martin Marietta Energy Systems, Inc., Oak Ridge Natnl. Lab., February 1964.

9. R. E Pawel, el al., The Development of a Preliminary Correlation of Data on Oxide Growth on 6061 Aluminum under ANS Thermal-Hydraulic Conditions, ORNLTM-11517, Mantin Marietta Energy Systems, Inc., Oak Ridge Natnl. Lab., June 1990.

10. K Farrell, personal communication to R. E Pawel, unpublished data, Oak Ridge Natnl. Lab., Oak Ridge, Tenn., March 1989.

11. C. J. Czajkowski, et al., Tensile and Impact Testing of an HFBR Control Rod Follower, BNL43367, Brookhaven Natnl. Lab., Upton, N.Y., August, 1989.

12. D. R. Miller, "Critical Flow Velocities for Collapse of Reactor Parallel-Plate Fuel Assemblies," J. Eng. Power, Trans. ASME, 83-95, April 1960.

13. G. S. Rosenbarg and C. K. Youngdahl, "A Simplified Dynamic Model for the Vibration Frequencies and Critical Coolant Flow Velocitics for Reactor Parallel Plate Fuel Assemblies," Nuc. Sci. Eng. 13(2): 91-102, Junc 1962. 
14. G. E Smissaert, "Static and Dynamic Hydroelastic Instabilities in MTR-Type Fuel Elements, Part II. Theoretical Investigation and Discussion," Nuc. Eng. Des. 9. 105-22, (1969).

15. G. E Smissaert, 'Static and Dynamic Hydroelastic Instabilities in MTR-Type Fuel Elements, Part I. Introduction and Experimental Investigation," Nuc Eng. Des. 7: 535-46, (1968).

16. R. D. Groninger and J. J. Kane, "Flow Induced Deflections of Parallel Flat Plates," Nuc. Sci Eng. 16. 218-26, 1963.

17. W. L Zabriskie, An Experimental Evaluation of the Critical Flow Velocity Formulas for Parallel Plate Assemblies, AECU-3936, General Engineering Laboratory, The General Eloctric Co., October 1958.

18. R. J. Scavuzzo, An Experimental Study of Hydraulically Induced Motion in Flat Plate Assemblies, Bettis Technical Review, WAPD-BT-25, Westinghouse Atomic Power Division, May 1962.

19. W. K. Sartory, Analysis of Hydraulic Instability of ANS Involute Fuel Plates, ORNLTM-11580, Martin Marietta Energy Systems, Inc., Oak Ridge Natnl. Lab., to be published.

20. W. F. Swinson and G. T. Yahr, "Dynamic Pressure Approach to Analysis of Reactor Fuel Plate Stability," Trans. Am. Nuc. Soc. 61, 390, June 1990.

21. DORT is a successor to the DOT -4 computer code and is documented as follows: W. A Rhoades and R. L. Childs, The DORT Two-Dimensional Discrete Ordinates Transport Code," Nuc. Sci Eng. 99 (1): 88-89, May 1988.

22. Advanced Neutron Source Plant Design Requirements, ORNL/MM-11625, Martin Marietta Energy Systems, Inc., Oak Ridge Natnl. Lab., July 1990.

23. R. L. Johnson, Systems Engineering Management Plan, Advanced Neutron Source Project, Martin Marietta Energy Systems, Inc., Oak Ridge Natnl. Lab., to be published.

24. Proposed Advanced Neutron Sounce, ERC/EDGe File No. C123, ERC/EDGe, Knoxville, Tenn., November 21, 1989.

25. G. R. McNutt, B. S. Maxon, R. Miller, Summary Repon of the ANS Reactor Cooling Systems Workshop, February 15-16, 1990, Martin Marietta Energy Systems, Inc., Oak Ridge Natnl. Lab., CONF-9002142, to be published.

26. R. M. Harrington, et al., Summary Repon of the ANS Containment Workshop, August 23-24, 1990, Martin Marietta Energy Systems, Inc., Oak Ridge Natnl. Lab., CONF-9008150, to be published.

27. D. B. Coffin, Advanced Neutron Source Equipment Data Base, ORNLANS/M-1317, Martin Marictta Energy Systems, Inc., Oak Ridge Natnl. 'Lab., August 1990. 
28. D. L. Selby, R. M. Harrinjton, and F. J. Peretz, ORNL Contributions to the Advanced Neutron Source (ANS) Project for Oasber 1986-March 1987, ORNL/TM-10579, Martin Marietta Energy Systems, Inc., Oak Ricige Natr.l. Lab., November 1987.

29. U.S. Nuclear Regulatory Commission, Safety Goak for the Operations of Nuclear Power Plants," Fed. Regist. 51, 162, Auzust 21, 1986.

30. U.S. Nuclear Regulatory Commission, "Regulation of Advanced Nuclear Power Plants," Fed. Regist. 51, 152, August 7, 1986.

31. G. F. Flanagan, et al., Risk and Safety Analysis in Support of the Operation at the High Flux Isotope Reactor at Oak Ridge," Proceedings of the October 1989 International Sympasium on Research Reactor Safety, Operations, and Modifications, AECL-9926, 2, 353, Chalk River, Ont, Canada, October 1989.

32 M. A. Azarm, et al., "Quantification of the PRA of the HFBR at Brookhaven National Laboratory," Proceedings of the Intemational Topical Meeting on the Safety, Status, and Future of Non-Commercial Reactors and Irradiation Facilities, 607, Boise, Idaho, October 1990.

33. C. D. Fletcher and L. S. Ghan, Analysis of Loss-of-Coolant Accidents in the Advanced Neutron Source Reactor, EGG-EAST-8700, EG\&G Idaho, Inc., Idaho Falk, Idaho, May 1990.

34. N. C. J. Chen and C. D. Fletcher, "Modeling Advanced Neutron Source Reactor Station Blackout Accident Using RELAPS," Joint REIAPS and TRAC-BWR Intemational User Seminar, Chicago, IIl., September $1^{\circ}-21,1990$.

35. F. E. Haskin et al., "Development and Status of MELCOR," Fourteenth Water Reactor Sajety Information Meeting, Nuclear Regulatory Commission, Gaithersburg, Md., October 1988.

36. R. K Cole, Jr., et al., CORCON-MOD2: A Computer Program for Analysis of Molien-Core Concrete Interactions, SAND84-1246 (NUREG/CR-3920), Sandia Natnl. Labs., Albuquerque, N.M., August 1984.

37. M. Saito et al., "Further Data of Silicide Fuel for the LEU Conversion of JMTR," Proceedings of the Intemational Symposium on Research Reactor Safery, Operations, and Modifications, IAEA-SM-310/59P, Chalk River, Ont., Canada, October 1989.

38. R. P. Taleyarkhan, "Analysis and Modeling of Fission Product Release from Heated UraniumAluminum Plate-Type Reactor Fuels," Proceetings of the Intemational Topical Meeting on the Safety, Status, and Future of Non-Commercial Reacins and Imadiation Facilities, Boise, Idaho, October 1990. 